\title{
Advances in Corrosion-Resistant Thermal Spray Coatings for Renewable Energy Power Plants. Part I: Effect of Composition and Microstructure
}

\author{
Esmaeil Sadeghi $^{1} \cdot$ Nicolaie Markocsan $^{1} \cdot$ Shrikant Joshi $^{1}$
}

Submitted: 31 May 2019/Published online: 7 November 2019

(C) The Author(s) 2019

\begin{abstract}
Power generation from renewable resources has attracted increasing attention in recent years owing to the global implementation of clean energy policies. However, such power plants suffer from severe high-temperature corrosion of critical components such as water walls and superheater tubes. The corrosion is mainly triggered by aggressive gases like $\mathrm{HCl}, \mathrm{H}_{2} \mathrm{O}$, etc., often in combination with alkali and metal chlorides that are produced during fuel combustion. Employment of a dense defect-free adherent coating through thermal spray techniques is a promising approach to improving the performances of components as well as their lifetimes and, thus, significantly increasing the thermal/electrical efficiency of power plants. Notwithstanding the already widespread deployment of thermal spray coatings, a few intrinsic limitations, including the presence of pores and relatively weak intersplat bonding that lead to increased corrosion susceptibility, have restricted the benefits that can be derived from these coatings. Nonetheless, the field of thermal spraying has been continuously evolving, and concomitant advances have led to progressive improvements in coating quality; hence, a periodic critical assessment of our understanding of the efficacy of coatings in mitigating corrosion damage can be highly educative. The present paper seeks to comprehensively document the current state of the art, elaborating on the recent progress in thermal spray coatings for high-temperature corrosion applications, including the alloying effects, and the role of microstructural characteristics for understanding the behavior of corrosion-resistant
\end{abstract}

Esmaeil Sadeghi

esmaeil.sadeghi@hv.se

1 Department of Engineering Science, University West, 46153 Trollhättan, Sweden coatings. In particular, this review comprises a substantive discussion on high-temperature corrosion mechanisms, novel coating compositions, and a succinct comparison of the corrosion-resistant coatings produced by diverse thermal spray techniques.

Keywords architecture $\cdot$ composition $\cdot$ high-temperature corrosion $\cdot$ microstructure $\cdot$ renewable energy power plants $\cdot$ thermal spray coatings

\section{Introduction}

\section{The Need for Coatings}

Global warming is already having adverse effects on climate change, leading to catastrophic consequences (Ref 16). The power generation industry, which makes a huge contribution $(\sim 25 \%$ of the total greenhouse gas emissions) to global warming (see Fig. 1a), has been swiftly moving toward employing more ecologically sustainable fuels to lessen the usage of fossil fuels and, thereby, reduce $\mathrm{CO}_{2}$ emissions (which is the main agent in global warming; see Fig. 1b) (Ref 7). In contrast to fossil fuels, renewable energy sources such as biomass and waste fuels are initially considered to be $\mathrm{CO}_{2}$-neutral, i.e., the $\mathrm{CO}_{2}$ released during the combustion can be reused for the growth of new plants. Thus, there is no net increase in the $\mathrm{CO}_{2}$ generated. Moreover, burning such low-cost fuels to produce electricity/heat reduces the number of waste landfills. Furthermore, the environmental legislations implemented in many countries have helped surge the application of renewable energies, which have accelerated interests in the combustion of biomass and waste-derived fuels. 
Fig. 1 (a) global greenhouse gas emissions by different economic sectors based on the global emissions in 2010 reported by Intergovernmental Panel on Climate Change (IPCC), and (b) various detrimental gases produced by economic sector based on the global emissions in 2010 reported by IPCC (Ref 210)

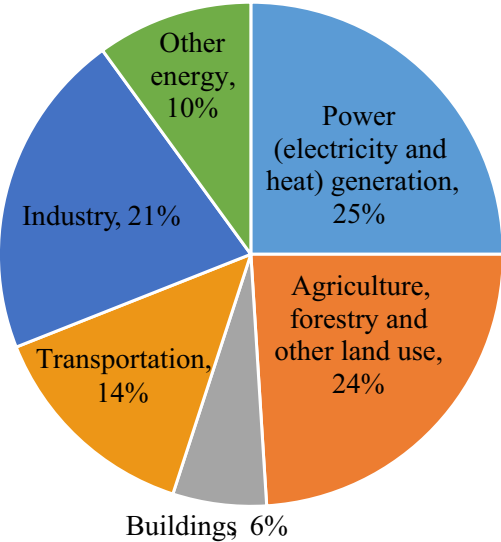

(a)

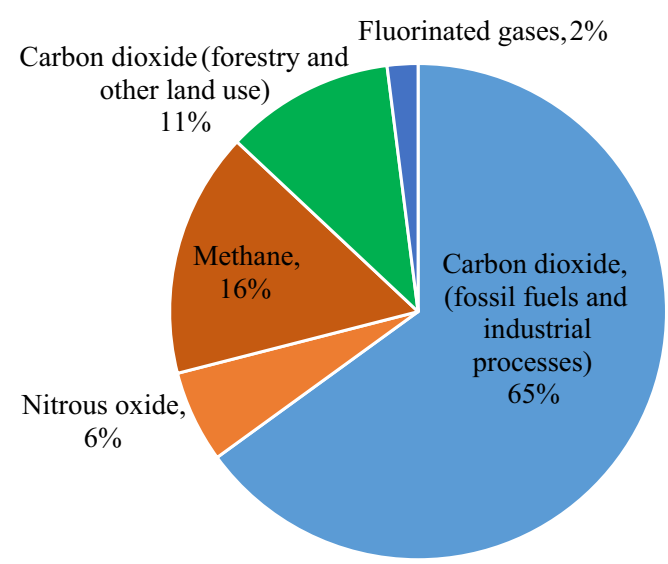

(b)

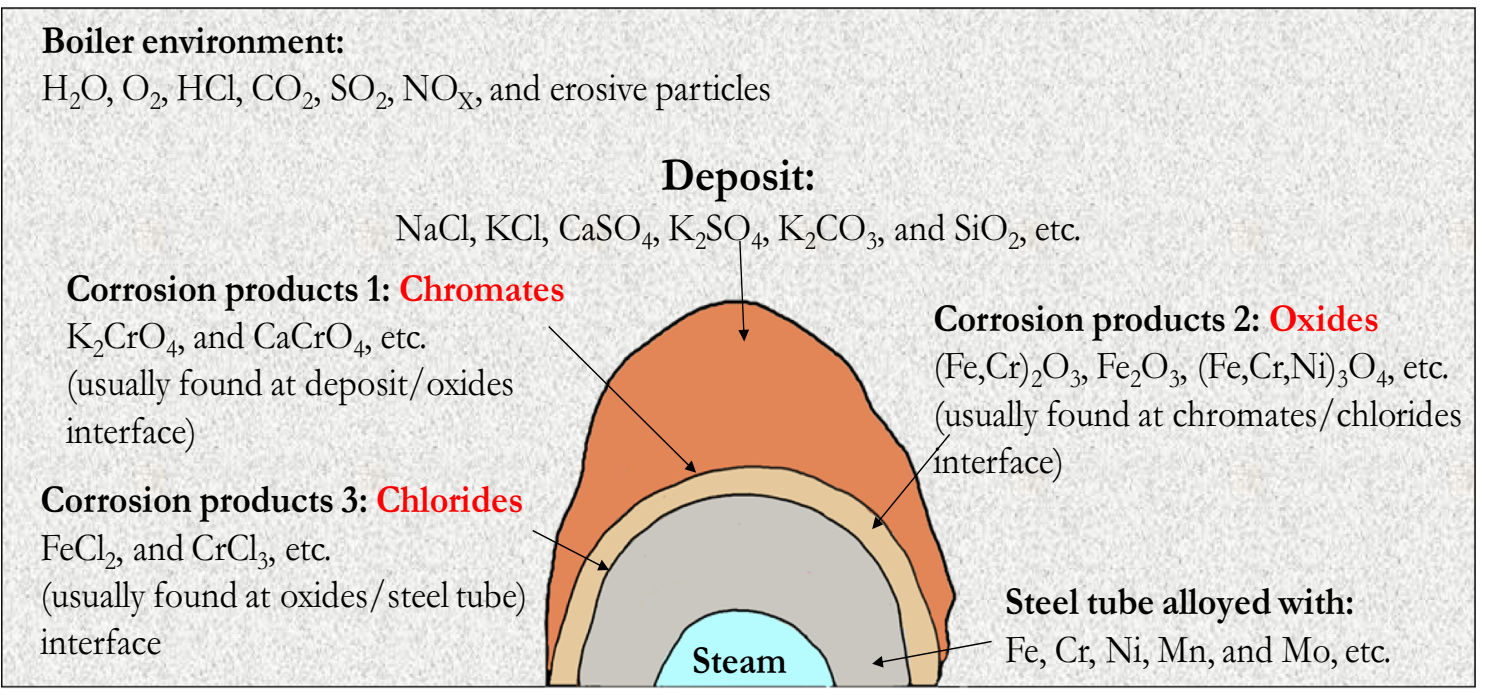

Fig. 2 Schematic view of a steel tube exposed to the corrosive environment of a boiler, showing the formation of various deposits and corrosion products

Despite several incentives to utilize biomass and waste fuels, there is a serious technical challenge in using such fuels. The biomass/waste fuels release high amounts of corrosive agents such as chlorine $\left(\mathrm{Cl}_{2}\right)$, hydrogen chloride ( $\mathrm{HCl}$ ), alkali chlorides (e.g., $\mathrm{KCl}$ or $\mathrm{NaCl}$ ), and moisture $\left(\mathrm{H}_{2} \mathrm{O}\right)$ during combustion which accelerate the corrosion of the power plant components, in particular, water walls and superheater tubes (Ref 8); see Fig. 2. During operation, the alkali chlorides are deposited on the boiler parts, not only reducing the heat transfer but also initiating corrosion. Corrosion leads to huge material wastage, tube failures, tube leakages, unplanned shutdowns, and shortened component lifetimes. It substantially reduces the thermal/electrical efficiency of a power plant and generates considerable maintenance, replacement, and outage costs (Ref 9).
It is pertinent to mention here that there have been many efforts to develop advanced alloys to achieve high strength, ductility, and producibility, which are required for power plant applications; however, high oxidation and corrosion resistance may not be directly achieved by pursuing these goals. For example, increased $\mathrm{Al}$ or/and $\mathrm{Cr}$ provides improved oxidation and high-temperature corrosion resistance. However, beyond a certain level, these elements reduce the creep strength of the resulting alloys. To achieve both high strength and high resistance to environmental degradation, the two functions need to be separated. Thus, coating-substrate systems can be considered as an excellent technical solution. Load-bearing capability is provided by the substrate alloy (structural material), while the oxidation and corrosion resistance is achieved through coatings (functional materials) with adequate $\mathrm{Al}$ or/and $\mathrm{Cr}$. 
Depending on the operating temperature, each alloy may require a coating that is compatible with its composition and structural (modulus) and thermal (coefficient of thermal expansion; CTE) properties. The main motivation for coating structural parts of power plants can be summarized as follows:

(1) to extend component life by increasing the corrosion resistance,

(2) to improve functional and mechanical performances (such as creep as well as thermo-mechanical fatigue) by enabling higher operating temperatures,

(3) possibility of refurbishment/repair, as well as

(4) to reduce component cost by improving the functionality of a low-cost material with a protective coating.

\section{Synopsis of the Review}

This review aims to present a comprehensive state-of-theart overview of the essential concepts in high-temperature corrosion-resistant coatings, particularly the coatings deposited by thermal spray techniques. The review takes a holistic approach to the relevant topics, at time being concise and critical, with a primary focus on the key developments, including the challenges and opportunities with thermal spray coatings. The review allows both fresh and skilled researchers entering the field to be informed of the various critical aspects of the field, and challenges, as well as their connection to high-temperature corrosion performance. The present paper is organized such that "Introduction" section is dedicated to introduction and need for coatings. "Corrosion in biomass/waste-fired boilers" section is devoted to a background on the power generation sector, mainly the renewable energy boiler industry. "Corrosion protection methods" section is dedicated to corrosion protection methods. In "Thermal spray coatings" section, the advances in thermal spray techniques, especially the newest methods, such as high-velocity air-fuel (HVAF) technique are discussed. The mature knowledge base of the conventionally used and recently developed thermal spray techniques can provide powerful synergistic benefits for deeper scientific understanding of advanced corrosion-resistant coatings. "Hightemperature corrosion in thermal spray coatings" section is a summary of the role of the coating composition in hightemperature corrosive environments. This section covers the recent advances in the understanding of the corrosion mechanisms operating in high-temperature coatings and the effect of alloying. The focus is particularly on the hightemperature corrosion behavior of $\mathrm{Ni}$ - and $\mathrm{Fe}$-based coatings, which are the most commonly used alloy systems in boiler applications.
Despite the growing interest in metallic coatings, a comprehensive treatment of the coatings from the experimental methodologies to the fundamentals and of their corrosion behavior in service environments is lacking. There are review papers on different aspects of coatings, including wear (Ref 10) or erosion-corrosion performance (Ref 11), hot corrosion (Ref 12), low-temperature corrosion (Ref 13) and corrosion in supercritical boilers (Ref 14). However, there are no comprehensive reviews on, for instance, the effect of coating microstructure and composition in high-temperature corrosive environments typical of renewable energy power plants. Furthermore, few reviews (Ref 15-17) adopt a comprehensive unbiased approach, in addition to the timely nature of capturing the surge in research activity in the past few years. Indeed, the previous and current research tendencies in the field of corrosion-resistant coatings are examined, recognizing the discernible knowledge gaps and at the same time seeking to identify the subsequent advancements and research directions in the field. To this end, this review has focused on high-temperature corrosion of metallic coatings and, as such, previously reviewed subjects such as ceramic coatings and high-temperature erosion/corrosion (Ref $11,12,18-22)$ are deliberately not covered.

\section{Corrosion in Biomass/Waste-Fired Boilers}

Biomass can be generally obtained from different sources, e.g., municipal solid waste (MSW), sewage, animal residues, industrial residues, as well as agricultural and forestry crops. Boilers can burn various types of biomass or waste fuels, including MSW, along with residues like straw, peat, wood chip, bark, rice husk, etc. The operating conditions of various boilers (flue gas composition, temperature, and fly ash, etc.) rely on the fuels, as well as on the operating process parameters, and may vary inside the boiler (Ref 23). The combustion of such complicated fuels results in highly aggressive conditions and may lead to failures due to fouling, slagging, agglomeration, caustic embrittlement or/and high-temperature corrosion of the critical components such as superheater and water wall tubes (Ref 24) (see Fig. 3). Moreover, corrosion can lead to severe material damage and tube leakage, resulting in serious operational efficiency problems and costly consequences such as unscheduled shutdowns, high maintenance costs, reduced availability of the plant for power generation, and decrease the lifetime of the boiler tubes. In addition, the requirement for improved electricity/heat efficiency of the boilers necessitates an increase in the steam temperature, which thereupon increases the temperature of the boiler tubes, leading to even more intense corrosion issues, in particular, for the superheater 


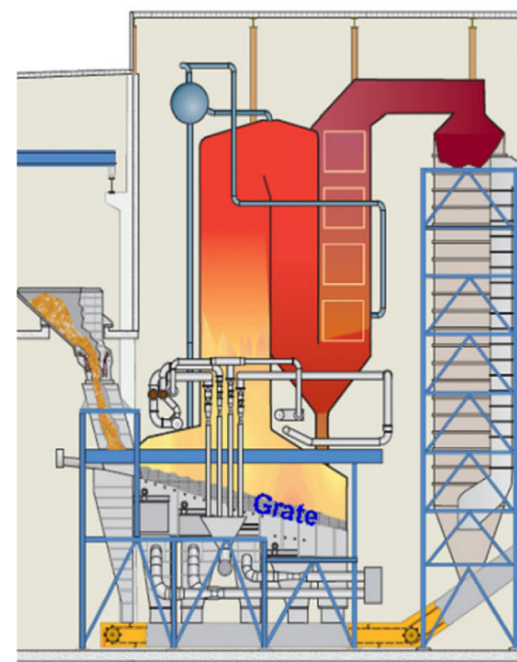

(a)

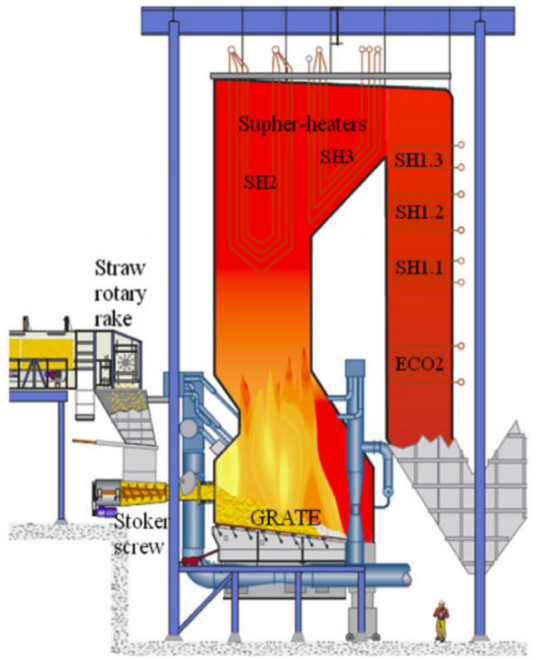

(b)

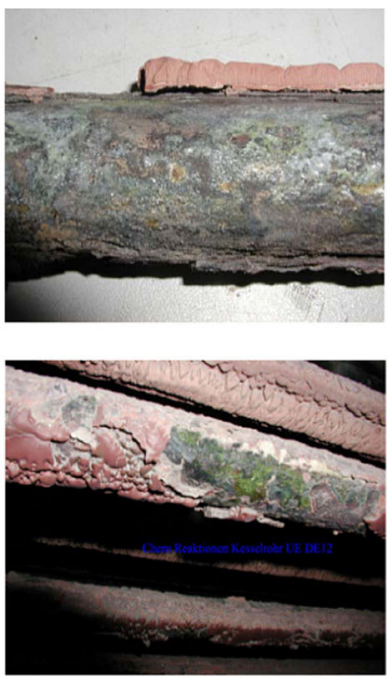

(c)
Fig. 3 Examples of biomass-fired boilers: (a) MSW-fired reciprocating-grate boiler, and (b) straw-fired vibrating-grate boiler (Ref 29); and (c) Tube failures resulting from a highly corrosive biomass fuel

components (Ref 25, 26). The corrosion problems in wastefired boilers are currently addressed through a relatively low steam temperature, which drastically limits the power production efficiency. The reduced steam temperature also affects the temperature of the water wall tubes, which is currently maintained in the range of $300-400{ }^{\circ} \mathrm{C}$. The highest temperatures of the superheater tubes in typical biomass and waste boilers are reported as $\sim 550$ and $450{ }^{\circ} \mathrm{C}$, respectively, during operation $(>10,000 \mathrm{~h}$ ) (Ref $27,28)$.

Biomass or waste fuels contain $\mathrm{C}, \mathrm{H}, \mathrm{O}, \mathrm{N}, \mathrm{S}$, and $\mathrm{Cl}$, major ash-forming elements $(\mathrm{Al}, \mathrm{Ca}, \mathrm{Fe}, \mathrm{K}, \mathrm{Mg}, \mathrm{Na}, \mathrm{P}, \mathrm{Si}$, and $\mathrm{Ti}$ ), as well as minor ash-forming elements (As, Ba, $\mathrm{Cd}, \mathrm{Co}, \mathrm{Cr}, \mathrm{Cu}, \mathrm{Hg}, \mathrm{Mn}, \mathrm{Mo}, \mathrm{Ni}, \mathrm{Pb}, \mathrm{Sb}, \mathrm{Tl}, \mathrm{V}$, and $\mathrm{Zn}$ ). The content of each species depends on the types of biomass and waste used in a boiler (Ref 29). Summarizes the elemental constituents reported in different types of biomass and waste fuels, as well as in fly and bottom ashes.

During combustion in boilers, $\mathrm{Cl}$ contained in the biomass/waste fuels mainly forms gaseous $\mathrm{HCl}$ or/and alkali chlorides (e.g., $\mathrm{KCl}$ and $\mathrm{NaCl}$ ) (Ref 30). Owing to the subsequent cooling of the flue gas in the boiler, a large fraction of $\mathrm{Cl}$ condenses as salts on the heat exchanger surfaces or the fly ash particles in the flue gas. The main consequences of the presence of $\mathrm{Cl}$ are the corrosive effect of chloride salts and $\mathrm{HCl}$ on the metal surfaces present in the boiler (Ref 31) and acidic pollutant emissions (e.g., $\mathrm{HCl}$ ) (Ref 32). In short, the release of the relevant inorganic elements (e.g., $\mathrm{Cl}$ and $\mathrm{K}$ ) not only leads to direct pollutant emissions (e.g., $\mathrm{HCl}$ ) but also causes corrosion problems when they are deposited on the metal surfaces. (from a circulating fluidized bed unit in Germany) (Ref 5). Reprinted with permission from Elsevier

There are various high-temperature corrosion mechanisms that can simultaneously take place in boilers operating with Cl-containing fuels; see Fig. 4. In the superheater tubes, corrosion is initiated through the reactions between the gaseous components and fly ash on the metal surface, where corrosion products can precipitate. The corrosion reactions may result from the combustion gases, which contain $\mathrm{HCl}$, or the deposited ash, which contains mixed (low melting point) salts such as alkalis $(\mathrm{KCl}$ or/and $\mathrm{NaCl})(\operatorname{Ref} 4,8,33)$. The $\mathrm{Cl}$-induced corrosion is initiated upon the release of Cl-containing compounds into the environment, which jeopardizes many alloying elements such as $\mathrm{Ni}, \mathrm{Fe}, \mathrm{Cr}, \mathrm{Al}$, and $\mathrm{Mo}$ by forming volatile metal chlorides. $\mathrm{Cl}$ can penetrate through cracks (in the form of $\mathrm{Cl}_{2}$ ) or/and grain boundaries (in the form of $\mathrm{Cl}^{-}$) of the oxide scale and leads to the oxide breakaway. At the metal-scale interface, $\mathrm{Cl}_{2} / \mathrm{Cl}^{-}$can also react with the alloying elements present and forms volatile metal chlorides (Ref 34-36).

Corrosion of the boiler tubes can also occur due to the presence of molten phases (Ref 37), which are part of an exceptionally harmful corrosion mechanism in biomass and waste-fired boilers. This type of corrosion is due to the low-melting-point eutectic compounds formed between the alkali chlorides $(\mathrm{NaCl}$ and $\mathrm{KCl})$ and other metal chlorides $\left(\mathrm{FeCl}_{2}, \mathrm{NiCl}_{2}, \mathrm{CrCl}_{2}\right.$, etc.) (Ref 38). In other words, it should be considered that the hot gases that are typically formed from the incineration of the waste pass through several sections of the boiler. In the first section, the water wall tubes are located where heat is transferred to the tubes by radiation. The flue gas temperature ranges from $\sim 650$ to $\sim 1000{ }^{\circ} \mathrm{C}$. The temperature of the surface of the water 


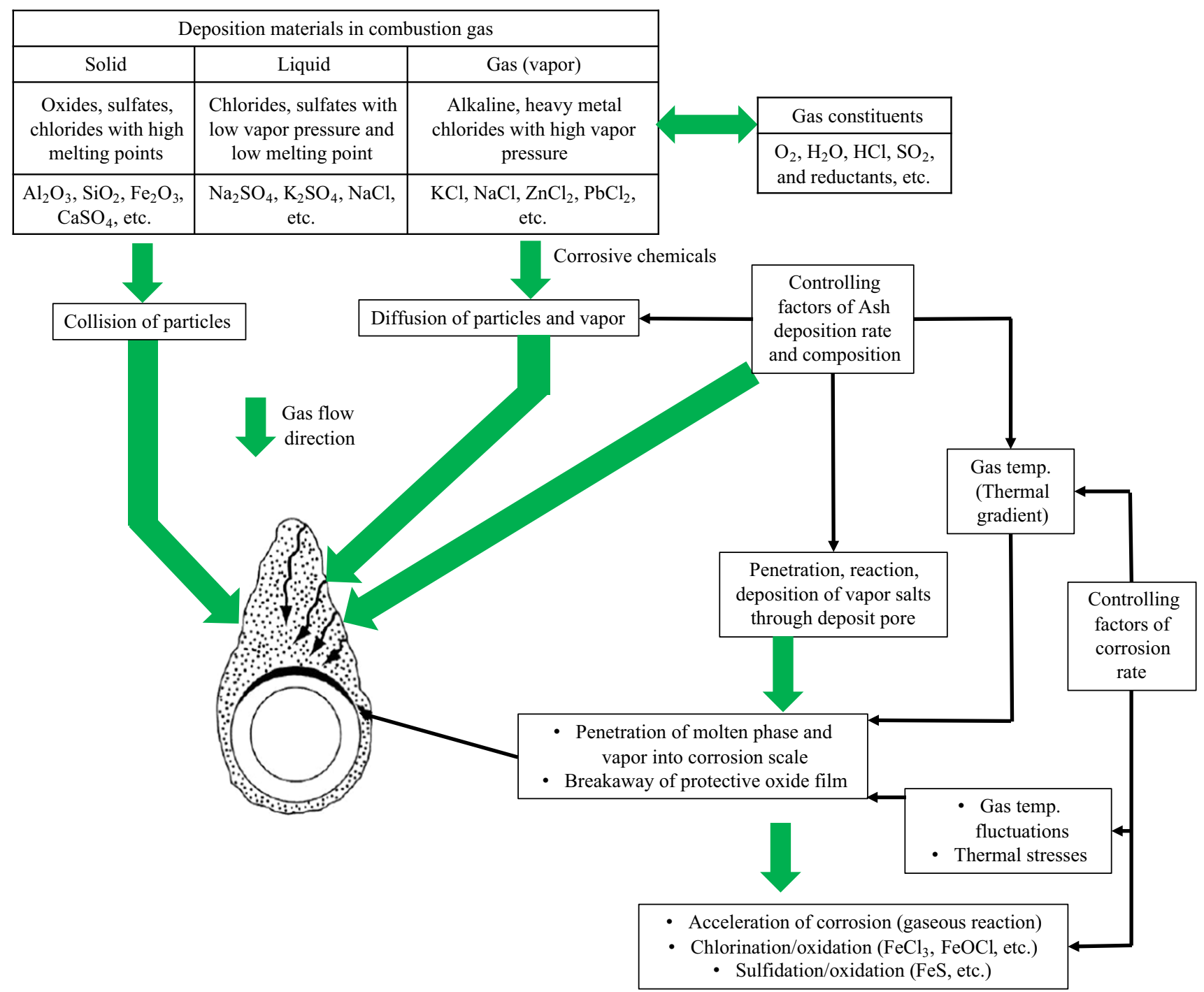

Fig. 4 Main factors of ash deposition and corrosion rate (Ref 18). Reprinted with permission from Elsevier

wall tubes is typically $\sim 250-300{ }^{\circ} \mathrm{C}$. In the second section, the superheater, evaporator, and economizer bundles are located where heat is transferred to the tubes by convection. The flue gas temperature that passes through this section is ranged between approximately 150 and $650{ }^{\circ} \mathrm{C}$. (Ref 39). The corrosion in the boiler is mainly caused by the interactions of chlorides, sulfates, polysulfates, and sulfides with iron or iron oxides on the tube surfaces and limits the steam temperature that can be achieved in wasteto-energy (WtE) plants, and accordingly, the electrical energy efficiency (Ref 40). These corrosive species originate from the waste that is incinerated and are condensed onto the colder tube surfaces as the temperature decreases further down the boiler.

Owing to a large number of gaseous, solid, and even liquid compounds that are concurrently present in boilers, various competing corrosion reactions can occur simultaneously. Hence, the prediction of corrosion rates or the type of corrosion attack is challenging. Nevertheless, through a combination of simplified and controlled laboratory exposures, the significant features associated with the fireside corrosion of superheater tubes in full-scale power plants can be highlighted. Although S-containing compounds (Ref 41) may also have an impact on alloy performance, the main mechanisms associated with material failure involve the $\mathrm{Cl}$-containing compounds present in the gaseous, liquid, or solid states, which are briefly explained below.

\section{Corrosion Protection Methods}

To control the corrosion caused by corrosive species and enhance the lifetimes of boiler components, two practical and widely accepted solutions are available, involving either a) the use of highly alloyed materials or b) 
alleviating the environment (Fig. 5). While in the case of the latter, adding S-containing additives or reducing the operating temperature is commonly proposed (Ref 42 ), austenitic stainless steels or Ni-based materials are frequently suggested as part of the former (Ref 18, 43). Reducing the working temperature leads to a significant decrease in the thermal/electrical efficiency of a boiler, whereas the development of highly alloyed materials is complex, time-consuming, and extremely expensive. Hence, the above solutions are not always alluring both from an economic perspective and from a technical point of view. Therefore, as an alternative, corrosion has been increasingly controlled in recent years through the deposition of dense defect-free adherent coatings by using the three extensively used techniques of thermal spraying, laser cladding, and weld overlay (Ref 44-48).

\section{Modification of the Environment}

Although different corrosion mechanisms are possible, depending upon the complexity of the environment prevailing during combustion, and although the details about protective oxide breakdown are still debated, it is evident that alkali chlorides are the main concern. Studies have therefore been performed to avoid the formation and accumulation of alkali chlorides on metallic surfaces. S compounds are often added during the combustion of biomass, in the form of ammonium sulfate, sewage sludge, etc., to convert alkali chlorides to less corrosive alkali sulfates according to the sulfation reaction (Eq 6), a schematic view of which is shown in Fig. 6. Indeed, the corrosion can be controlled by capturing the alkalis from their chlorides before the deposition onto the tube surfaces.
The alkali chlorides have already been shown to be much more detrimental owing to their lower melting points compared to those of the sulfates. Spiegel and Grabke (Ref 49) studied the effect of S-containing gases (e.g., $\mathrm{SO}_{2}$ ) on the corrosion occurring under alkali chloride deposits and found that the corrosion rates decreased in the presence of $\mathrm{SO}_{2}$. They found that the chlorides are transformed into sulfates at high concentrations of $\mathrm{SO}_{2}$, with the sulfates being less aggressive than the corresponding chlorides. Such alkali sulfates are considered to be rather stable in $\mathrm{WtE}$ plants and are not expected to cause severe corrosion. Salmenoja et al. (Ref 50) obtained a similar positive effect of $\mathrm{S}$ after investigating the corrosiveness of different fuel blends. A S:Cl ratio of 4:1 in the fuel was proposed as an optimum condition to prevent severe corrosion problems. During combustion, the $\mathrm{S}: \mathrm{Cl}$ ratios are usually significantly lower. Recently, actual boiler tests have also been performed with S-containing additives in the fuel, which have proven to be effective in reducing the corrosion rates (Ref 51-54).

However, the sulfation of condensed $\mathrm{KCl}$ particles on the surface of a superheater tube can have serious implications on corrosion attack, because $\mathrm{HCl}$ released close to the metal surface may serve as a source of $\mathrm{Cl}$ to propagate the corrosion. Moreover, the present understanding of the progression of the corrosion attack with time under such conditions is inconsistent (Ref 55). On the one hand, laboratory-scale studies with very low deposit coverages $\left(0.01 \mathrm{mg} / \mathrm{mm}^{2}\right)$ at $600{ }^{\circ} \mathrm{C}(\operatorname{Ref} 56)$ have revealed that the conversion of $\mathrm{KCl}$ to the less corrosive $\mathrm{K}_{2} \mathrm{SO}_{4}$ is complete after $1 \mathrm{~h}$ of exposure; accordingly, the corrosion attack should reduce significantly afterward. On the other hand, by using a high deposit coverage $\left(0.75 \mathrm{mg} / \mathrm{mm}^{2}\right)$,

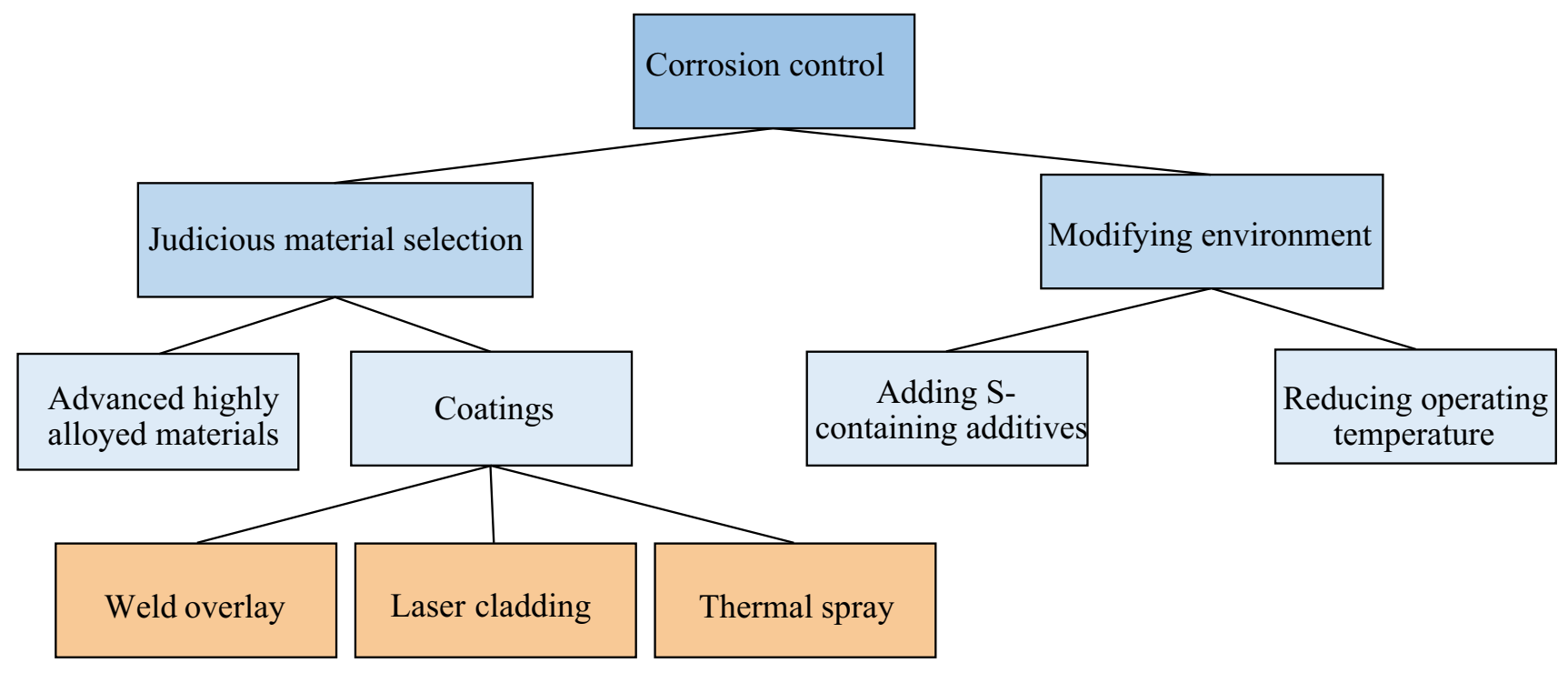

Fig. 5 Commonly proposed approaches to controlling high-temperature corrosion in boilers (Ref 211). Reprinted with permission from Elsevier 


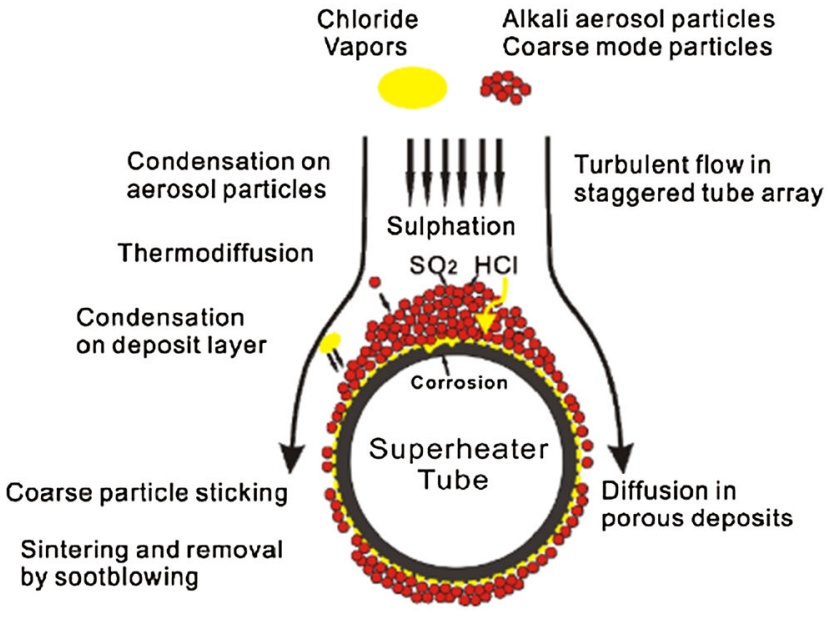

(a)

Fig. 6 (a) Schematic view of the mechanisms of ash formation and deposition on a superheater tube surface in the presence of $S$; (b) the $S$ recirculation system at the Renova WtE plant consists of a hydrogen peroxide dosage system and a system for sulfuric acid recirculation by using air atomization and flue gas recirculation. The photographs

laboratory-scale investigations at $560{ }^{\circ} \mathrm{C}$ under the same gas atmosphere have shown that the conversion of $\mathrm{KCl}$ to $\mathrm{K}_{2} \mathrm{SO}_{4}$ is below $10 \%$ after $72 \mathrm{~h}$ (Ref 57 ).

Andersson et al. (Ref 58) investigated S recirculation through full-scale tests at a WtE plant over nearly two months of operation; see Fig. 6(b). S was recirculated as sulfuric acid $\left(\mathrm{H}_{2} \mathrm{SO}_{4}\right)$ from the flue gas used for cleaning back to the boiler, thus creating a $\mathrm{S}$ loop. The new technology was extensively evaluated by measurement campaigns during operation under normal conditions (as a reference) and during an operation involving $\mathrm{S}$ recirculation. The $\mathrm{Cl}$ content of both fly and bottom ashes decreased, while the $\mathrm{S}$ content increased, during the $\mathrm{S}$ recirculation tests. The deposit growth and particle concentration decreased with the $S$ recirculation and with a reduction in the dioxin concentration of the flue gas by approximately $25 \% . \quad \mathrm{H}_{2} \mathrm{SO}_{4}$ dew point measurements showed that $\mathrm{H}_{2} \mathrm{SO}_{4}$ dosage did not lead to increased $\mathrm{SO}_{3}$ concentrations, which may otherwise induce low-temperature corrosion. In the $\mathrm{S}$ recirculation, the corrosion rate of the corrosion probe exposures (see Fig. 6c) decreased for all the materials tested (16Mo3, Sanicro 28, and Alloy 625) at the temperatures of 450 and $525{ }^{\circ} \mathrm{C}$, compared to the reference exposure. The corrosion rates reduced by $60-90 \%$. The $\mathrm{S}$ recirculation prevented the formation of transition metal chlorides at the metal/oxide interface, the formation of chromate, and reduced the presence of $\mathrm{Zn}$ in

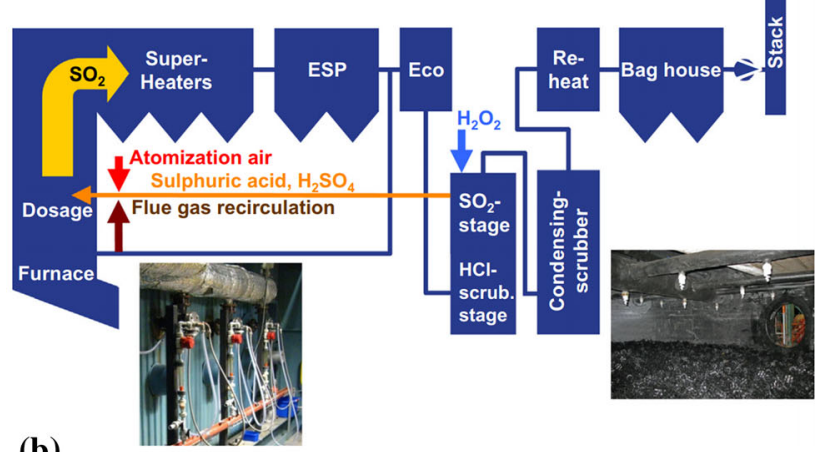

(b)

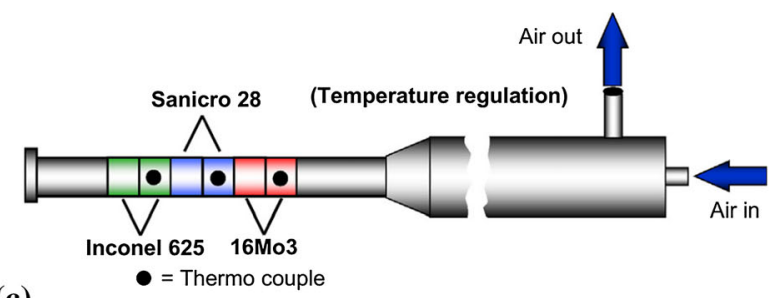

(c)

show three of the injection lances (left) and the tower packings and spray lances of the desulfurization stage (right); and (c) a schematic view of the corrosion probes installed to monitor corrosion in the presence of S recirculation (Ref 212, 213). Reprinted with permission from Elsevier

the corrosion products. Furthermore, the measured corrosion rates at $525{ }^{\circ} \mathrm{C}$ with the $\mathrm{S}$ recirculation in operation were similar or lower compared to those at $450{ }^{\circ} \mathrm{C}$ in the reference condition, which corresponds to normal operation at normal steam temperatures. This implies that $\mathrm{S}$ recirculation allows for higher steam temperatures and electricity production without increasing corrosion (Table 1).

\section{Advanced Materials}

Several different materials are commonly used in the various parts of a boiler; see Table 2. For instance, in superheater tubes, low-alloy ferritic steels, $9-12 \% \mathrm{Cr}$ ferriticmartensitic steels, austenitic stainless steels, and Ni-base alloys are employed (Ref 59). These materials combine good thermal conductivity with good mechanical properties, as well as exhibit desired machinability and weldability. It is pertinent to mention here that materials for pressurized components are strictly regulated by pressure vessels regulations and developing new materials is usually complex, time-consuming, and more importantly, extremely expensive. Hence, the use of highly alloyed materials is not always attractive from both economic and technical perspectives, especially for the power plant applications where cost is highly important. 
Table 1 Detrimental elements found in wood-derived fuels as well as in bottom and fly ashes taken from biomass boilers (Ref $51,203)$

\begin{tabular}{lccccc}
\hline Element, mg/kg & \multicolumn{3}{c}{ Wood-derived fuels } & Fly ash & Bottom ash \\
\cline { 2 - 4 } & Forest residue & Bark & Recycled wood & & \\
\hline Organic carbon, C & 51.7 & 52.5 & 49.4 & 21,000 & $<1000$ \\
Fluoride, $\mathrm{F}^{-}$ & $\ldots$ & $\ldots$ & $\ldots$ & $<100$ & $<100$ \\
Chloride, $\mathrm{Cl}^{-}$ & 0.031 & 0.019 & 0.09 & 4400 & 200 \\
Sulfate, $\mathrm{SO}_{4}{ }^{2-}$ & 0.01 & 0.03 & 0.07 & 44,000 & 300 \\
Arsenic, $\mathrm{As}$ & 0.11 & 0.11 & 69 & $<15$ & $<15$ \\
Barium, Ba & 67 & 120 & 583 & 5300 & 3700 \\
Cadmium, Cd & 0.26 & 0.38 & 1.8 & 6.8 & $<0.1$ \\
Chromium, Cr & 21 & 35 & 90 & 52 & 15 \\
Copper, $\mathrm{Cu}$ & 2.4 & 3.9 & 50 & 160 & 43 \\
Mercury, $\mathrm{Hg}$ & 0.022 & 0.033 & 0.11 & 0.47 & $<0.03$ \\
Molybdenum, Mo & 0.74 & 1.3 & 0.41 & 6.9 & 2.7 \\
Nickel, $\mathrm{Ni}$ & 6 & 11 & 1.2 & 71 & 11 \\
Lead, $\mathrm{Pb}$ & 0.64 & 1 & 213 & 100 & 11 \\
Antimony, Sb & $\ldots$ & $\ldots$ & $\ldots$ & $<10$ & $<10$ \\
Selenium, Se & $\ldots$ & $\ldots$ & $\ldots$ & 17 & $<15$ \\
Zinc, $\mathrm{Zn}$ & 85 & 150 & 1950 & 1500 & 650 \\
\hline
\end{tabular}

Table 2 Conventional and advanced materials utilized in boilers and their operating temperatures (Ref 76)

\begin{tabular}{lcc}
\hline Boiler part & Temperature range, ${ }^{\circ} \mathrm{C}$ & Applied materials \\
\hline Superheaters & $450-750$ & DIN X20CrMoV121, 13CrMo44(T12), T91, HCM 12 (P122, SUS410J3TB), Super \\
& & 304H, Sanicro 25, HR3C, TP347H(FG), Alloy 617, AC66, Alloy 625, A263 \\
Reheaters & $290-500$ & 10CrMo910 (T22, SA213), 13CrMo44 (T12), HCM 12, Super 304H, TP347H, Alloy \\
& & 617 \\
Economizers & $150-300$ & ST35.8, DIN 15Mo3, SA201-Gr.A1 \\
Furnace walls & Max. 500 & 13CrMo44(T12), DIN 15Mo3, T22, T23, T24, HCM 12, Alloy 617 \\
Steam pipes & $500-620$ & P91, P92 (NF616), P122, DIN X20CrMoV121, HCM 12, SAVE121, NF121, Alloy \\
& & 617, A263 \\
\hline
\end{tabular}

\section{Coatings}

Although it is impossible to completely eliminate corrosion, the deployment of suitable corrosion control strategies is promising for significantly mitigating its impact. The need for protection and the challenge of ensuring its adequacy has exponentially grown, especially when hightemperature environments are involved. As mentioned above, the early efforts to combat high-temperature corrosion involved the development of new alloys, which resulted in a progressive evolution of a host of materials for boiler components (Ref 60,61). Nonetheless, the growing use of biomass/waste fuels for power generation, combined with the incessant demands for enhancing the operational efficiency, has necessitated the need for improved corrosion protection, and it is clear that further significant advancements can only be achieved through the use of advanced protective coatings as the first line of corrosion attack. Moreover, another purpose of applying the above coatings is to ensure the formation of a protective oxide scale; see Fig. 7.

At present, the most economically and technically favored method for corrosion protection of boiler components is deploying an overlay coating. Coatings can be used to extend the limits of application of materials to their maximum performance capabilities by allowing the mechanical properties of the underlying materials to be preserved while protecting them in high-temperature corrosive environments (Ref 62, 63). A large number of coating processes, such as weld overlay, laser cladding, and thermal spraying, are available for providing surface protection. Although the coatings can increase the high-temperature corrosion resistance of a component, there are a few technical challenges in producing coatings that can meet the high-performance requirements. 
Fig. 7 A typical coating targeted to form a suitable oxide scale to protect against corrosion attack

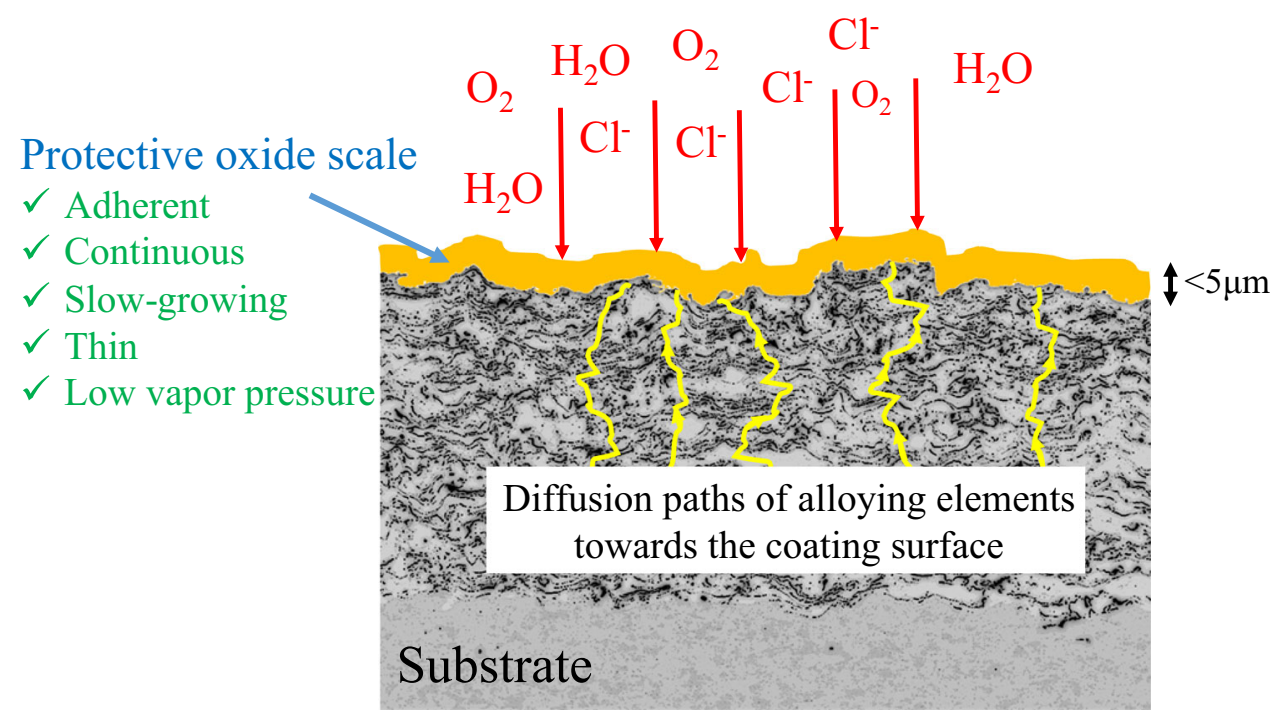

Weld overlays are metallic coatings that are directly welded onto the substrate. The high-heat welding process results in the formation of a metallurgical bond with the base metal, essentially alloying the coating on the substrate at the interface. The result is a durable and almost nonporous coating that has good resistance to corrosion (Ref 48, 64). Furthermore, the application of Ni-based weld overlay coatings has been found to provide effective protection, and this practice has become widespread (Ref 65). However, a major concern regarding the weld overlay is that repeated applications at the same area may lead to embrittlement of the old overlay and cause cracks that propagate into the overlaid tube. Moreover, dilution of alloying elements such as $\mathrm{Fe}$ from base material to the weld overlay (for instance, Alloy 625 (Ref 66)) can occur, which reduces the corrosion resistance of the weld. Besides, the surface of the weld overlay coatings is typically rough, and uneven which can accelerate corrosion through easier sticking of slag or produce lower coating thickness areas that concentrate heat flux. The weld overlays can only be applied in high thicknesses ( 2-3 mm) (Ref 21), which may increase the temperature drop across the layer. The lowered thermal conductivity of the weld overlay coatings due to their high thickness leads to an increase in the proportion of heat absorbed in the upper furnace and convection pass, resulting in a deviation from the design heat balance of the boiler, as well as the tendency of thermal fatigue cracking of the coated tubes.

Since weld overlays are typically applied in high thicknesses, substantial amounts of materials may be applied in a comparatively short time, so the process needs to be interrupted several times. The technical challenges associated with the weld overlay coatings mainly consist of varying corrosion resistance of the beads due to dilution of alloying elements, an increased risk of cracking due to a high level of residual stresses, and a mismatch in the CTE between the weld and substrate.

In laser cladding, a laser beam fuses a consumable onto the substrate surface to produce a dense uniform crack-free coating. During the deposition, the top layer of the substrate is melted to form a metallurgical bond, with some of it diluting the coating. The laser beam can be focused to a very small area and keeps the heat affected zone (HAZ) of the substrate very shallow. This minimizes the chance of cracking, distorting, or changing the metallurgy of the substrate. Additionally, the lower total heat input minimizes the dilution of the coating with material from the base material and prevents distortion of the substrate. Moreover, the laser beam can more rapidly treat larger surface areas. However, a big concern regarding the laser cladding is its high cost, which prevents the technique to be attractive in the boiler industry.

\section{Thermal Spray Coatings}

In a thermal spray process, metallic or non-metallic material of target chemistry is deposited on a substrate (Ref 67). The feedstock material, typically in the form of a powder, wire, or solution/suspension, is heated to a molten or semi-molten state and accelerated in a flame, before being propelled onto the substrate; see Fig. 8 . The fully or partially melted particles deform when they impact the substrate and form the so-called splats. The coating material bonds to the substrate by mechanical interlocking upon impact and/or solidification. Not only a wide variety of materials can be deposited but also worn parts can be recoated easily by using thermal spray techniques (Ref 67).

The earliest records of thermal spraying can be found in the patents of Max Ulrich Schoop (Zurich, Switzerland), 


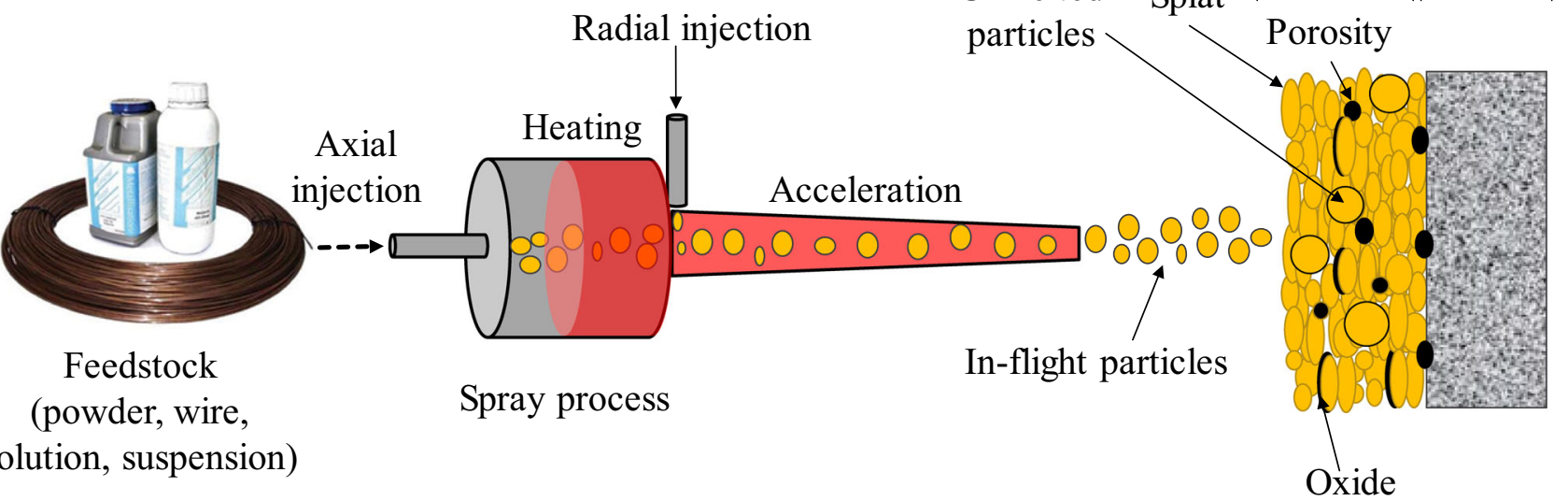

Fig. 8 Schematic diagram of a thermal spray process. The feedstock material which is in forms of powder, wire, solution, or suspension can be radially or axially injected into the spray process

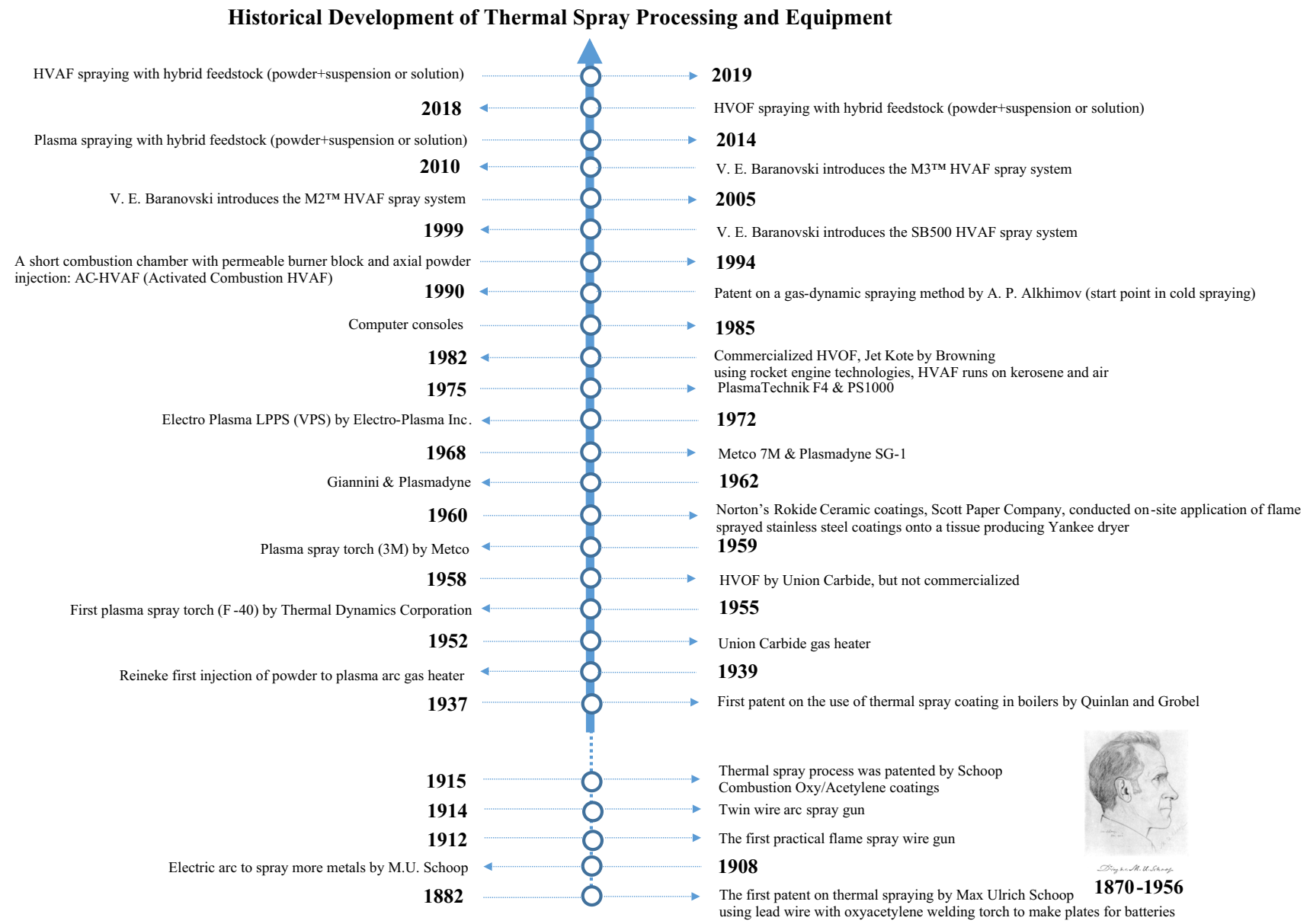

Fig. 9 Timeline of the scientific and technological developments of thermal spray coatings, indicating prominent "landmarks" since introduction in 1882

dating back to the period 1882 to 1889 ; see Fig. 9. These patents describe a process of feeding $\mathrm{Pb}$ and $\mathrm{Sn}$ wires into a modified oxyacetylene welding torch. Later, the torches were modified to accept powder feedstock. The powders were injected in a hot expanding jet flow, where the particles were heated while being accelerated toward the 
surface for impaction, splash (if molten), and solidification. The results were coatings that were incrementally formed from the impacting droplets. Schoop developed the thermal spraying techniques during his lifetime and patented a few of them.

Upon perusal of early documents and the associated analysis, it can be inferred that most of the early applications were designed bottom-up. That is, the believers of the thermal spray technology pushed the applications upstream by demonstrating the value proposition of surface engineering. Corrosion and material reclamation were the primary drivers. A key demonstration of material reclamation was in the paper industry. The engineering components are generally large and, as such, the value propositions of surface engineering for both protection and reclamation were very high.

The thermal spray technology was then developed in many countries, especially Russia, Germany, and the USA, where the technology continued to be introduced to various applications over the years. The principle behind the thermal spray process during the early years of the 1920s to the 1950s was wire and powder flame spraying. Quinlan and Grobel (Ref 68) in 1937 were the first to introduce thermal spray coatings in boilers for high-temperature corrosion protection. The 1950s saw the emergence of DC atmospheric plasma spraying (APS) for application to refractory materials, notably ceramic oxides. It involved the use of the latent heat of ionized inert gas (plasma) to generate a heat source. The most common gas utilized to form the plasma was Ar, which was also referred to as the primary gas. The convergence of these developments led to the integration of thermal spraying as a process of choice in the 1970s and 1980s for component protection and performance enhancement in the aero-engine industry. It was in the early 1980s that Browning and Witfield (Ref 69) developed a new approach to spraying metal powders by using rocket engine technologies, which was known as high-velocity oxy-fuel (HVOF) spraying. The powder was partially melted in a jet stream by using straight (in the 1st and 2nd generations) or more advanced convergent-divergent (or so-called De Laval; in the 3rd generation) nozzles, and deposited on the substrate.

Like HVOF, the developments of high-velocity air fuel (HVAF) spraying started by Browning (Ref 70) and involved the concept of "Hypervelocity Impact Fusion." According to this original HVAF concept, powder is injected into a nozzle and entrained by a hot supersonic gas stream, the temperature of which is below the melting point of the powder material (the melting point of the binder phase in the case of hard metals). The solid powder particles are heated and accelerated to extreme velocities by using a De Laval nozzle. Upon impact with the substrate, the kinetic energy of the particles is converted into thermal energy, which further heats the particles and melts or deforms them sufficiently to form a part of the coating. Several gun models have been developed for this process. After the first improvement of the HVAF gun design through the introduction of a permeable burner block into an internal combustion chamber, further progress was made by introducing a catalytic member in the internal burner. Hybrid coatings using two different types of feedstock materials (a coarse powder and a fine structured suspension) have been shown as a promising approach to obtain coatings with enhanced functional performance (Ref 71-74). The spraying processes will be individually discussed in detail in the subsequent sections.

Generally, the thermal spray processes can be classified based on the type of energy source; see Fig. 10. The processes can also be categorized based on the temperature (T) and velocity (V) of the produced jet stream; see Fig. 11. As seen in Fig. 11, the in-fight particle temperature and velocity may vary across different thermal spray processes, as each process has its own inherent characteristics in terms of gas temperature and gas velocity that govern particle heat-up and acceleration. The difference in the velocity and temperature of in-flight particles across the various methods is a major factor that explains the diversity observed in the resulting coating microstructures.

Although all thermally sprayed coatings typically contain splats, there are huge differences among the coatings in terms of the nature of splat boundaries (like oxide pickup, which is usually observed at such boundaries), level of porosity, and residual stress. While the formation of the in situ oxides leads to depletion of the scale-forming elements (e.g., Al, Cr, etc.), the exact effect of such oxides on corrosion mechanism of the coatings is still unclear. Moreover, the intersplat bonding and interconnected pores can act as short-circuit diffusion paths for corrosive agents (Ref 75). Therefore, the microstructure and composition of the coatings should be tailored to ensure their high capability in various applications; for instance, high protection in harsh corrosive conditions.

It is pertinent to mention that to design an advanced coating for a target application such as a boiler, a thorough understanding of the relationship between the process, microstructure, properties, and performance of the coating is generally required; see Fig. 12(a). The coating process can be assessed by identifying the characteristics of the jet stream (such as velocity and temperature) and the effect of any change in the process parameters on the coating microstructure. By considering the formed microstructure and the properties of the coatings, along with the spray characteristics, an understanding of the spraying process can be obtained, and the connection between the process parameters and coating formation can be possibly established. Therefore, a critical understanding of the 


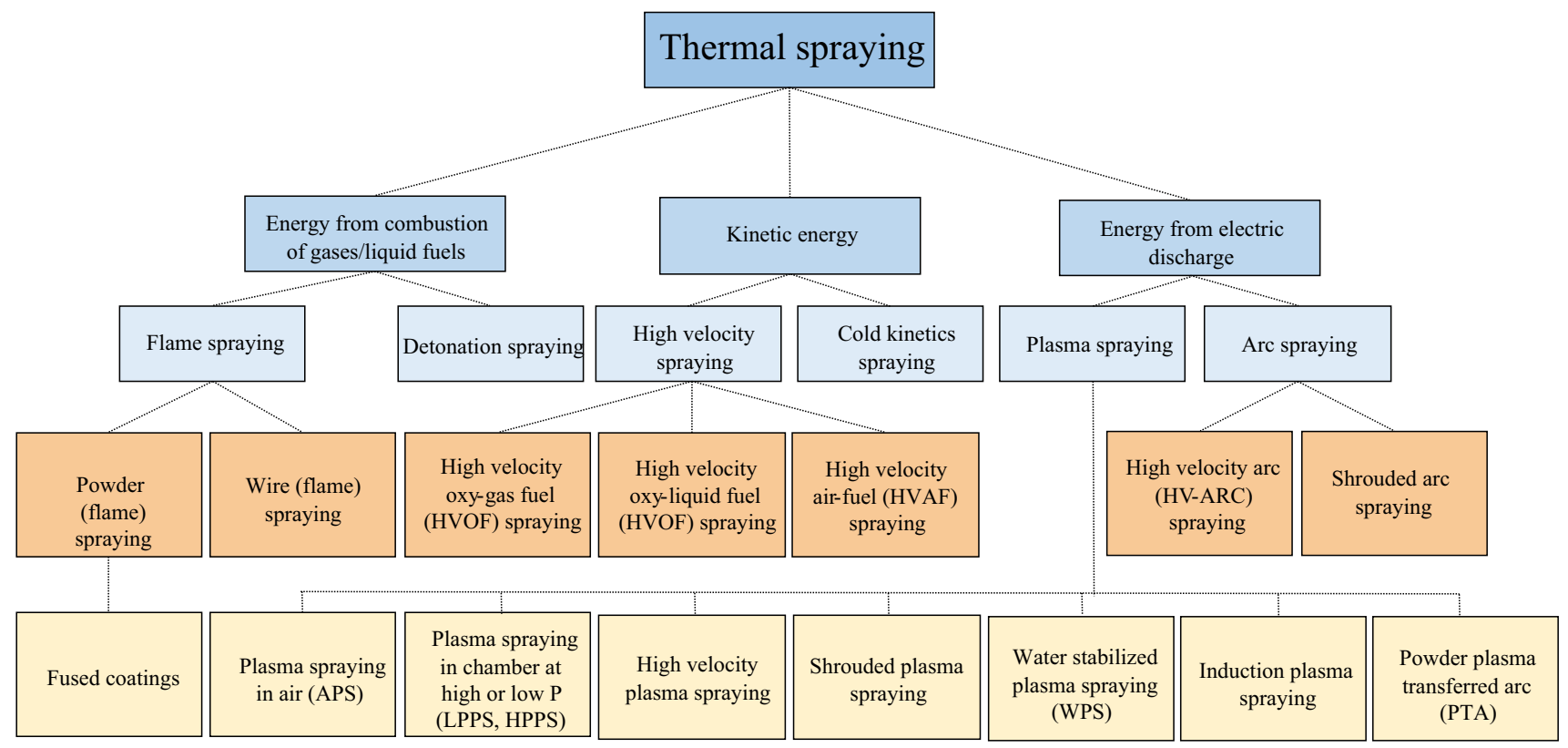

Fig. 10 Classification of the thermal spray processes (Ref 214). Reprinted with permission from Elsevier

Fig. 11 Thermal spray processes categorized in terms of the temperature and velocity of the produced jet stream (Ref 69). Reprinted with permission from Elsevier

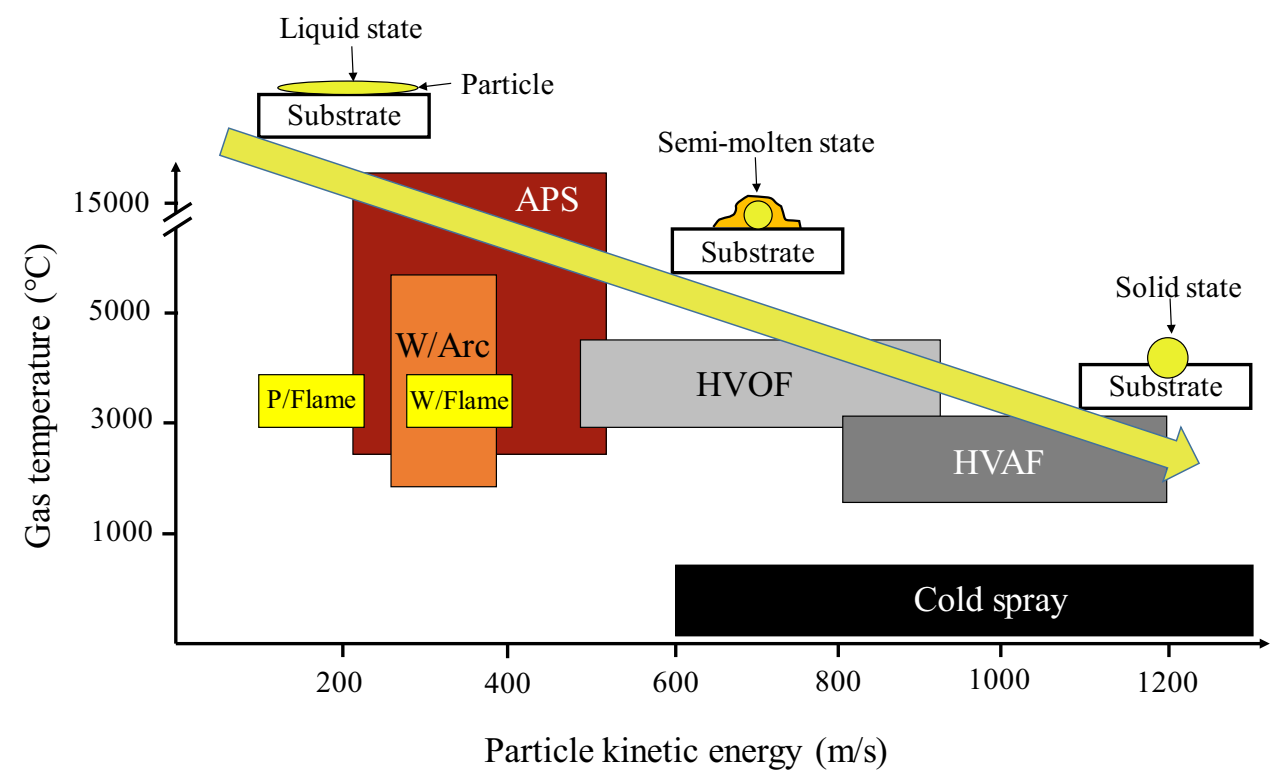

A few of the thermal spray techniques, along with their implementations in high-temperature corrosion-resistant applications, are reviewed below; see Fig. 13.

\section{Flame Spray Technique}

Flame spraying, a century-old process, involves a gun nozzle (Fig. 13a and b) in which a mixture of $\mathrm{O}_{2}$ and a fuel $\left(\mathrm{C}_{x} \mathrm{H}_{y}\right)$ such as acetylene $\left(\mathrm{C}_{2} \mathrm{H}_{2}\right)$ or propane $\left(\mathrm{C}_{3} \mathrm{H}_{8}\right)$ is injected. The gas mixture is combusted in front of the nozzle (according to Eq 1) to generate a flame. Depending 
(a)

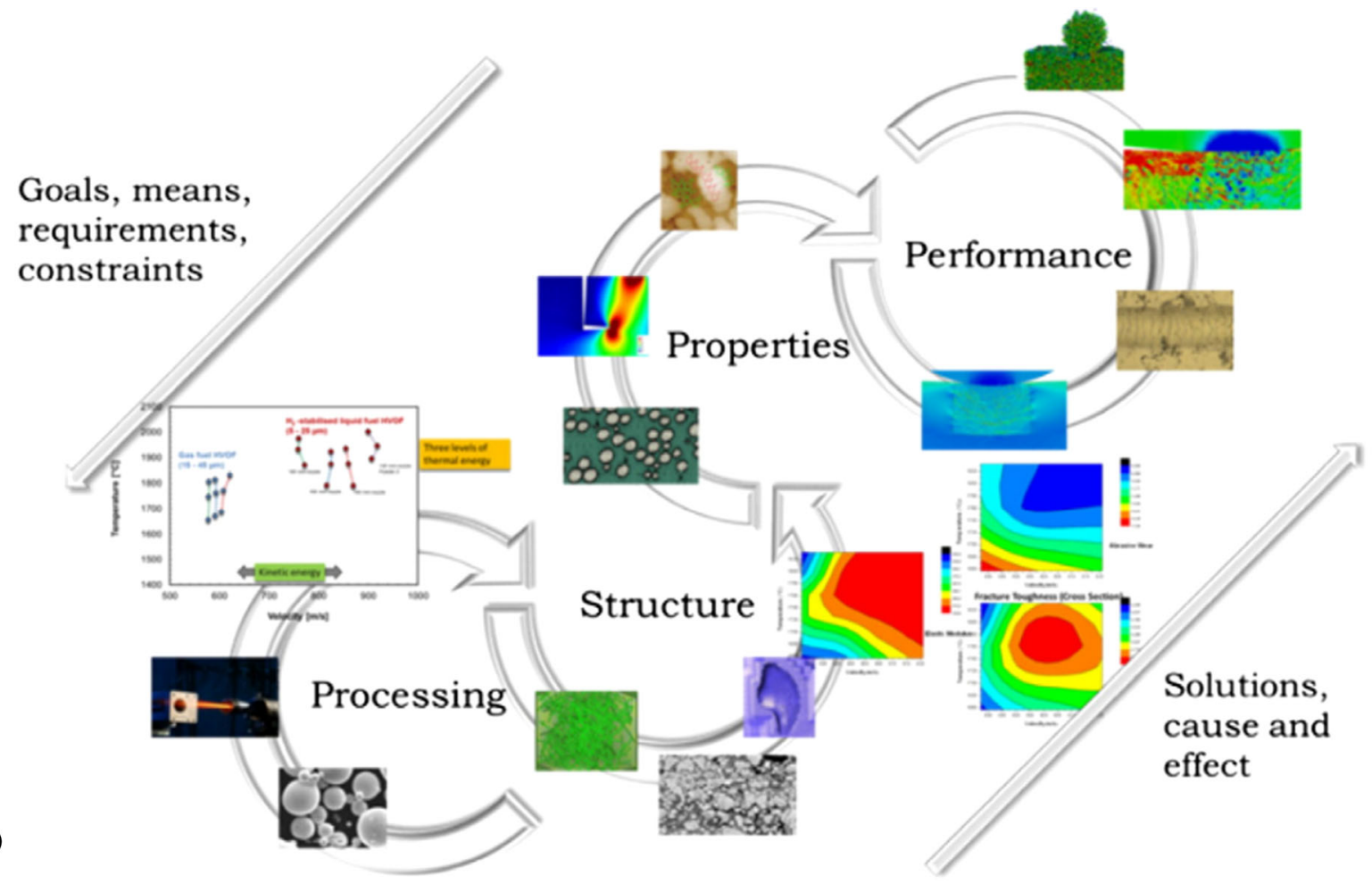

Operation conditions

\section{Coating}

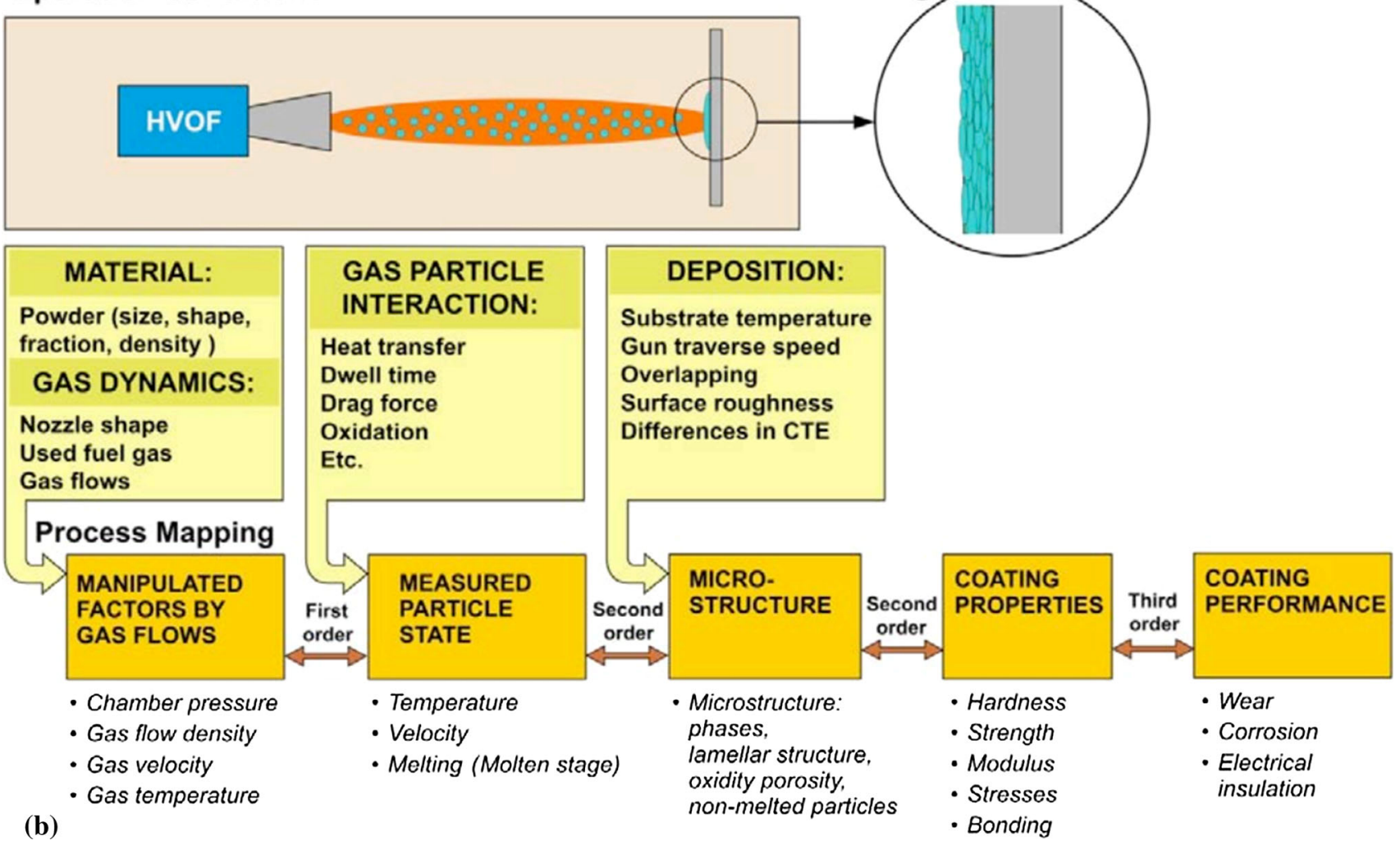

Fig. 12 (a) The process-structure-properties-performance approach to designing coatings (Ref 215), and (b) a typical process map designed for the HVOF process (Ref 77). Reprinted with permission from Elsevier 


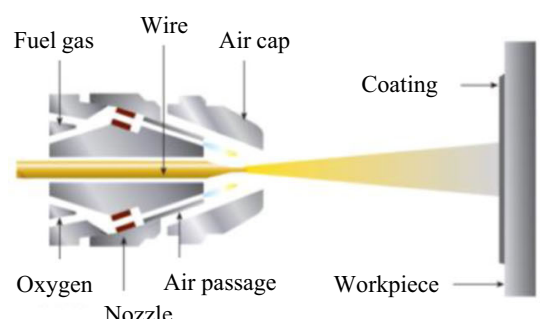

(a)

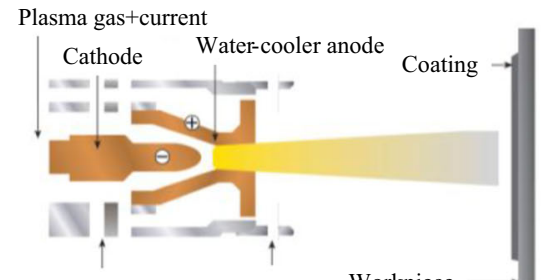

(d) Insulator

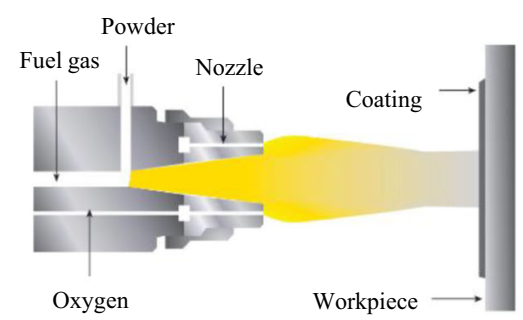

(b)

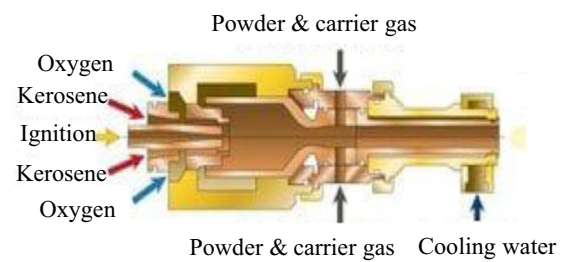

(e)

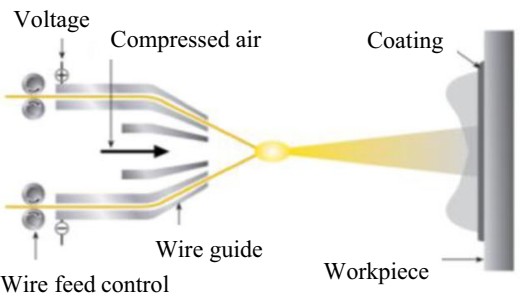

(c)

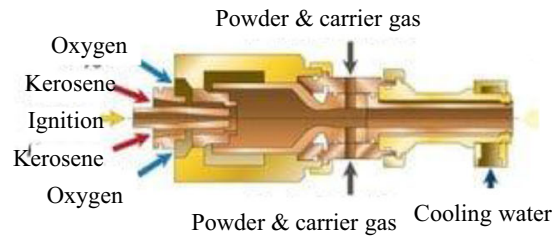

(f)

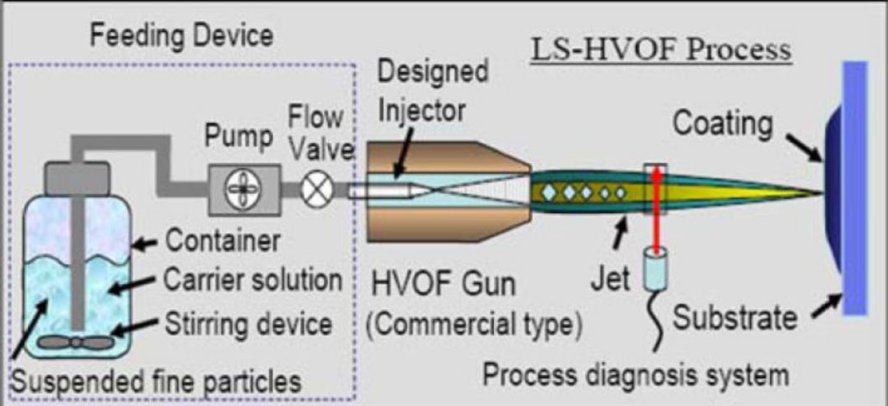

(g)

Process diagnosis system

(h)
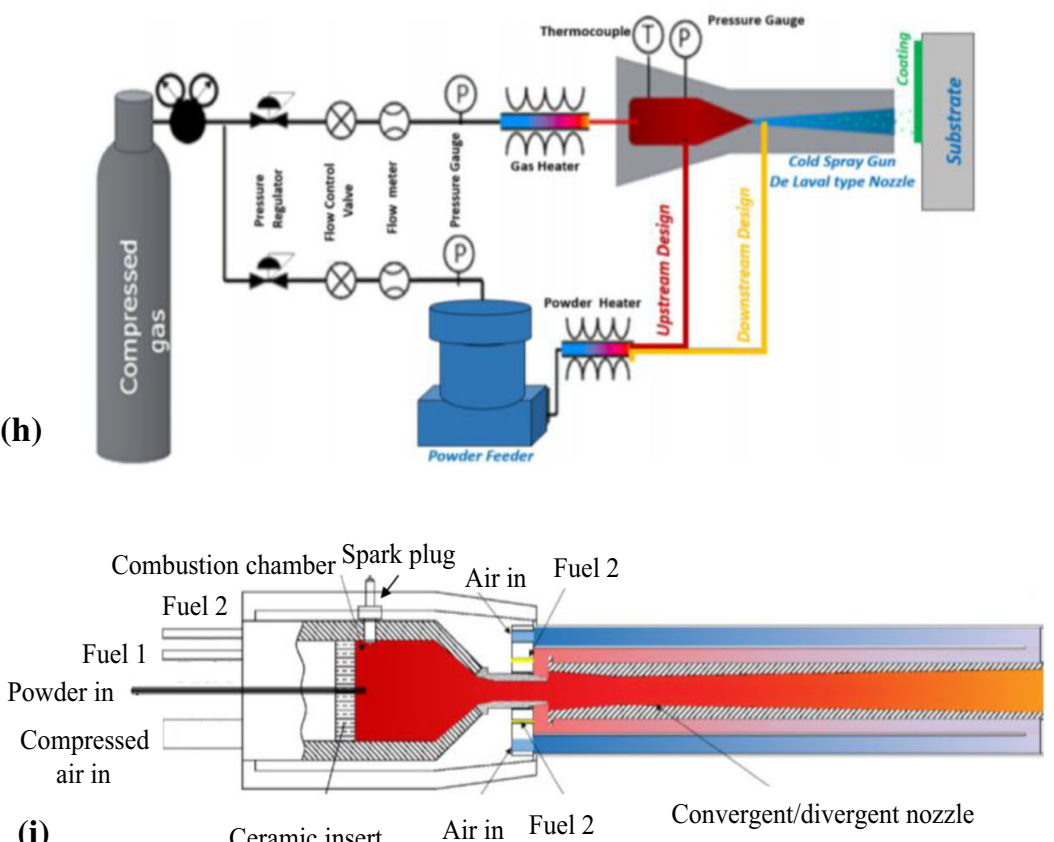

Fig. 13 Schematic diagram of (a) the wire flame process and (b) the powder flame process; (c) schematic diagram of the wire arc process; (d) schematic diagram of APS; schematic diagram of HVOF with

HVOF process setup (Ref 93); (h) a schematic view of an HVAF gun (Uniquecoat $\mathrm{M}^{\mathrm{TM}}$ ) (Ref 217), and (i) a schematic of the cold spray process (Ref 218). Reprinted with permission from Elsevier 
on the ratio of $\mathrm{O}_{2}$ to fuel, the temperature of the flame is between 3000 and $3300{ }^{\circ} \mathrm{C}$. The feedstock materials used can be in the form of powders or wires. The materials deposited by this method typically include $\mathrm{Ni}$ - and $\mathrm{Co}-$ based alloys, some refractory metals, $\mathrm{Cr}_{2} \mathrm{C}_{3}$ in a $\mathrm{NiCr}$ matrix, $\mathrm{Al}_{2} \mathrm{O}_{3}, \mathrm{ZrO}_{2}$, and $\mathrm{TiO}_{2}$. The advantage of the spray process lies in its versatility, portability, and low capital cost. With this technique, coatings with high content of porosity are usually obtained (Ref 24). Flame spraying is a low-energy process that may prove to be more economical than other thermal spray processes; however, the level of corrosion protection might not be satisfactory. Rana et al. (Ref 78) investigated NiCrAlY coatings deposited by the flame spray technique that are exposed to ambient air and $\mathrm{Na}_{2} \mathrm{SO}_{4}+\mathrm{V}_{2} \mathrm{O}_{5}$ salt at $900{ }^{\circ} \mathrm{C}$. The peculiar morphology of the as-sprayed coatings showed pre-oxidized regions composed of alumina and unoxidized regions containing $\mathrm{Ni}$ and $\mathrm{Cr}$. This morphology inherently provides protection against air oxidation and also assists in resisting the aggressive molten salt. In the case of a molten-salt environment, the oxides of $\mathrm{Ni}, \mathrm{Cr}$, and spinels were observed to have grown throughout the surface. However, in the case of air oxidation, the pre-oxidized area remained unaffected. The porosity of the coatings showed a minimal effect on the air oxidation. In the case of hot corrosion, $\mathrm{V}$ penetrated the pores but did not intensify the corrosive attack. In general, it seems that high amounts of in situ oxides and pores in flame-sprayed coatings limit their performance in high-temperature applications.

$\mathrm{C}_{x} \mathrm{H}_{y}+\mathrm{zO}_{2} \rightarrow x \mathrm{CO}_{2}+\frac{y}{2} \mathrm{H}_{2} O \quad$ where $z=x+\frac{y}{4}$

\section{Electric Arc Spray (Wire Arc) Technique}

In this process, the coating material is melted not by the application of heat from external sources, such as a flame but by producing a controlled electric arc between two consumable electrode wires. The wires have compositions close to that of the desired coating. The arc melts the wire at the tip. A compressed air or inert gas stream fragments the molten material and propels the droplets toward the substrate. A schematic of the electric spraying system is shown in Fig. 13(c). Greater bonding strengths, lower porosities, and higher spray rates are attained by using this process rather than by using the flame spray technique. However, it produces ozone, arc light, and fumes, which have detrimental effects on human health and environment. Fantozzi et al. (Ref 44) exposed an arc spray Alloy 625 coating to ambient air at $550{ }^{\circ} \mathrm{C}$ under $\mathrm{KCl}$ salt deposit for $168 \mathrm{~h}$. The coating performed rather good and it was found that the higher degree of melting of the particles during the spraying process was perhaps beneficial in reducing the interconnected porosity and acting as a barrier to the penetration of $\mathrm{Cl}$. Although the dense non-porous oxides formed at the splat boundaries might act as a barrier, their effect on the corrosion resistances of the coatings remains unclear. Highly alloyed Fe-based coatings like FeCrAlBY sprayed by this process were also shown to be satisfactory in reducing high-temperature corrosion (Ref 79), which was mainly due to their chemical compositions rather than their microstructures. While both flame and arc spray processes are cost effective in boiler applications, the in situ oxides and pores formed in the coatings limit their use in high-temperature applications.

\section{Atmospheric Plasma Spray (APS) Technique}

Figure 13(d) shows a schematic view of the APS process. In APS, a plasma jet is used in atmospheric conditions to spray the feedstock material. Owing to the high flame temperature in the plasma $\left(\sim 15,000{ }^{\circ} \mathrm{C}\right)$ and, therefore, the high thermal energy of the plasma jet, the APS process enables the spraying of almost all types of feedstock materials, including ceramics (Ref 80). The APS technique uses a direct current (DC) electric arc to generate a stream of high-temperature-ionized plasma from one or a mixture of inert gases (Ar, $\mathrm{He}, \mathrm{H}_{2}$, or $\mathrm{N}_{2}$ ), which acts as the spraying heat source (Ref 67). The feedstock material is transported by a carrier gas (typically Ar) into the plasma jet, where it is heated and propelled at a typical particle velocity of $200-500 \mathrm{~m} / \mathrm{s}$ upon impact with the substrate (Ref 81, 82). Sadeghimeresht et al. (Ref 83) deposited three different coatings of $\mathrm{Ni}, \mathrm{Ni5Al}$ and $\mathrm{Ni2} 1 \mathrm{Cr}$ using APS. A typical microstructure of the APS coatings including splat boundaries, pores, and oxides can be observed in Fig. 14. It was reported that the high level of porosity and a large number of unmelted particles made this process unfavorable for corrosion protection applications.

Hussain et al. (Ref 84) studied four different Ni- and Febased compositions (Alloy 625, NiCr, FeCrAl, and NiCrAlY) of alloys that were sprayed by using the APS process and exposed in advanced fossil fuel plants to address the fireside corrosion involving coal/biomassderived flue gases. The exposure was performed in a furnace under controlled atmosphere for $1000 \mathrm{~h}$ at $650{ }^{\circ} \mathrm{C}$ under a coal ash deposit (containing $\mathrm{Na}_{2} \mathrm{SO}_{4}, \mathrm{~K}_{2} \mathrm{SO}_{4}$, and $\mathrm{Fe}_{2} \mathrm{O}_{3}$ ). While the $\mathrm{NiCr}$ coating performed better than the others (with the order from the best to the worst coating being $\mathrm{NiCr}>\mathrm{FeCrAl}>$ Alloy $625>\mathrm{NiCrAlY}$ ), all the coatings suffered from a significant corrosion attack. The high level of porosity and the poor intersplat bonding allowed the corrosion to progress rapidly in the coatings. In another work, Singh et al. (Ref 85) investigated an APS $\mathrm{NiCrAlY}$ coating that was exposed to air at $900{ }^{\circ} \mathrm{C}$ under cyclic conditions (each cycle: $1 \mathrm{~h}$ heating followed by 


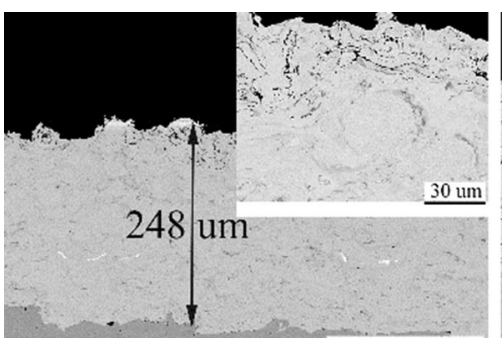

(a)
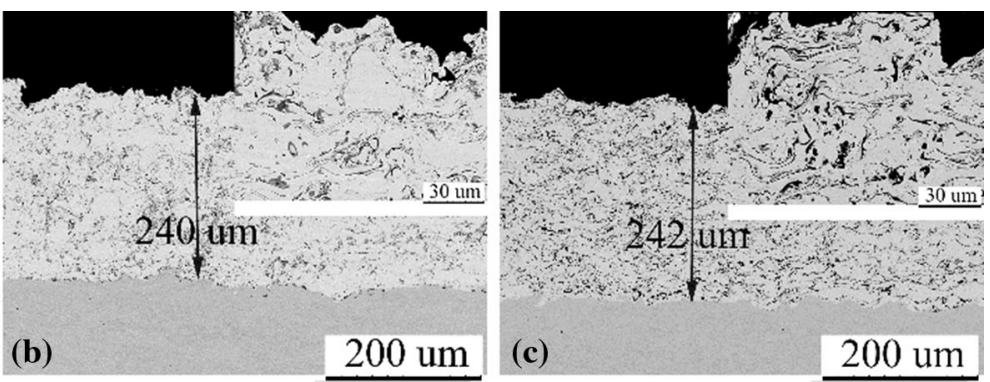

Fig. 14 Back-scattered cross-sectional scanning electron microscopy (SEM) images of APS coatings: (a) Ni, (b) Ni21Cr, and (c) Ni5Al (Ref 111). Reprinted with permission from Elsevier
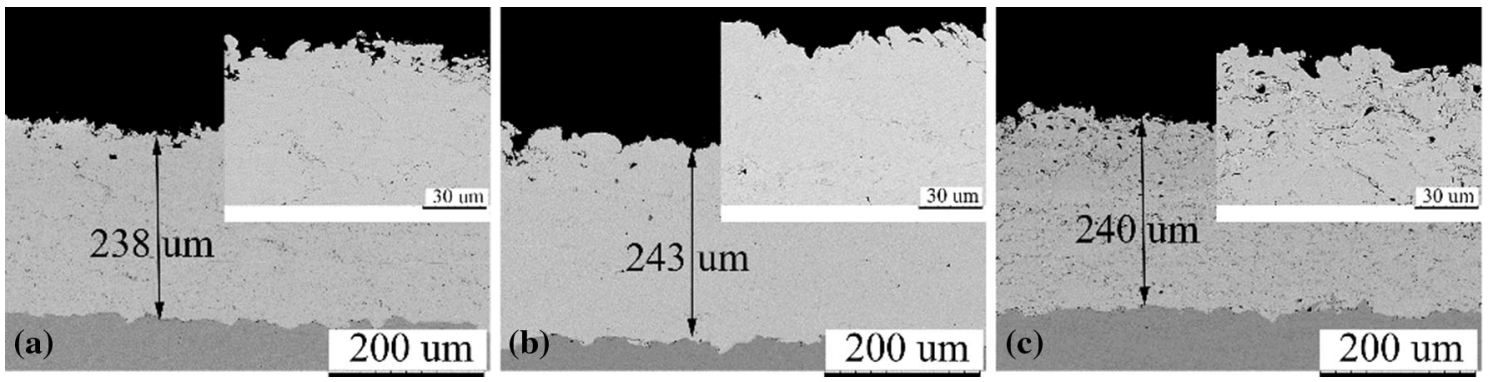

Fig. 15 Back-scattered cross-sectional SEM images of HVOF-sprayed coatings: (a) Ni, (b) Ni21Cr, and (c) Ni5Al (Ref 111). Reprinted with permission from Elsevier

20 min cooling). While the coating showed fairly good adherence to the substrate and developed oxide scales that protected the substrate from oxidation, the main reason for the coating failure was reported to be the pores and poor intersplat bonding.

\section{HVOF Technique}

HVOF coatings have been widely used for high-temperature corrosion protection in boiler applications. Figure 13(e) and (f) shows a schematic view of two HVOF processes. In the HVOF process, the fuel (kerosene, acetylene, propylene, or hydrogen) is mixed with $\mathrm{O}_{2}$ and burned in a combustion chamber. The energy produced by combustion is channeled through a nozzle to produce a jet stream with a temperature of around $3000{ }^{\circ} \mathrm{C}$ and velocity of about $550 \mathrm{~m} / \mathrm{s}$ (Ref 86) (Fig. 14). The feedstock powder is radially or axially injected into the jet, heated, and accelerated toward the substrate. The high velocity of fully or partially melted particles produces compact/dense coatings (Ref 87 ). The coatings produced by HVOF exhibit a slightly lower amount of porosity $(<3$ vol. $\%$ ) and usually lower amounts of oxides, compared to the APS, electric arc and flame spray coatings (Ref 88), due to faster in-flight particles that are propelled on to the substrate (Ref 89). A typical coating microstructure produced by this process can be seen in Fig. 15 and includes splat boundaries, some unmelted particles, pores, oxides, and inclusions (Ref 90).
Bai et al. (Ref 91) studied the high-temperature corrosion behavior of HVOF-sprayed $\beta$-NiAl coatings in a synthetic gas containing $500 \mathrm{ppm} \mathrm{HCl}$ with $10 \mathrm{wt} . \% \mathrm{KCl}$ ash deposit at $700{ }^{\circ} \mathrm{C}$ for $250 \mathrm{~h}$. Severe corrosion was observed with the fast-growing $\mathrm{Al}_{2} \mathrm{O}_{3}$ at the coating/steel interface, starting from the sample edges to the center, where both $\mathrm{Cl}_{2}$ and $\mathrm{O}_{2}$ diffuse into and corrode the samples; see Fig. 16(a). The corrosion mechanism is suggested to follow the "active corrosion" mechanism, in which $\mathrm{Cl}_{2}$ acts as a catalyst. It involves the formation of volatile gaseous $\mathrm{NiCl}_{2}$ and $\mathrm{AlCl}_{3}$ and subsequent oxidation and evaporation that are driven by a gradient of the vapor pressure along with the coating/substrate interface, which significantly promotes the growth of $\mathrm{Al}_{2} \mathrm{O}_{3}$. This study has demonstrated that although $\mathrm{NiAl}$ coatings are effective in the corrosion protection of steels, it is essential to avoid any direct exposure of the coating/substrate interface to the $\mathrm{Cl}_{2} / \mathrm{O}_{2}$ gas, which can significantly deplete the $\mathrm{Al}$ and transform to $\gamma^{\prime}-\mathrm{Ni}_{3} \mathrm{Al}$ after long-term service; see Fig. 16(b) and (c).

Hong et al. (Ref 92) studied HVOF-sprayed NiCrBSiWFeCoC coatings. An amorphous phase and nanoclusters were obtained in the coating, and the major crystalline phases were $\mathrm{Cr}_{23} \mathrm{C}_{6}, \mathrm{Cr}_{7} \mathrm{C}_{3}, \mathrm{Ni}_{3} \mathrm{~B}$, WC, and solid solution $\gamma$-Ni. The formation of the amorphous phase was attributed to the high cooling rates of the molten droplets and the multicomponent alloy system of the feedstock powder. The coating was recommended for corrosion applications 

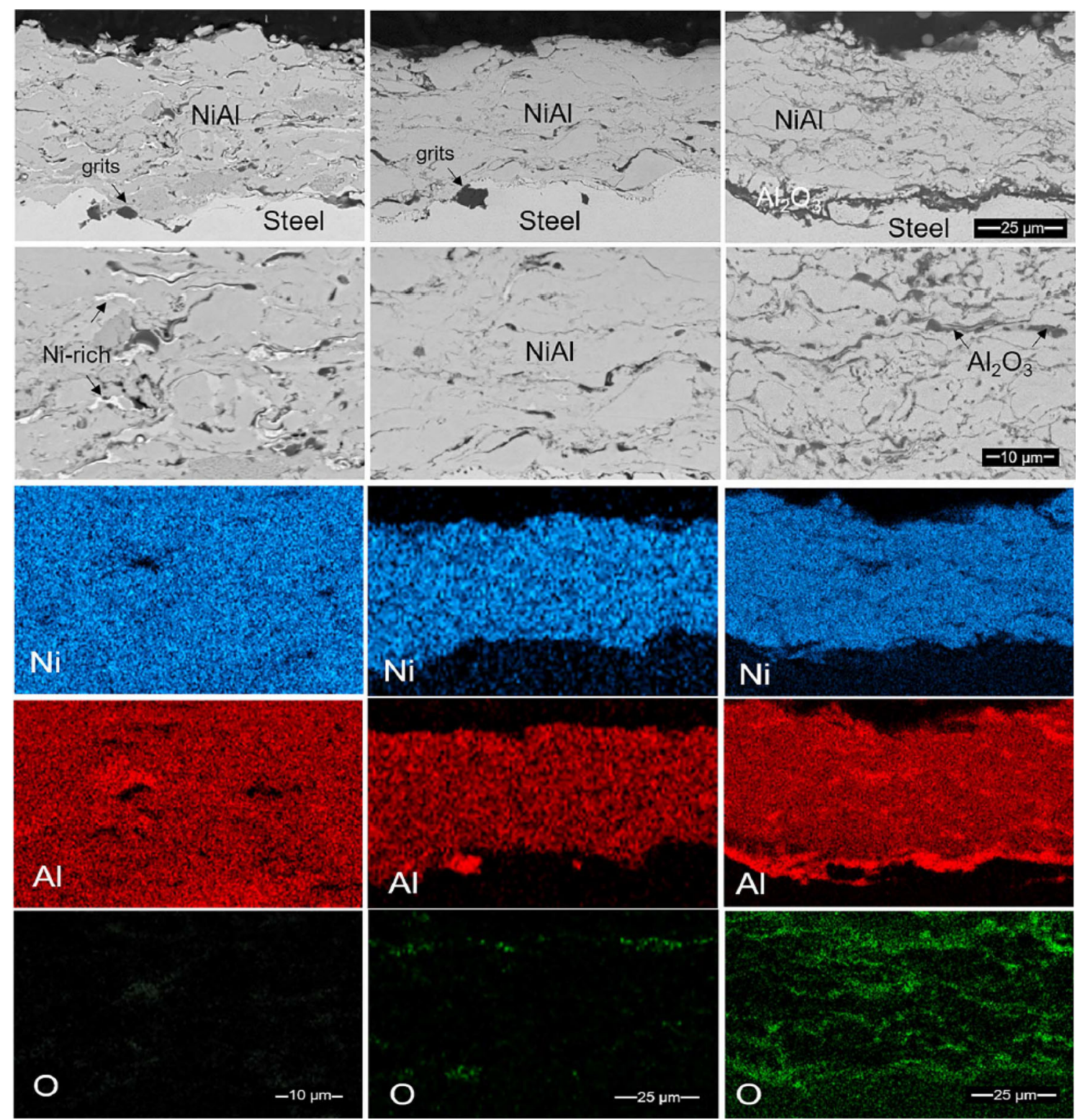

O

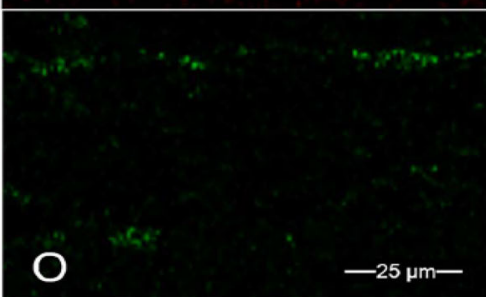

(b) $700^{\circ} \mathrm{C}-250 \mathrm{~h}$ in air

(c) $700^{\circ} \mathrm{C}-250 \mathrm{~h}$ in $\mathrm{HCl} / \mathrm{KCl}$

(a) as-sprayed

Fig. 16 Cross-sectional back-scattered electron (BSE) mode images and energy-dispersive $\mathrm{x}$-ray (EDX) mappings of (a) as-sprayed NiAl coatings; (b) the coatings after oxidation at $700{ }^{\circ} \mathrm{C}$ for $250 \mathrm{~h}$ in air;

owing to the presence of the amorphous phase and low porosity.

Ma et al. (Ref 93) developed a new HVOF process "LSHVOF," where a liquid state suspension/slurry containing small metallic particles was used to deposit an ultrafinegrained alloy coating; see Fig. 13(g). The LS-HVOF NiCrBSi coating obtained exhibited a superior corrosion performance compared to the conventional HVOF. The LS-HVOF coating also displayed a nano-grained microstructure with a high percentage of melted splats, low and (c) the coatings after corrosion at $700{ }^{\circ} \mathrm{C}$ for $250 \mathrm{~h}$ in synthetic gas with $500 \mathrm{ppm} \mathrm{HCl}$ and $10 \% \mathrm{KCl}$ ash deposit at low and high magnifications (Ref 91). Reprinted with permission from Elsevier 

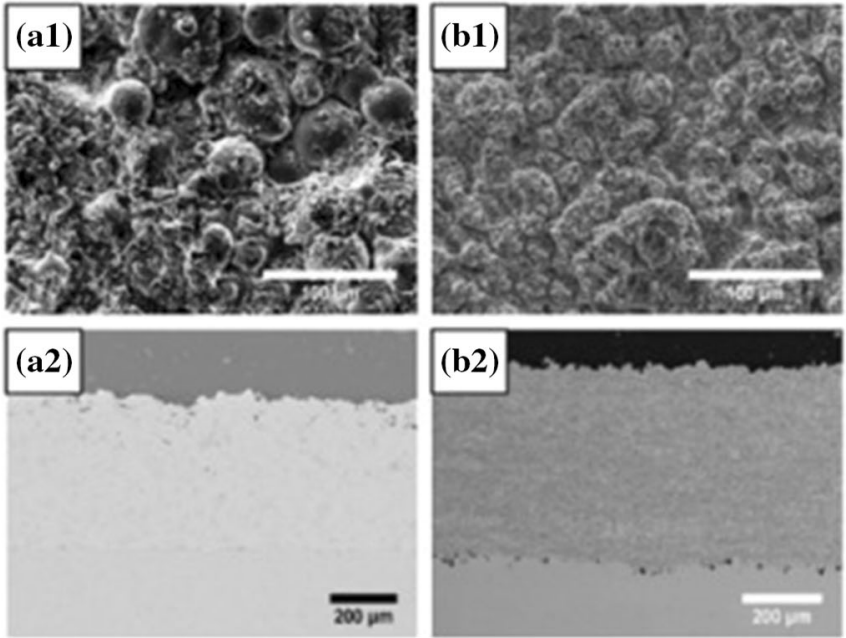
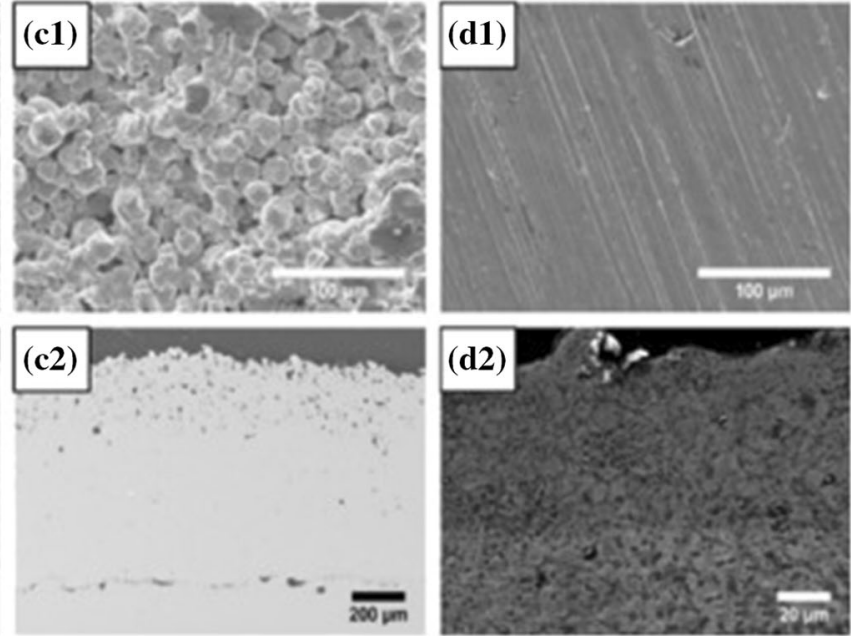

Fig. 17 SEM (secondary electron (SE) mode) images of the top morphology and cross-section of as-sprayed coatings: (a) HVOLF; (b) HVOGF; (c) cold spraying; and (d) laser cladding (Ref 64). Reprinted with permission from Elsevier

\section{Cold Spray Technique}

As the name implies, the cold spray process produces coatings at relatively lower temperatures $\left(<1000{ }^{\circ} \mathrm{C}\right)$ compared to the above-mentioned processes. The kinetic energy rather than the thermal energy imparted to the feedstock material drives the formation of the coating. The coating material, in the form of powders with particle sizes ranging between 1 and $50 \mu \mathrm{m}$, is injected into the nozzle by using a carrier gas; see Fig. 13(h). The gas, typically air, nitrogen, helium, or their mixtures, may be resistively heated to increase the propulsion velocity. However, the temperature is always kept well below the melting point of the coating material (Ref 94). The technique can be used in corrosion protection applications where the absence of process-induced oxides may offer improved performance. Due to its low temperatures, the cold spray process is an alternative method for spraying nanostructured materials as there is no particle melting and all the nanostructure is kept intact during the process (Ref 95). Despite several advantages of the process including high deposition efficiency, lower oxide content of metallic coatings, and the absence of oxidation, phase change, decomposition, grain growth, as well as post-coating component distortion, the cost of the process might be a major drawback for its application in boilers.

Song et al. (Ref 64) compared the high-temperature corrosion of liquid-fueled HVOF (HVOLF)- and gas-fueled HVOF (HVOGF)-sprayed, as well as cold-sprayed and laser cladding Ni50Cr coatings exposed to $700{ }^{\circ} \mathrm{C}$ in a controlled atmosphere with $500 \mathrm{ppm} \mathrm{HCl}+5$ vol. $\%$ $\mathrm{O}_{2}+\mathrm{N}_{2}$ for $250 \mathrm{~h}$. $\mathrm{KCl}$ was introduced onto a few samples to understand the high-temperature $\mathrm{Cl}$-induced corrosion mechanism. The microstructure of the as-sprayed coatings is shown in Fig. 17. In the absence of a $\mathrm{KCl}$ deposit, the cold-sprayed coating presented the poorest performance as the corrosive ions penetrated $\sim 600 \mu \mathrm{m}$ after $250 \mathrm{~h}$ of exposure, which is most probably due to the presence of interconnected pores. When $\mathrm{KCl}$ was introduced, the laser cladding coating exhibited the best corrosion performance. In this condition, there was a thin scale of chromia with oxidized splats on the surface of the coldsprayed coating, along with a porous structure. With the $\mathrm{KCl}$ deposit, a faceted $\mathrm{MnCr}_{2} \mathrm{O}_{4}$ oxide covered the entire coating surface. In all the four coatings, there was no continuous oxide scale when $\mathrm{KCl}$ was not present as a deposit, whereas the oxide scale deteriorated further in the presence of the $\mathrm{KCl}$ deposit. These phenomena indicate the detrimental effect of $\mathrm{Cl}$ on the oxide scales and the accelerating influence of $\mathrm{K}$ ions on the $\mathrm{Cl}$-induced corrosion. In the presence of the $\mathrm{KCl}$ deposit, cold-sprayed and HVOGF coatings displayed the poorest performances since the corrosive ions penetrated deep inside the coatings ( $\sim 600$ and $450 \mu \mathrm{m}$, respectively).

\section{HVAF Technique}

The HVAF process is a relatively new technology in the family of thermal spray processes receiving increasing attention during the last decade in several applications including power plants. In this process, compressed air and fuel gas (propane, propylene, or natural gas) are pre-mixed before entering the combustion chamber, where ignition occurs with the help of an electric spark plug (Fig. 13i). When the catalytic ceramic wall of the chamber is heated above the auto-ignition temperature of the mixture (shortly after the process starts), it provides further ignition and promotes combustion, thus taking over the role of the spark 
plug (Ref 96). Powder is injected into the process axially by using an injector through the hot back wall, with $\mathrm{N}_{2}$ as the carrier gas. The operating cost is low owing to the use of air in combustion. A fuel (such as propane) is also added between the first and second nozzles of the chamber to further increase the in-flight particle velocity and control the temperature of the particles (Ref 97). The type of fuel, nozzle features (length, diameter), amount of gas injected into both the primary (input chamber) and secondary (indie) processes are of high importance in controlling the combustion process. The temperature and velocity of the in-flight particles are also influenced by the feedstock material characteristics (chemical composition, particle size/distribution, and morphology), which in turn will influence the properties and performance of the coating. The HVAF process produces a jet stream with a high velocity, which accelerates the injected powder particles to velocity over $1100-1200 \mathrm{~m} / \mathrm{s}$ (Ref 98). This high velocity of particles establishes a good adhesion strength between the coating and the substrate. Moreover, compressive stresses are formed in the coatings due to peening (hammering effect) at such high particle velocities (Ref 77). The temperature of the HVAF flame is reported to be less than $1950{ }^{\circ} \mathrm{C}$, which results in the in-flight particles being heated to around $1500{ }^{\circ} \mathrm{C}$ (Ref 98), depending upon the thermo-physical properties of the material being sprayed. The comparatively low process temperature, combined with low residence time, enables the spraying of materials that are inherently sensitive to high temperature and oxidation, such as materials comprising $\mathrm{Cr}$ or/and $\mathrm{Al}$ (Ref 67). Therefore, the protective scale-forming elements such as $\mathrm{Cr}$ or/and $\mathrm{Al}$ are not depleted during the spraying process but preserved for oxidation protection. The low heat input during the process also leads to a negligible oxide content in the coating. Under typical spraying conditions, the total oxygen content in HVAF coatings can be kept below 1 wt.\% for most materials, particularly Ni-based coatings (Ref 99). The coatings have been shown to yield high bond strengths that are sometimes much higher than what can be determined by the most common adhesion test method
ASTM C633 (Ref 100). The feedstock material characteristics (such as optimal particle size with narrow distribution) combined with the optimized process parameters increases the DE. The few studies performed so far on HVAF-sprayed coatings show that the coatings possess excellent oxidation behavior in high-temperature environments (Ref 101-103). However, the high-temperature corrosion mechanisms in HVAF-sprayed coatings exposed to a given corrosive environment need to be further studied.

The coating produced by the HVAF process reveals a lamellar structure embedded with a few solid particles, porosity, and almost no oxides or inclusions (Ref 104-109). The high velocity of particles within the flame, in addition to the plastic deformation of the particles, produces compact/dense coatings with minimal voids/pores at the surface and splat boundaries (Ref 110). A typical coating microstructure produced by this process can be seen in Fig. 18.

Sadeghimeresht et al. (Ref 111) performed a processmicrostructure-properties-performance correlation study to determine the main characteristics and corrosion performance of the coatings produced by different thermal spray techniques such as HVAF, HVOF, and APS. Previously optimized HVOF and APS process parameters were used to deposit $\mathrm{Ni}, \mathrm{NiCr}$, and $\mathrm{NiAl}$ coatings and compare them with the HVAF-sprayed coatings obtained with randomly selected process parameters. The HVAF process presented better coating characteristics (a denser microstructure with fewer pores and in situ oxides) and, accordingly, higher corrosion resistances. Jafari et al. (Ref 112-114) investigated KCl-induced corrosion of four HVAF-sprayed coatings (Ni21Cr, Ni5Al, Ni21Cr7Al1Y,

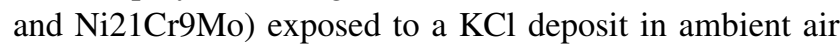
at $600{ }^{\circ} \mathrm{C}$ for up to $168 \mathrm{~h}$. Good interlocking at the substrate/coating interface, well-adhered splats, and low porosity content provided evidence of proper parameter selection and the potential of HVAF for the manufacture of dense and uniform coatings. All the coatings showed much lower corrosion rates compared to the reference materials (16Mo3C steel, stainless steel 304L, and Sanicro 25), as
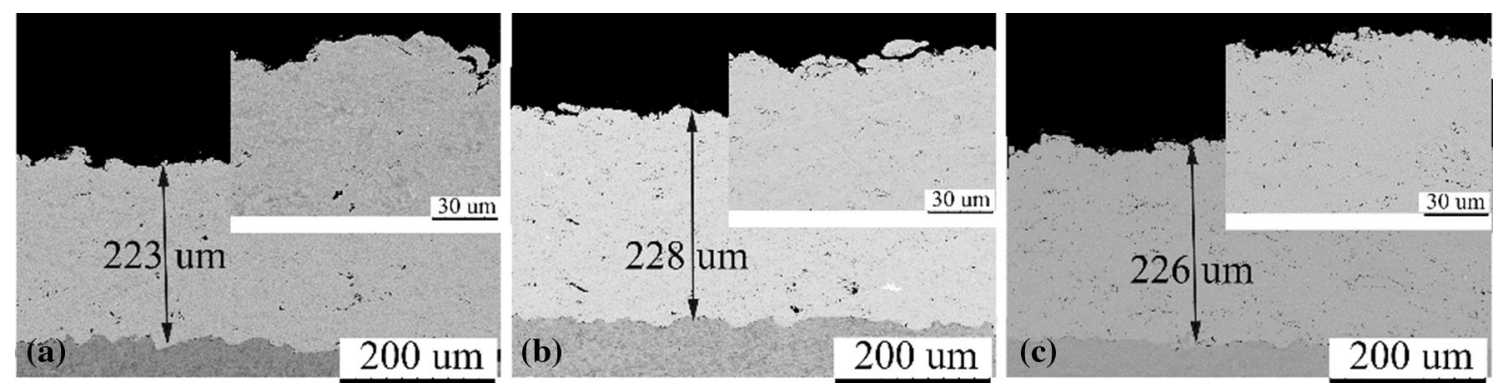

Fig. 18 Back-scattered cross-sectional SEM images of HVAF-sprayed coatings: (a) Ni, (b) Ni21Cr, and (c) Ni5Al (Ref 111). Reprinted with permission from Elsevier 
Fig. 19 Visual observation of the coatings and the reference samples after exposure to $\mathrm{KCl}$ at $600{ }^{\circ} \mathrm{C}$ for $168 \mathrm{~h}$. Significant spallation and degradation of the reference materials compared to the coated samples is noticed (Ref 112). Reprinted with permission from Springer
Polished

As-sprayed

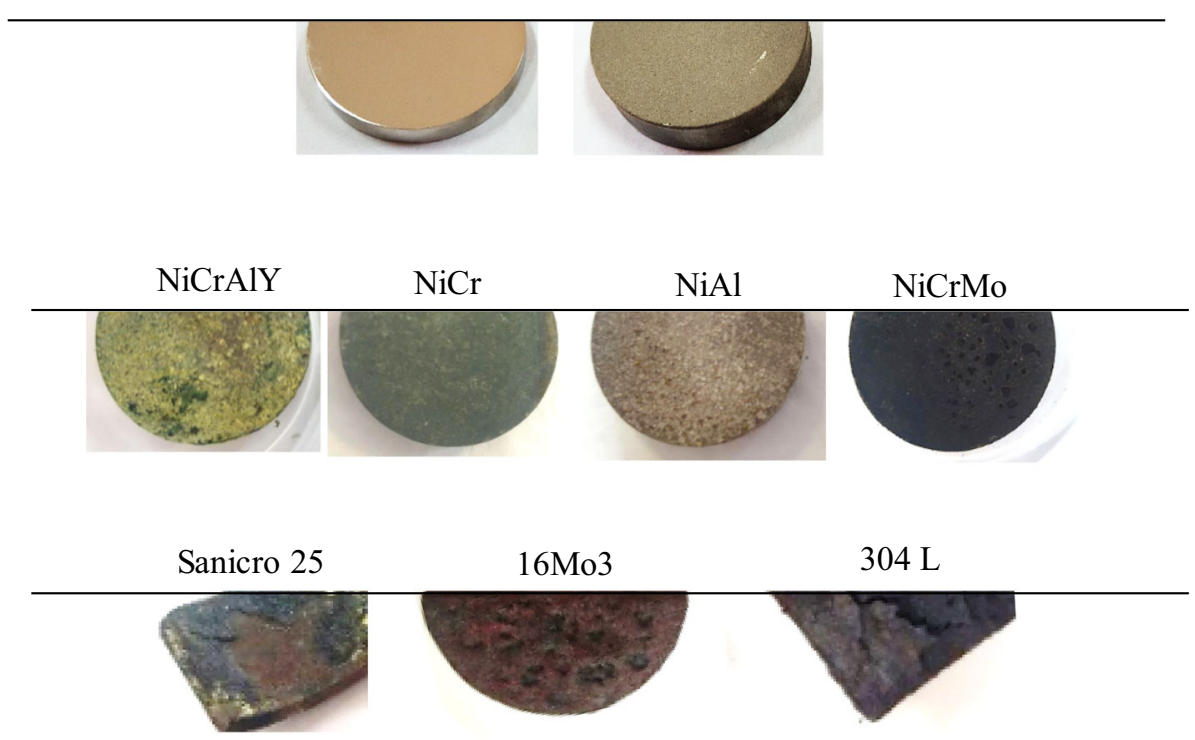

presented in Fig. 19. The coatings could be ranked from the best to the worst corrosion performance as $\mathrm{Ni5Al}>$ $\mathrm{Ni21Cr}>\mathrm{Ni21Cr} 7 \mathrm{~A} 11 \mathrm{Y}>\mathrm{Ni21Cr} 9 \mathrm{Mo}$. It was shown that the formation of a stable Al-rich oxide scale on the Ni5Al sample provided an acceptable level of protection, whereas the other coatings were slightly affected by corrosion attacks beneath $\mathrm{Cr}$-rich oxide scales.

\section{Advances in Thermal Spray Processes for Power Plant Application}

To summarize, Table 3 shows a comparison of the major thermal spraying techniques in terms of the heat source, flame temperature, gas velocity, porosity, and coating adhesion. As already explained, in all thermal spraying techniques, the composition and microstructure (which is

Table 3 Comparison of thermal spray processes

\begin{tabular}{|c|c|c|c|c|c|c|}
\hline Features & Flame spray & Electric arc & APS & HVOF & HVAF & Cold spray \\
\hline \multicolumn{7}{|l|}{ Jet } \\
\hline Jet temperature $\left({ }^{\circ} \mathrm{C}\right)$ & 3000 & 4000 & 15,000 & 2800 & 2000 & $200-1000$ \\
\hline Jet velocities $(\mathrm{m} / \mathrm{s})$ & $50-100$ & $50-100$ & $300-1000$ & $500-900$ & $800-1400$ & $400-1200$ \\
\hline Gas flow (slpm) & $100-200$ & $500-3000$ & $100-200$ & $400-1300$ & 300 & $1000-2000$ \\
\hline Gas nature & $\mathrm{O}_{2}, \mathrm{C}_{2} \mathrm{H}_{2}$ & Air, $\mathrm{N}_{2}, \mathrm{Ar}$ & Ar, $\mathrm{He}, \mathrm{H}_{2}, \mathrm{~N}_{2}$ & $\mathrm{CH}_{4}, \mathrm{C}_{3} \mathrm{H}_{6}, \mathrm{H}_{2}+\mathrm{O}_{2}$ & $\mathrm{C}_{3} \mathrm{H}_{6}$ (+Air) & $\mathrm{He}, \mathrm{N}_{2}$ \\
\hline Power input (kW) & 20 & $2-5$ & $40-150$ & $150-300$ & 300 & $40-100$ \\
\hline \multicolumn{7}{|l|}{ Particle feed } \\
\hline Particle temperature $\left({ }^{\circ} \mathrm{C}\right)$ & 2500 & $>3800$ & $>3800$ & 3000 & $<1600$ & $<600$ \\
\hline Particle velocities $(\mathrm{m} / \mathrm{s})$ & $50-100$ & $50-200$ & $200-600$ & $600-1000$ & $800-1200$ & $800-1000$ \\
\hline Feed rate $(\mathrm{g} / \mathrm{min})$ & $30-50$ & $150-2000$ & $50-150$ & $20-100$ & $50-500$ & $20-200$ \\
\hline \multicolumn{7}{|l|}{ Deposit/coating } \\
\hline Density range $(\%)$ & $85-90$ & $80-95$ & $90-95$ & 95 & 98 & 95 \\
\hline Bond strength (MPa) & $7-18$ & $10-40$ & $40-70$ & $70-100$ & $100-200$ & $80-100$ \\
\hline Oxide level & High & Moderate to high & Moderate to coarse & Moderate to low & low & None \\
\hline Hardness (WC coating) (HRC) & $45-55$ & $\ldots$ & $50-65$ & $55-72$ & $65-75$ & $55-65$ \\
\hline
\end{tabular}




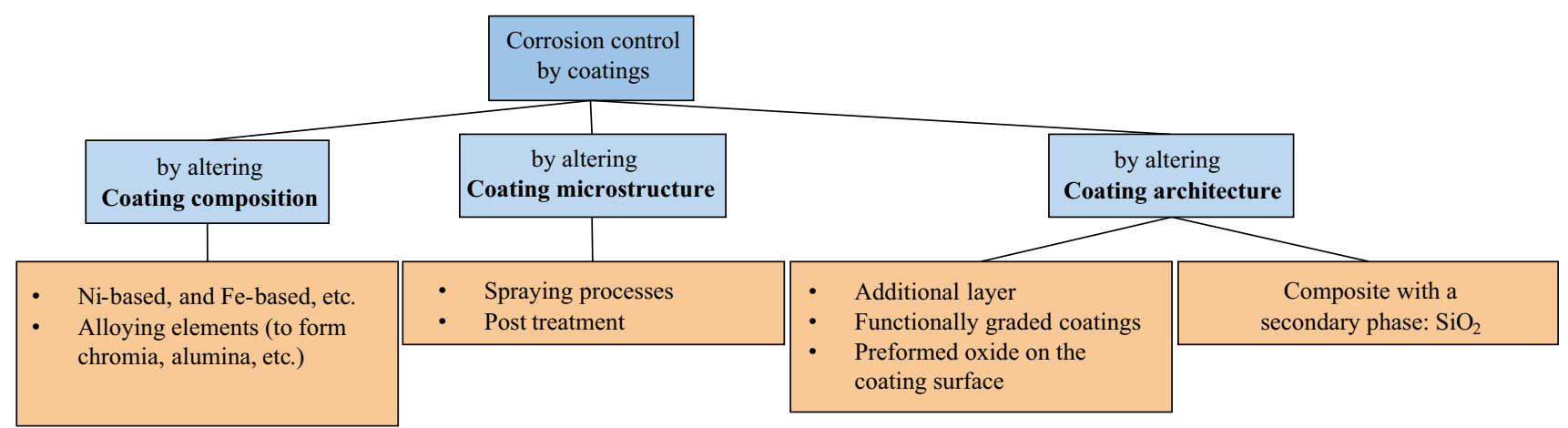

Fig. 20 Approaches to control corrosion by using coatings

partly influenced by the feedstock material) of the assprayed coating can be altered by the magnitude of the thermal energy, as well as the kinetic energy. In a process like APS, thermal energy is very high, whereas the kinetic energy is very low. In such processes, the coating is composed of fully melted particles. In contrast, in cold spraying or HVAF, the kinetic energy is very high, while the thermal energy is rather low. In these processes, the particles are plastically deformed and flattened on the substrate. It seems that to obtain a dense and oxide-free coating, high kinetic energy is more important than high thermal energy.

\section{High-Temperature Corrosion in Thermal Spray Coatings}

The extent of corrosion could be generally reduced by tailoring the composition, microstructure, and architecture of the coatings; see Fig. 20. Alloying elements like Ni or protective scale-forming elements such as $\mathrm{Al}$ or/and $\mathrm{Cr}$ can alter the corrosion mechanism (Ref 115). The microstructural features of the coating, such as pores and splat boundaries, can also significantly affect the corrosion performance (Ref 116). The coating microstructure can be varied depending on the selection of the spraying process, spraying parameters, or post-spray treatment (Ref 117) (Ref 118). Another potential approach would be altering the architecture of the coating, either through a new coating design, such as what has already been achieved in multilayered or functionally graded coatings (Ref 119), or by incorporating certain oxygen-active elements into the coatings, to fabricate composite structures (Ref 120).

Several prior efforts have focused on the oxidation behavior of coatings deposited by the commonly used thermal spraying techniques such as APS and HVOF (Ref 47, 121-126). However, the coating features associated with the above techniques, such as splat boundaries, pores, and in situ formed oxides ( $\operatorname{Ref} 75)$, lead to the formation of a discontinuous oxide scale, which motivates to seek even more efficient protective barriers. The high amount of interconnected pores, as well as poor splat cohesion due to the oxides and/or voids formed at the splat boundaries in the coatings, have an adverse effect on the oxidation behavior of the coatings (Ref 127). Previous studies, while claiming that the HVOF-sprayed coatings could provide oxidation protection (Ref 47,84), showed that oxidation occurred through the splat boundaries and pores of the coating. $\mathrm{Cr}$ or/and $\mathrm{Al}$ cannot be uniformly supplied to the surface to form a uniform protective oxide scale if such coating features are present within the diffusion paths. Therefore, a highly cohesive, pore-free, and less in situ oxidized coatings could provide superior performance in high-temperature corrosive environments.

There are a few microstructural characteristics, such as splat boundaries, pores, and surface roughness (Ref 128) that directly affect the corrosion performance of thermal spray coatings. Apart from the microstructure, the chemistry of the coatings is important to achieve high corrosion resistance. Therefore, in the next section, the effect of these features on the high-temperature corrosion behavior of the coatings, especially in boiler environments, is discussed.

\section{Role of Coating Microstructure}

\section{Intersplat Boundaries}

As mentioned earlier, "splat" is the term given to a single impacted particle, seen in Fig. 21(a). Many overlapped splats solidified and adhered to each other form a thermally sprayed coating. Therefore, a splat is the basic structural building block of thermal spray coatings. Splats are formed when accelerated particles impact a surface. The arriving molten or semi-molten droplets are generally spherical, and, on impact with the substrate surface, flatten and disperse in the form of disk-like structures (splats) to fill the underlying interstices (free spaces). Splats and splat boundaries exist in every thermal spray coating irrespective 


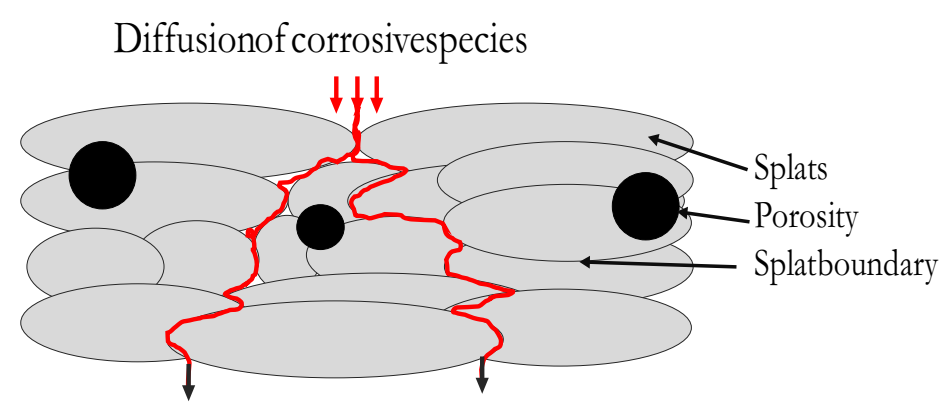

(a)

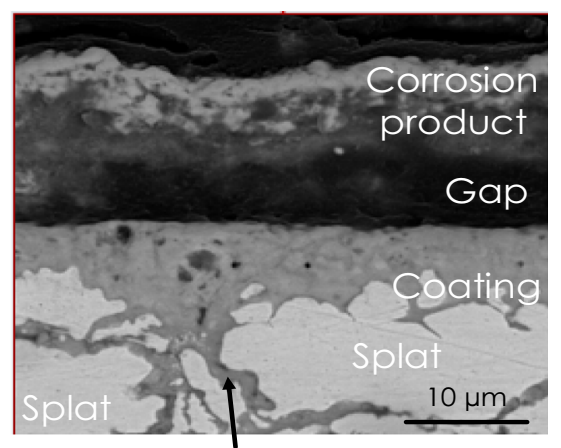

(b) Splat boundaries

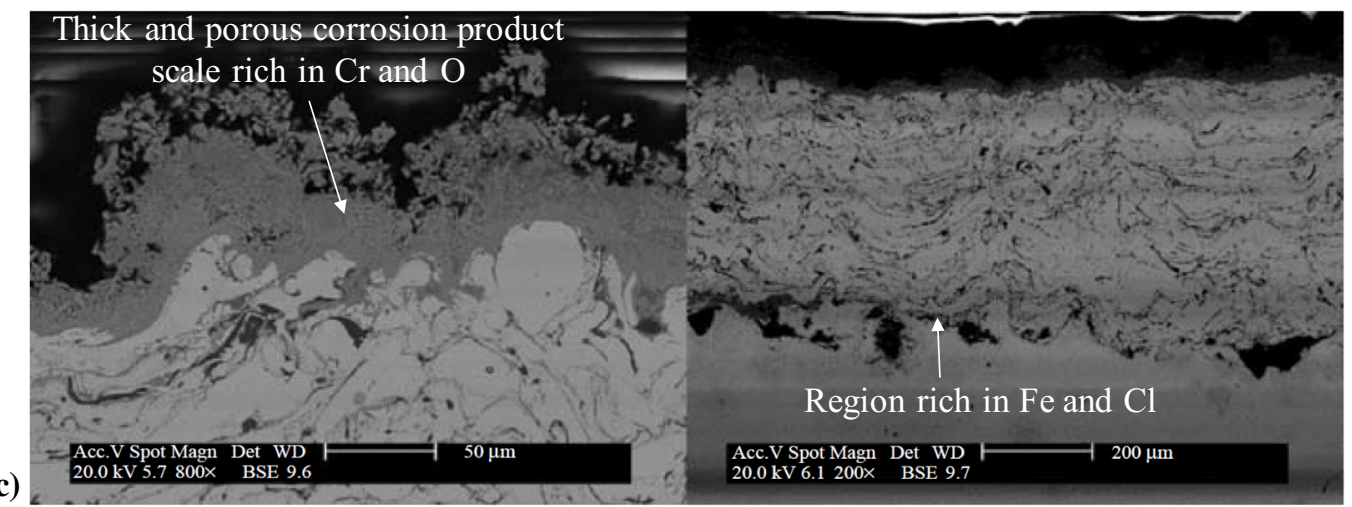

Fig. 21 (a) Role of splat boundaries in the corrosion of coatings (Ref 186), (b) the corrosion path mainly involving the splat boundaries (Ref 112), and (c) cross sections of the arc-sprayed FeCrAl coating

of the thermal spray process. The area between two splats is indicative of the degree of particle melting achieved in flight, as well as the deformation under the impact (if the particle does not melt completely). The degree of melting, as indicated by these splats, largely determines the adhesion, cohesion, porosity, and subsequent corrosion properties of the coating (Ref 115).

The observation of high-temperature corrosion damage in thermal spray coatings suggests that attack at the splat boundaries is the major corrosion mechanism, because most likely, they represent short-circuit diffusion paths for $\mathrm{O}$ or $\mathrm{Cl}$; see Fig. 21(b). Indeed, the most severe corrosion failure takes place along with the boundaries of rounded, unmelted particles and, more generally, along with the splat boundaries (Ref 129). These areas are important in corrosion protection for several reasons. First, poor splat cohesion (lack of intimate contact between splats) causes the splat boundaries to act as corrosion sites; thus, passivation is prevented and the corrosion processes can be triggered (Ref 130, 131). Secondly, in situ oxidation of the feedstock particles (occurring either in the gas jet or just after particle impact) leads to the presence of oxides around the splats. This oxidation depletes the protective scaleforming elements like $\mathrm{Cr}$ or $\mathrm{Al}$ from the coating, which after exposure to $650{ }^{\circ} \mathrm{C}$ for $192 \mathrm{~h}$ (Ref 137). Reprinted with permission from Elsevier

may favor the onset of selective corrosion (Ref 132, 133). The presence of elements like $\mathrm{Cr}$ and $\mathrm{Al}$ is crucial for the coating to provide passivation and corrosion protection (Ref 134-136). However, owing to their in situ oxidation, their effective content in the coating is reduced and the protection is limited. For instance, Rezakhani (Ref 137) investigated two arc-sprayed ( $\mathrm{FeCrAl}$ and Tafaloy 45CT) and two HVOF-sprayed (50Ni-50Cr and $\mathrm{Cr}_{3} \mathrm{C}_{2}-\mathrm{NiCr}$ ) coatings exposed to 550 and $650{ }^{\circ} \mathrm{C}$ for $192 \mathrm{~h}$ with a synthetic ash mixture of $70 \% \mathrm{~V}_{2} \mathrm{O}_{5}-20 \% \mathrm{Na}_{2} \mathrm{SO}_{4}-10 \% \mathrm{NaCl}$. The coatings were mainly attacked through the oxides and voids present at the splat boundaries; see Fig. 21(c). $\mathrm{FeCrAl}$ and $50 \mathrm{Ni}-50 \mathrm{Cr}$ were prone to spalling. The $\mathrm{Cr}_{3} \mathrm{C}_{2^{-}}$ $\mathrm{NiCr}$ coating remained almost intact as its splat boundaries were less affected. In most HVAF coatings, cohesion among the splats is excellent, which makes it very difficult for the corrosive species to readily diffuse along with the splat boundaries and find direct paths to the substrate (Ref 138).

\section{Pores}

The most common source of coating porosity is unmelted particles. Depending on the particle temperature, the 
arriving droplets may cover the full range, from a fully molten liquid to an entirely unmolten solid state. The liquid particles (droplets) flow easily and fill most of the voids. On the other hand, the solid or partially melted particles need to have a high enough impact velocity to be able to be plastically deformed upon impact. Thus, it can be seen that higher particle velocities lead to greater particle deformation, and therefore, better closure of the voids. The solid particles may either rebound from the solid surface or get trapped in the coatings due to the subsequently arriving particles if the impact velocity is low. These undeformed particles are not well bonded, nor are they in intimate contact with the underlying splat, which creates voids.

It is well known that the corrosion resistance of the coatings strongly depends on the pore content (Ref 90, 139145). If the coatings are porous, the corrosive species can easily penetrate through the pores and reach the substrate. In such cases, the coating will tend to delaminate prematurely, and its ability to impart protection is lost. Porosity can be categorized as through-porosity (interconnected) and closed porosity, and each of these plays roles of varying importance in determining the corrosion behavior of the coatings, as seen in Fig. 22. If the pores are interconnected, it leads to a rapid corrosion attack of the substrate. Compared to closed porosity, interconnected porosity is much more sensitive to corrosion, as it forms direct channels between the corrosive environment and the substrate (Ref 146).

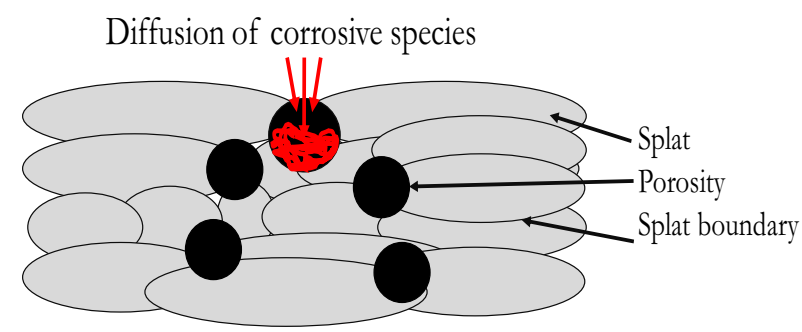

(a) Closed pores

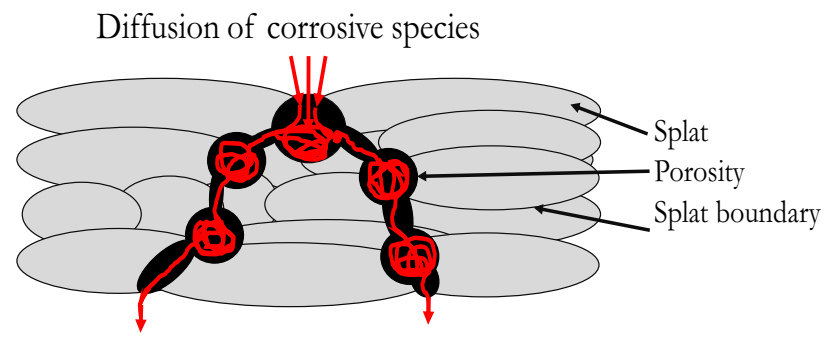

(b) Interconnected pores

Fig. 22 Effect of different types of porosity on the corrosion behavior of coatings. Long corrosion exposure leads the closed pores to be interconnected (Ref 186)
If closed pores exist in a coating, the roles of (a) porosity itself and (b) the chemistry around the pores on the corrosion resistance of the coating should be taken into close consideration (Ref 145). During a long-term corrosion reaction, especially when a molten salt is present, the chemical/electrochemical reaction occurring in the region surrounding the pores makes the isolated pores grow and eventually interconnect with the nearby pores. In this way, open channels can be formed, which facilitate the corrosive medium in reaching the coating/substrate interface (Ref 147). This effect can be explained based on the amount of porosity available in the coatings: the higher the pore content, the easier is the interconnection of isolated pores.

The second role is that porosity alters the local chemistry of the coating and thereby promotes corrosion (Ref 145). It has already been shown by $\mathrm{x}$-ray photoelectron spectroscopy (XPS) analysis that the surface film in zones of higher porosity in a Fe49.7Cr18Mn1.9Mo7.4W1.6B15.2C3.8Si2.4 (at.\%) amorphous coating has a slightly higher $\mathrm{Cr}$ concentration (the difference was around 3-4 at.\%), being mainly rich in $\mathrm{Cr}^{6+}$ and relatively lacking in $\mathrm{Cr}^{3+}$. This high-valence species constitutes the outer layer of the passive film, which is generally more defective. More importantly, a highly inhomogeneous distribution of $\mathrm{Cr}$ on the coating surface is responsible for the poor corrosion resistance of coatings with high porosities; see Fig. 23, the schema of the evolution of the corrosion damage caused by porosity on the coating surface.

Since a dense and homogenous structure is essential for thermal spray coatings to provide adequate protection against corrosion, particular attention needs to be paid to the selection of the spraying technique and the optimization of the spraying process parameters. Dense and well-adherent coating microstructures that are required for corrosion protection can be developed by altering the spraying process and the spray parameters. The microstructures and properties of the coatings can then be analyzed to find interdependencies between the process parameters, coating microstructure, and corrosion behavior. In recent work, the least and most porous microstructures were obtained by using the HVAF and APS processes, respectively (Ref 111). The highest density of the HVAF coatings was attributed to the high velocity of the in-flight particles impacting the substrate. Even in HVAF itself, the coating microstructure can be altered by changing the process parameters. For instance, a change in the nozzle design can lead to the in-fight particles experiencing different temperatures and dwell times in the jet stream; see Fig. 24. The thicker solid wall of a nozzle with a small internal diameter (like 3L2) does not transfer heat efficiently toward the cooling air circulating along its outer face. Therefore, the expanded gas resulting from combustion becomes hotter, 
Fig. 23 Schema (not to scale) of the evolution of the corrosion damage caused by porosity defects on the surface of a Febased amorphous alloy coated sample during long-term corrosion in a chloridecontaining solution (Ref 145). Reprinted with permission from Elsevier

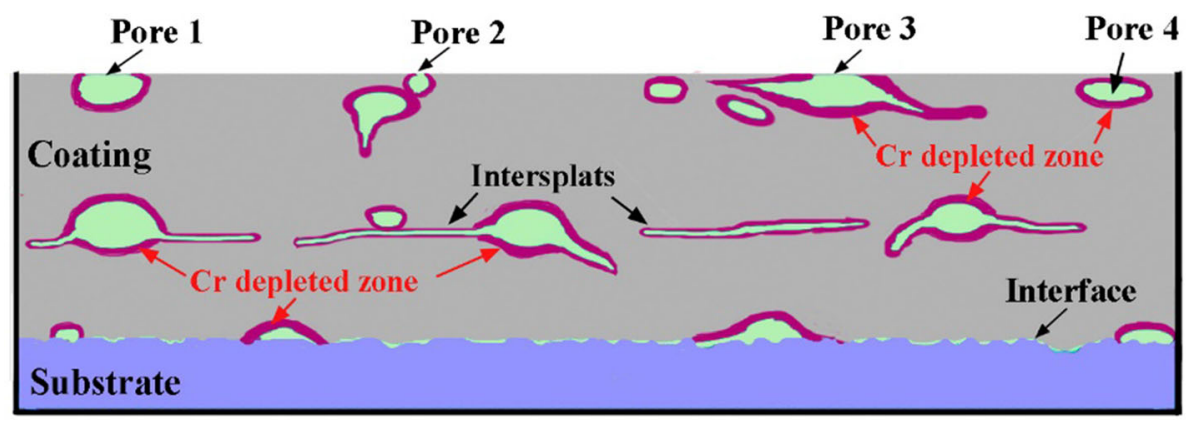

(a)

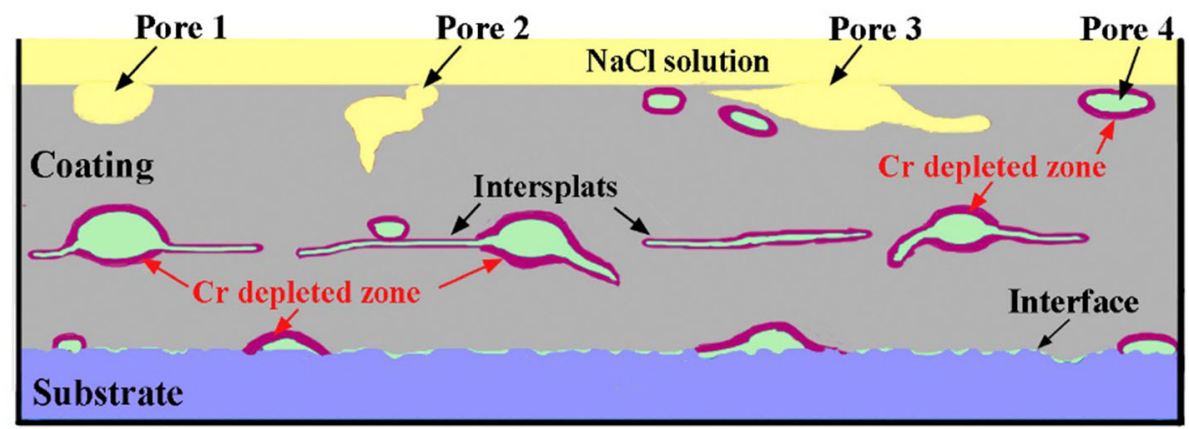

(b)

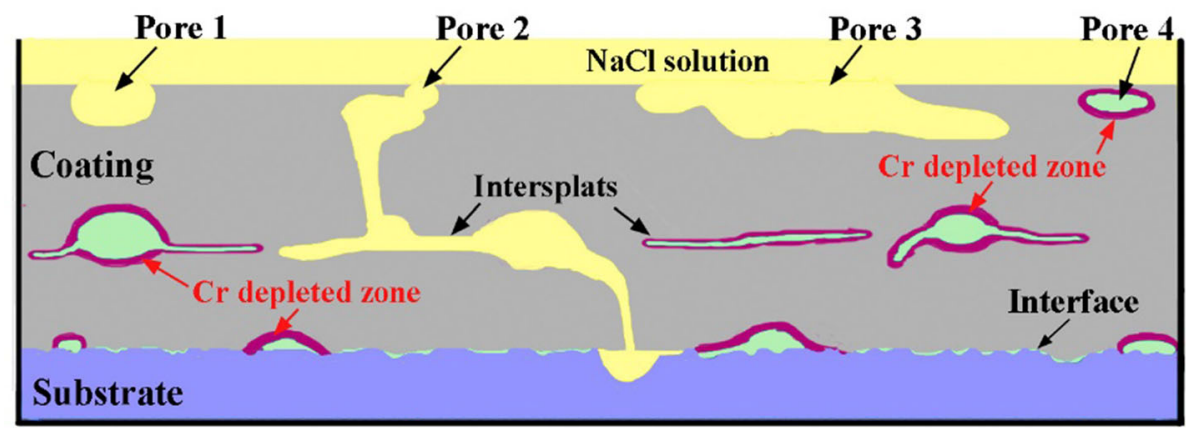

(c)

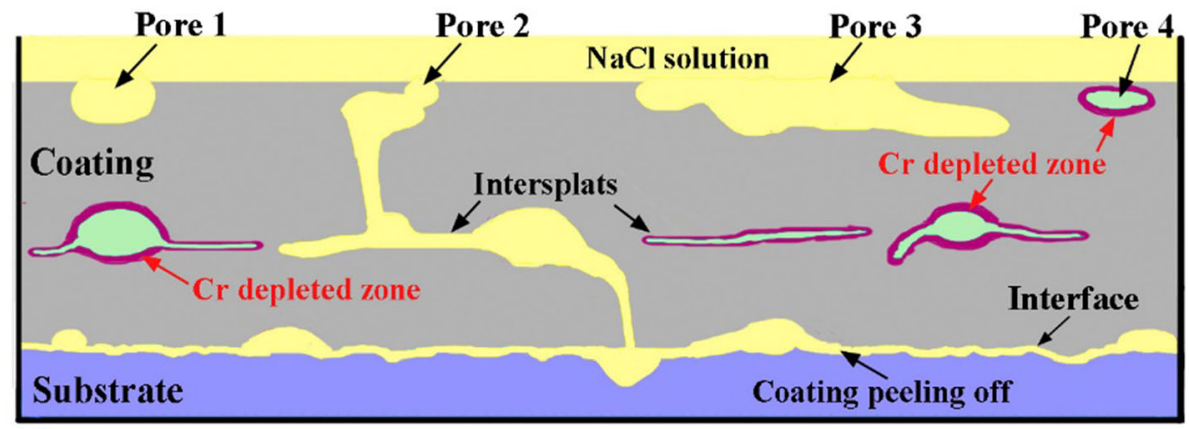

(d)

which promotes the secondary air + fuel reaction to release the highest possible amount of heat. The combustion is sustained even in the free jet regime in front of the nozzle tip. Such hot gases may result in thermal shock cracks in the produced coating (Ref 148). In 4L2, the incomplete reaction of the secondary flowing propane is probably caused by the colder inner face, and, as the gas experiences greater expansion, its cooling probably results in the combustion being extinguished shortly after the exit to the atmosphere. The heat delivered to the substrate by using the 4L4 nozzle is lower, which reduces the probability of fine particles to stick to its surface, thereby avoiding nozzle clogging. 
Fig. 24 Different types of nozzles that are commonly used in the HVAF process

\section{L2}

shortest nozzle + smaller exit

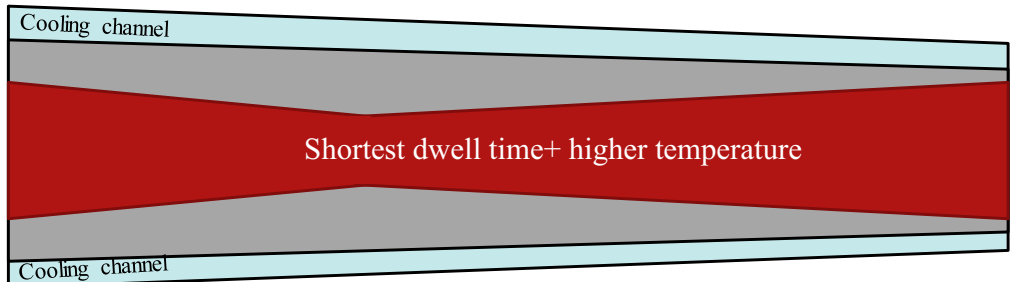

4L2

longest nozzle + smaller exit

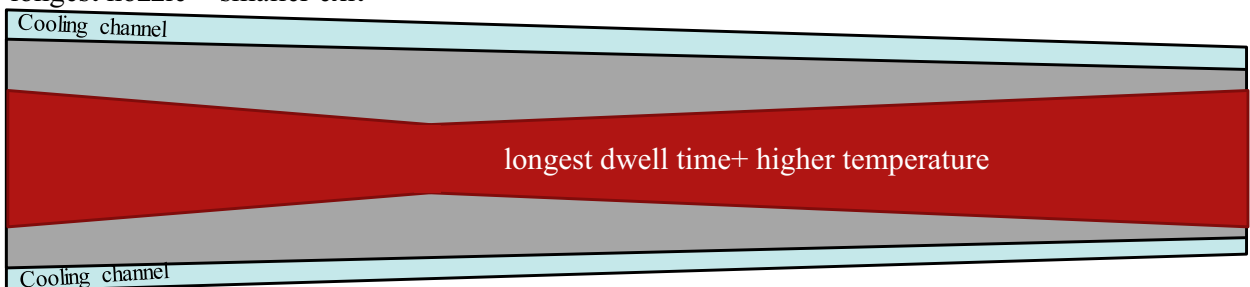

\section{L4}

longest nozzle + larger exit

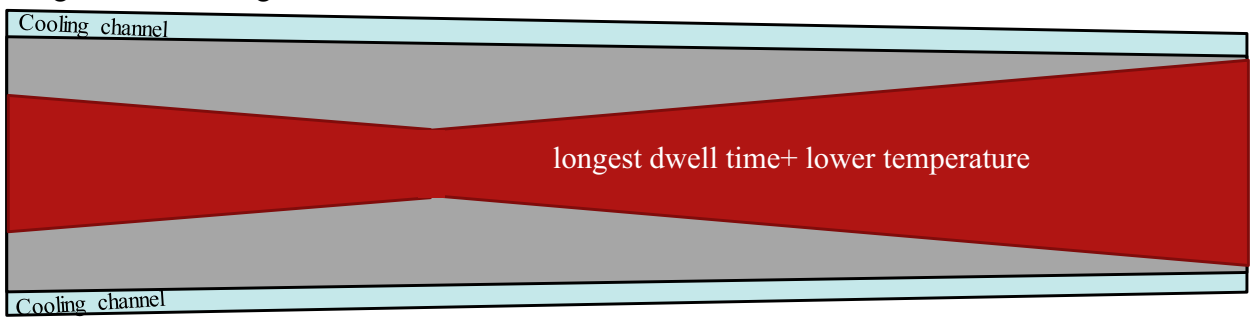

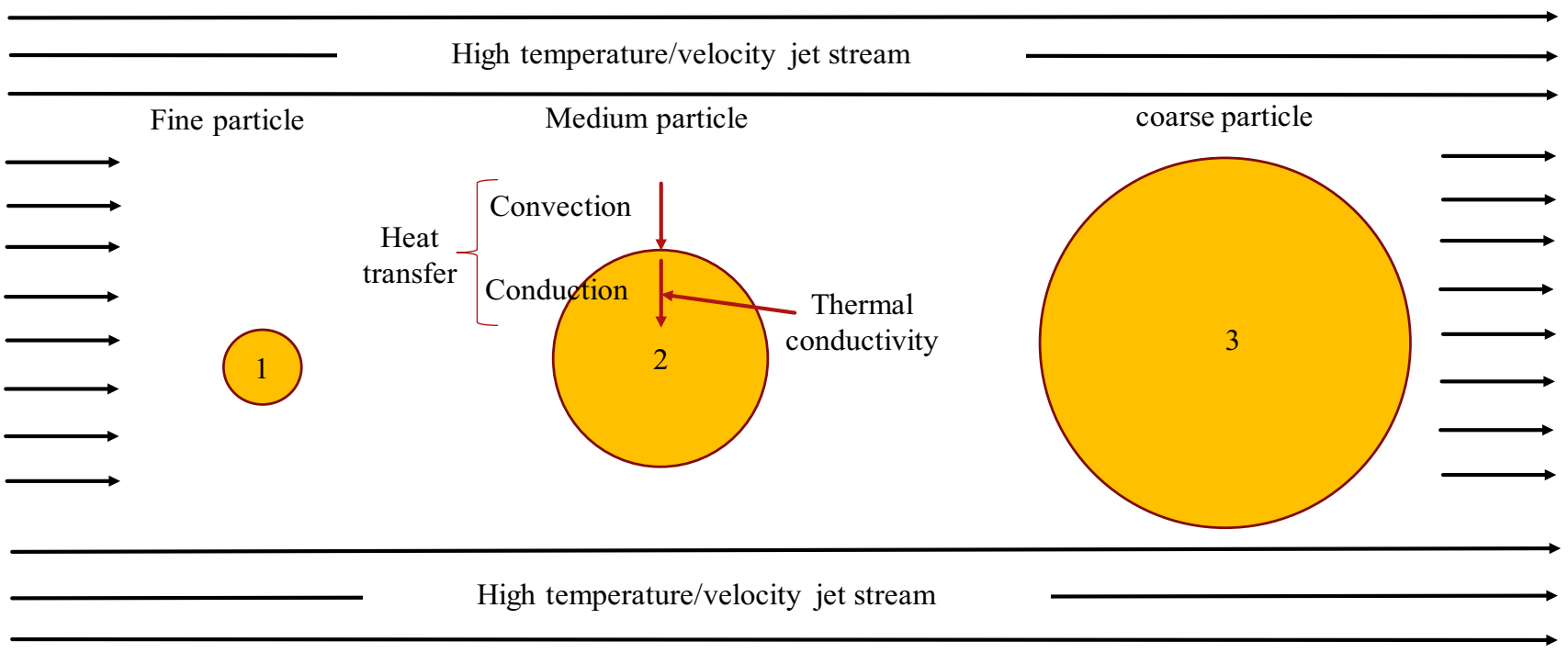

Fig. 25 Particles of different sizes experiencing the high temperature/velocity jet stream during the HVAF process

The interaction between an in-flight particle and the hot flue gas is also important in thermal spraying to achieve a dense defect-free coating. Figure 25 shows the interaction of in-flight particles of different sizes upon experiencing the high temperature/velocity jet stream during the HVAF process. A medium-size particle sufficiently absorbs heat to be superficially melted once it reaches the substrate. The heat is transferred to the particle through convection from the jet stream to the particle surface and through conduction within the particle itself. Many parameters attributed 
to the feedstock powder can alter the flame/particle interaction, e.g., particle material, size, density, and morphology. When a very fine particle is present in the powder, owing to its higher surface-to-volume $(\mathrm{S} / \mathrm{V})$ ratio, a higher amount of specific heat (heat per unit of mass) is absorbed when the particle is transported within the jet stream. Receiving a higher amount of heat from the hot jet stream may lead to oxidation of the particle surface. While the fine particles gain heat faster, it can be argued that they lose heat faster as well. Therefore, it can be concluded that fine particles are more sensitive to heat. A fine particle can also be easily deflected by a bow-shaped shock wave as part of the process (Ref 149). Therefore, in general, fine particles might get stuck as speckles in the coating, oxidized, or in the worst case, be vaporized. On the other hand, a coarse particle might stay unmolten, get trapped, or bounce back from the coating.

By increasing the particle temperature, the in-flight particles become more prone to oxidation. The particles are plastically deformed at high temperatures, which generally results in a less porous coating. The melting state of the inflight particles and their oxidation are influenced by the dwell time, heat transfer, and interactions of the particles upstream with the flame and downstream with ambient air (Ref 150). The level of intersplat bonding and oxidation has an impact on coating performance (Ref 151).

As already mentioned, the HVAF spray gun can generate very high velocities of the jet stream, with particle velocities being up to $1200 \mathrm{~m} / \mathrm{s}$. Thus, highly dense coatings can be achieved. The higher velocity of in-flight particles in the HVAF coatings promotes a denser structure, thereby hindering the transport of the corrosive species through the coating. Sadeghimeresht et al. (Ref 152, 153) deposited five different types of HVAF-sprayed coatings ( $\mathrm{NiCr}, \mathrm{NiAl}, \mathrm{NiCrAlY}, \mathrm{NiCrMo}$, and $\mathrm{NiCrMo-SiO}{ }_{2}$ ). Figure 26 shows the microstructure of the as-sprayed coatings along with the corresponding EDX analysis. The level of pores was measured by using an image analysis technique, see Table 4. It was shown that the amounts of pores are (apart from NiCrMo) all below 1 vol.\%, which is satisfactory for corrosion protection applications. In another similar work of the authors (Ref 154), the porosities of the HVAF-sprayed $\mathrm{NiCr}$ and NiCrAlY coatings were compared with those of coatings of similar compositions that were obtained by spraying through the HVOF and APS processes, and it was shown that HVAF provides less porosity; see Table 5. The higher hardness of the HVAF coatings was attributed to the lower content of pores.

\section{Role of Coating Composition}

Under ordinary oxidation conditions, it is mainly three alloying elements that are capable of forming a protective oxide scale: $\mathrm{Al}, \mathrm{Cr}$, and $\mathrm{Si}$. In some cases, $\mathrm{Fe}$ or even $\mathrm{Ni}$ oxides at lower temperatures can provide a certain level of protection through scale formation. Under oxidizing-chloridizing conditions, the situation is much more complex, since not only the scale-forming alloying elements have to be regarded but also a severe type of internal selective attack can occur, depending on the alloying elements present in the material. Therefore, detailed knowledge of the behavior of different alloying elements in commercial materials, in particular, coatings, is important.

The aim of this section is to investigate the role of several elements that are currently used in thermal spray coatings under process atmospheres of the type mentioned above. A further aim of this section is to determine how a protective coating can be developed. The composition of this coating should be based on the results obtained from an investigation of the effect of the different alloying elements.

The alloying elements discussed in this review are mainly $\mathrm{Al}, \mathrm{Cr}, \mathrm{Fe}, \mathrm{Ni}, \mathrm{Mo}$, and $\mathrm{Si}$. Furthermore, the influence of the rare earth elements present in the coating has been discussed. The most important elements for forming protective oxide layers at high temperatures are $\mathrm{Cr}, \mathrm{Al}$, and $\mathrm{Si}$. Other alloying elements, e.g., Mo, can also influence the high-temperature corrosion behavior in $\mathrm{Cl}$ containing environments (Ref 155-157).

\section{Thermodynamic Considerations}

It is pertinent to mention that thermodynamic investigations only provide information regarding whether an oxide (or any other corrosion product) can possibly form in an equilibrium state. Such an investigation can provide equilibrium phase diagrams for the prediction of the corrosion and oxidation products of alloys at high temperatures. For instance, Fig. 27 shows the ternary phase diagram of the Me-O-Cl system at $600{ }^{\circ} \mathrm{C}$ taken from HSC Chemistry 6.0 (Outotec, Espoo, Finland), which indicates how various corrosion products (oxides and chlorides) can form based on $p \mathrm{O}_{2}$ and the partial pressure of chlorine $\left(p \mathrm{Cl}_{2}\right)$. These diagrams involve not only the compositions but also the $\mathrm{O}_{2}$ and $\mathrm{Cl}_{2}$ partial pressures, phases, temperatures, etc. Thermo-Calc ${ }^{\circledR}$, HSC chemistry, and FactSage are useful tools for studying the selective oxidation behavior of alloys, especially complex multicomponent alloys (Ref 158-165). However, it is also worth noting that corrosion is essentially a non-equilibrium process, with a degree of uncertainty associated with the formation of metastable phases. Moreover, the formation of new corrosion products may also change the $p \mathrm{Cl}_{2}$ and $p \mathrm{O}_{2}$ beneath the newly formed layer. The partial pressures of the gases, as well as the composition of the alloy underneath, are not constant, e.g., both $\mathrm{Cr}$ and $\mathrm{Fe}$ are depleted as a result of the 
(a)
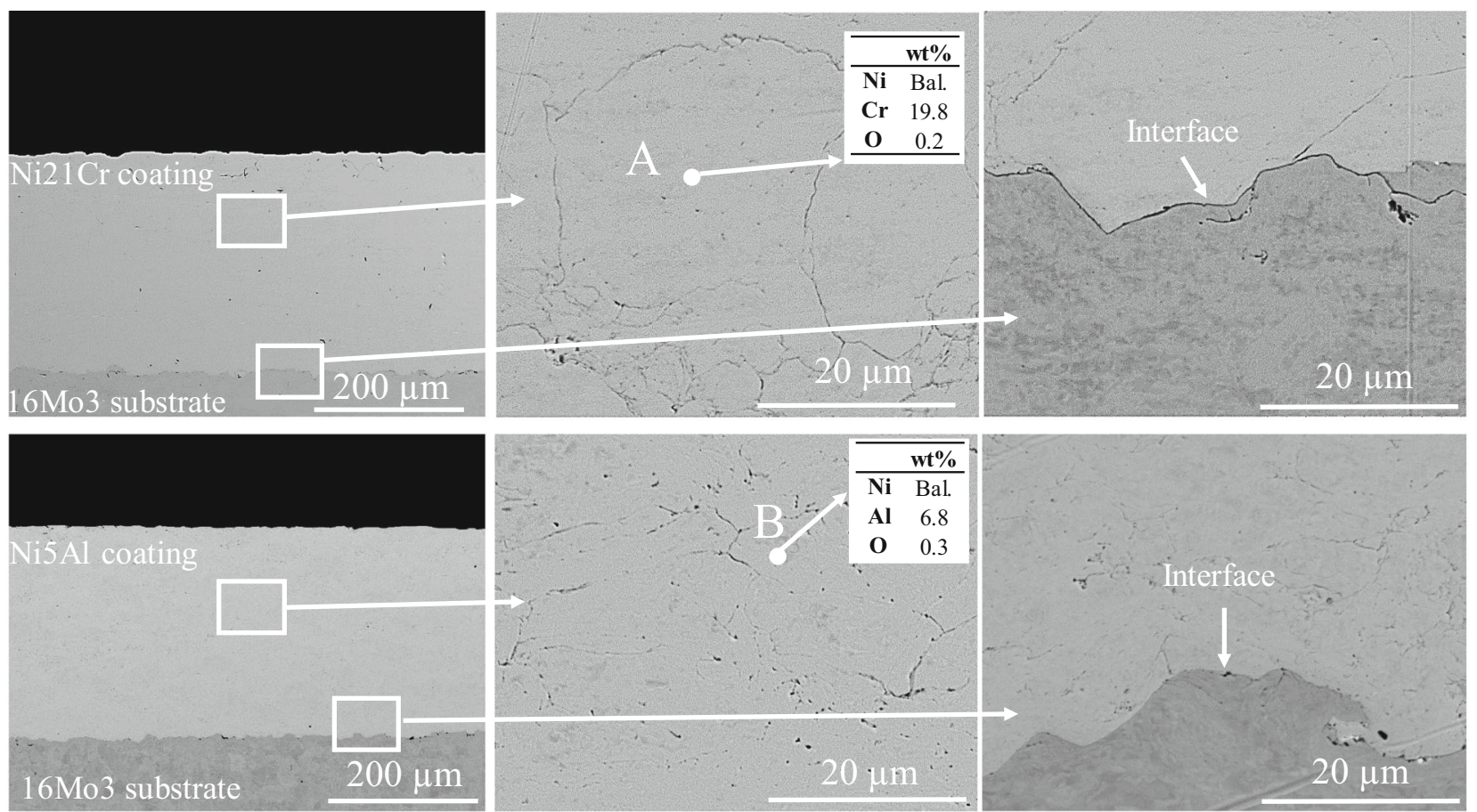

(b)
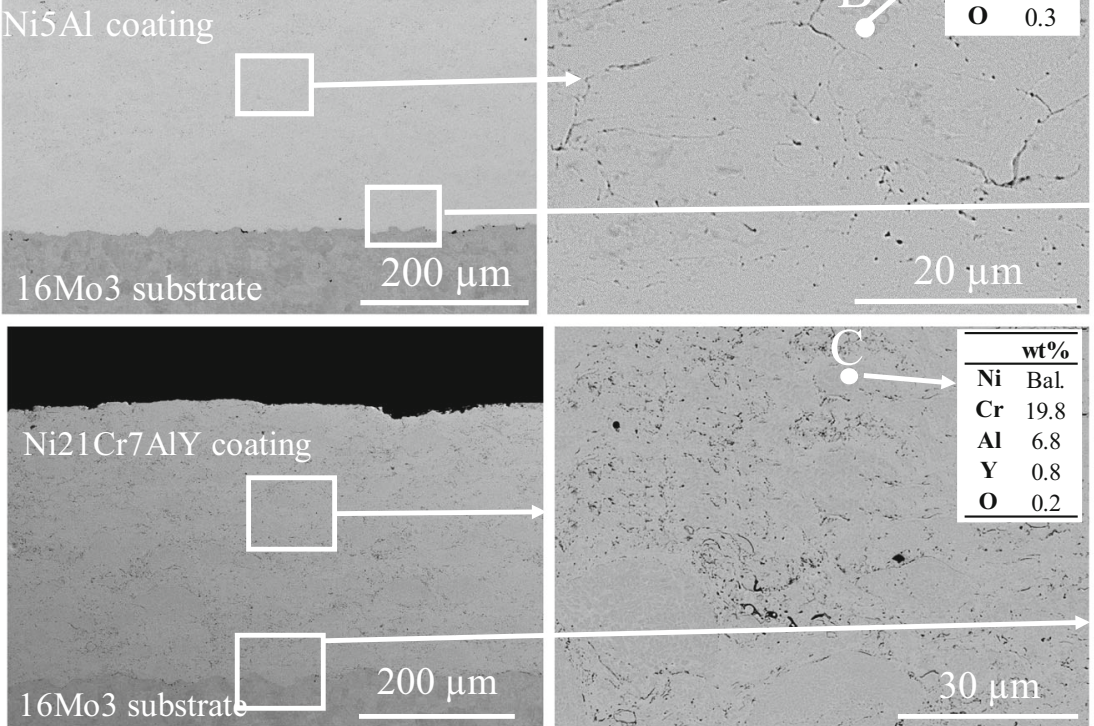

(c)
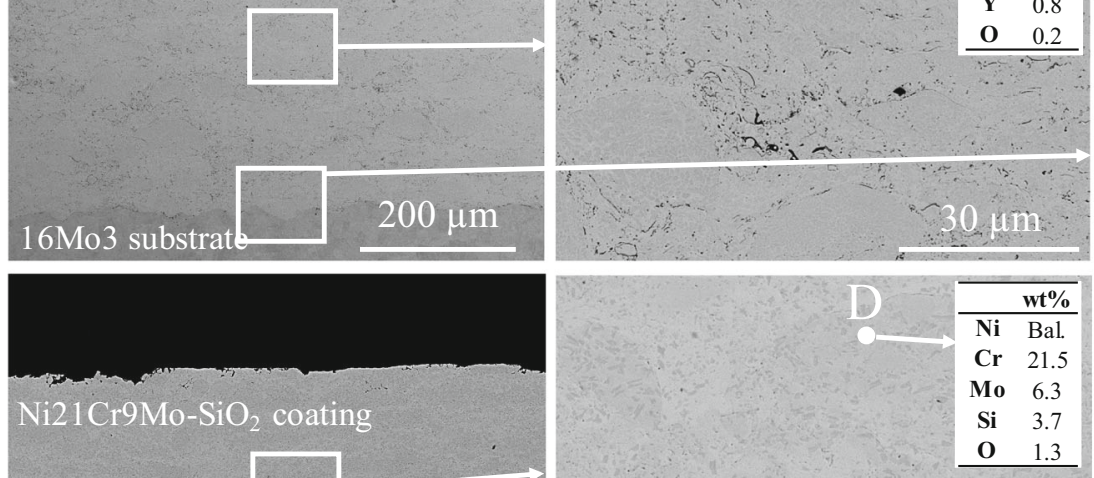

$\mathrm{Ni} 21 \mathrm{Cr} 9 \mathrm{Mo}-\mathrm{SiO}_{2}$ coating

(d)
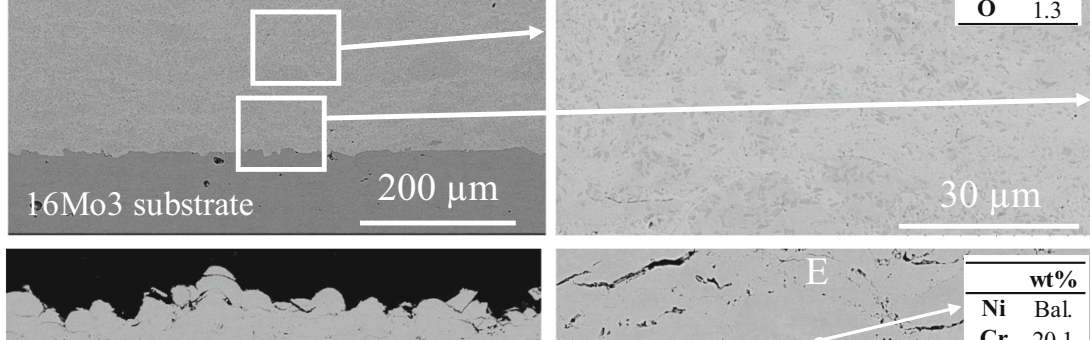

(e)
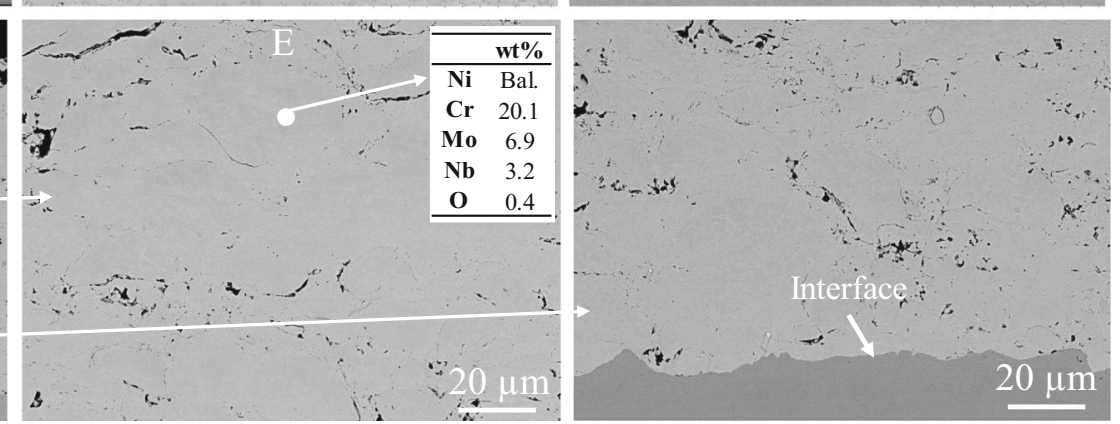

Fig. 26 Back-scattered cross-sectional SEM images of the HVAF-sprayed coatings: (a) Ni21Cr, (b) Ni5Al, (c) Ni21Cr7AlY, (d) Ni21Cr9Mo$\mathrm{SiO}_{2}$, and (e) Ni21Cr9Mo, and the corresponding EDX point analysis (Ref 186) 
Table 4 Porosities of different HVAF-sprayed Ni-based coatings (Ref 186)

\begin{tabular}{llc}
\hline & \multicolumn{1}{c}{ Coatings } & Pore content, vol.\% \\
\hline 1 & Ni5Al & $0.2 \pm 0.07$ \\
2 & Ni21Cr & $0.1 \pm 0.02$ \\
3 & Ni21Cr7AlY & $0.4 \pm 0.10$ \\
4 & Ni21Cr9Mo & $1.5 \pm 0.30$ \\
5 & Ni21Cr9Mo-SiO & $0.2 \pm 0.06$ \\
\hline
\end{tabular}

fast-growing oxide scale during the corrosion, which significantly modifies the alloy composition locally. Thus, a large deviation of the calculated phase compositions from the experimental results is anticipated in materials that are far from thermodynamic equilibrium. Therefore, thermodynamics is not always a favorable tool to predict the phases present. The practical implications of the flow of gases (non-equilibrium condition) over the exposed samples are generally needed. It was suggested that the relevance and reliability of the thermodynamic calculations could be improved significantly if their results are complemented by chemical and microstructural analyses (Ref 166). In other words, a combination of thermodynamic calculations and experimental investigation of the phase compositions in real samples extend the application potential of both the methods.

\section{$\mathrm{Cr}$}

$\mathrm{Cr}$ is a commonly used alloying element in materials for high-temperature applications $\left(<850^{\circ} \mathrm{C}\right)$ that can form a stable oxide $\left(\mathrm{Cr}_{2} \mathrm{O}_{3}\right)$ with hexagonal corundum structure. $\mathrm{Cr}$ is also a typical alloying element in many thermal spray powder chemistries such as Ni21Cr, Ni49Cr, and MCrAlY $(\mathrm{M}=\mathrm{Ni}, \mathrm{Co}$, or/and $\mathrm{Fe})$ to provide high-temperature corrosion protection $(\operatorname{Ref} 75,78,167)$. The diffusion of a corrosive species through $\mathrm{Cr}_{2} \mathrm{O}_{3}$ is rather slow. Therefore, it is considered as a protective oxide. As long as the oxide scale well adheres to the underlying alloy and the growth rate of the scale is controlled by the diffusion of ions through the scale, the oxidation rate follows a parabolic trend (Ref 168). Figure 27(a) shows the ternary phase diagram of the $\mathrm{Cr}-\mathrm{O}-\mathrm{Cl}$ system at $600{ }^{\circ} \mathrm{C}$ taken from HSC Chemistry 6.0 (Outotec, Espoo, Finland), which indicates that the formation of various corrosion products including oxides like $\mathrm{Cr}_{2} \mathrm{O}_{3}$ and chlorides like $\mathrm{CrCl}_{2}$ and $\mathrm{CrCl}_{3}$ depends on $p \mathrm{O}_{2}$ and $p \mathrm{Cl}_{2}$. 

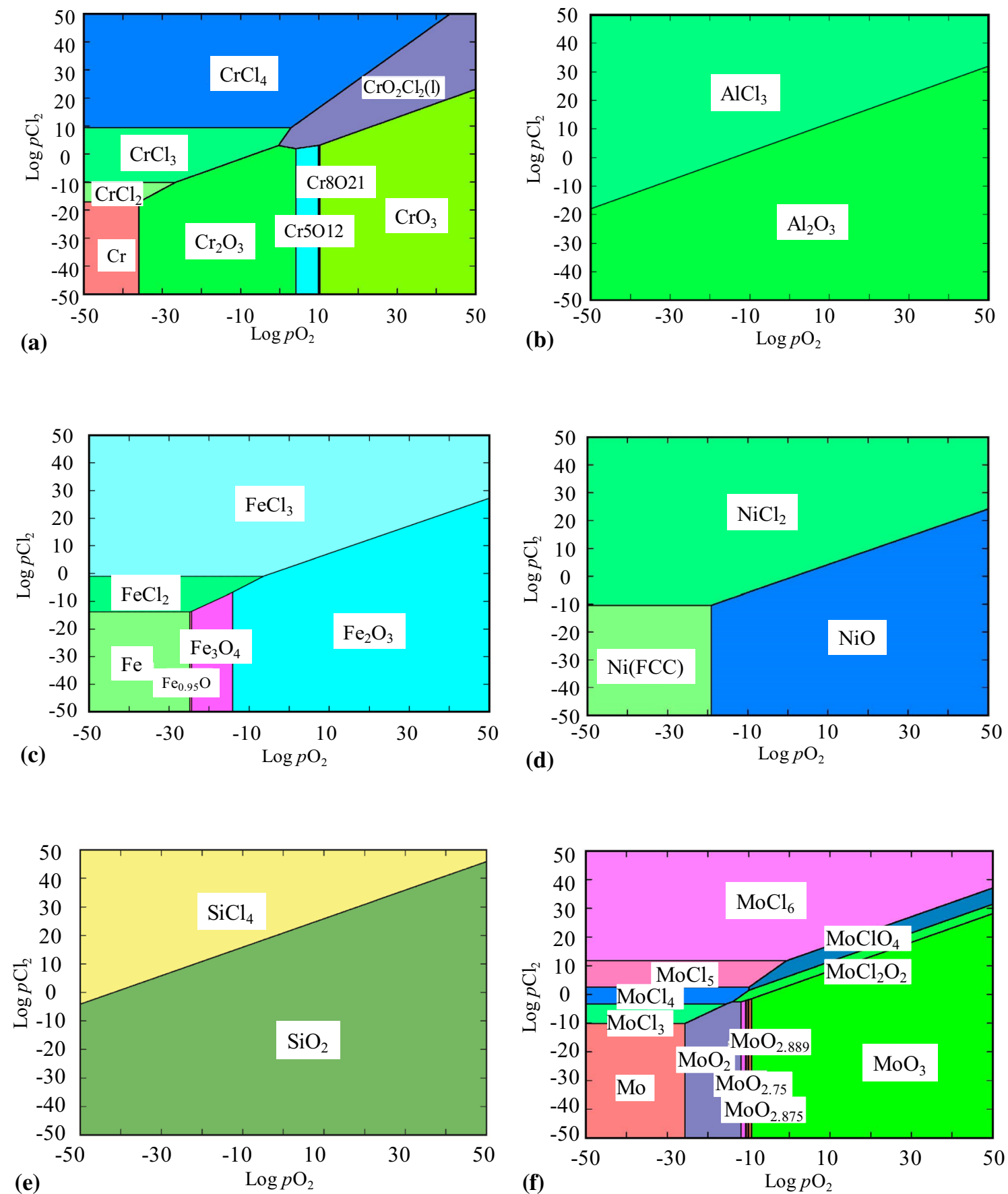

Fig. 27 Predominance diagram for the $\mathrm{M}-\mathrm{O}-\mathrm{Cl}$ system produced by using $\mathrm{HSC} 6.0$ Chemistry software; (a) $\mathrm{Cr}-\mathrm{O}-\mathrm{Cl}$; (b) $\mathrm{Al}-\mathrm{O}-\mathrm{Cl}$; (c) $\mathrm{Fe}-\mathrm{O}-\mathrm{Cl}$; (d) Ni-O-Cl; (e) Si-O-Cl; and (f) Mo-O-Cl (Ref 186)

$A l$

Similar to $\mathrm{Cr}$, Al is also widely used in thermal spray powder composition, particularly for high-temperature corrosion applications. Al forms only one thermodynamically stable oxide $\left(\alpha-\mathrm{Al}_{2} \mathrm{O}_{3}\right)$, which has a hexagonal corundum structure. The $\alpha-\mathrm{Al}_{2} \mathrm{O}_{3}$ phase has excellent protective properties with a lower growth rate than the other oxides found on engineering alloys. However, during the transient oxidation of $\mathrm{Al}$, other crystal structures such as $\theta-\mathrm{Al}_{2} \mathrm{O}_{3}, \gamma-\mathrm{Al}_{2} \mathrm{O}_{3}$, and $\delta-\mathrm{Al}_{2} \mathrm{O}_{3}$ may also form (Ref 169). It should be considered that $\alpha-\mathrm{Al}_{2} \mathrm{O}_{3}$ is unable to form in the temperature range typical of boiler applications $\left(400-700{ }^{\circ} \mathrm{C}\right)$. Since the transient oxides are less protective, it is recommended that $\mathrm{Al}_{2} \mathrm{O}_{3}$-forming alloys are pre-oxidized in controlled atmospheres to ensure the formation of 
the protective $\alpha-\mathrm{Al}_{2} \mathrm{O}_{3}$. However, the formation of such a layer involves a few technical challenges. The $\alpha-\mathrm{Al}_{2} \mathrm{O}_{3}$ layer is highly sensitive to failures, especially those caused by scratching during handling. Moreover, if the pre-oxidation is performed inside an actual boiler, as the typical temperature for $\alpha-\mathrm{Al}_{2} \mathrm{O}_{3}$ formation is typically above $900{ }^{\circ} \mathrm{C}$, the other temperature-sensitive materials inside the boiler will be damaged. Therefore, great attention needs to be paid to such a post-processing step. In general, in watercontaining atmospheres, $\mathrm{Al}_{2} \mathrm{O}_{3}$ has no volatile form and is not sensitive to moisture.

A high addition of protective scale-forming elements such as Al is usually recommended for high-temperature applications; however, the mechanical properties may be impaired by the high $\mathrm{Al}$ content. Interestingly, if $\mathrm{Cr}$ is added to an $\mathrm{Al}_{2} \mathrm{O}_{3}$-forming alloy, the level of $\mathrm{Al}$ needed for forming a protective oxide layer is lowered (Ref 170). This is commonly referred to as the third element effect, but the exact mechanism is still under debate. Figure 27(b) shows a ternary phase diagram of the Al-O-Cl system at $600{ }^{\circ} \mathrm{C}$. The formation of $\mathrm{Al}_{2} \mathrm{O}_{3}$ is expected at high $p \mathrm{O}_{2}$ and low $p \mathrm{Cl}_{2}$ (see Fig. 27b). However, the formation of $\mathrm{AlCl}_{3}$ could be anticipated at low $p \mathrm{O}_{2}$ and high $p \mathrm{Cl}_{2}$. A vast majority of thermal spray efforts to combat high-temperature corrosion have sought to utilize $\mathrm{Al}_{2} \mathrm{O}_{3}$-forming alloys, with materials such as Ni5Al, and Ni30Al being among the most widely used compositions (Ref 91, 109).

\section{Fe}

There are a sizeable number of reports on the influence of $p \mathrm{Cl}_{2}$ and $p \mathrm{O}_{2}$ on $\mathrm{Fe}$ as a bulk material or coating. The main motivation for using Fe-based alloys is that they are rather cheaper and more environmentally friendly compared to many other alloying elements (Ref 171-173). In an oxidizing-chloridizing environment, $\mathrm{Fe}$ oxides are formed that are rather porous, allowing the outward diffusion of $\mathrm{Fe}$ chlorides. Figure 27(c) shows the predominance diagram of the $\mathrm{Fe}-\mathrm{O}-\mathrm{Cl}$ system. There is a new category of Fe-based alloys called "Fe-based metallic glasses" which has been less explored. Fe-based bulk metallic glasses with a disordered and defect-free structure are emerging as highperformance materials for high-temperature corrosive applications. However, poor plastic deformation after yielding and no work hardening during room temperature deformation significantly limit their potential for application as structural materials (Ref 174-176). Such drawbacks with bulk glassy alloys make Fe-based amorphous coatings more suited for industrial applications in aggressive environments (Ref 177-180). There has recently been an upsurge in research interest on Fe-based amorphous coatings deposited by thermal spraying techniques. Thermal spraying leads to exceptional properties of the Fe-based coatings, particularly in terms of high corrosion and wear resistances (Ref 181-185).

$N i$

Ni-based thermal spray coatings such as $\mathrm{Ni} 21 \mathrm{Cr}$, Ni30Al, or Ni21Cr6Al1Y often display good resistance to hightemperature corrosion (Ref 186). The Ni matrix is preferred over other metal matrices like $\mathrm{Fe}$ in $\mathrm{Cl}$-containing environments as the formation of $\mathrm{NiCl}_{2}$ is thermodynamically less favored than other detrimental metallic chlorides such as $\mathrm{FeCl}_{2}$; see Eq 2-3:

$$
\begin{aligned}
\mathrm{Fe}(\mathrm{s})+\mathrm{Cl}_{2}(\mathrm{~g}) & =\mathrm{FeCl}_{2}(\mathrm{~s}) \\
\Delta G_{f}\left(\mathrm{FeCl}_{2}\right) & \approx-231.8 \mathrm{~kJ} / \mathrm{mol} \text { at } 600{ }^{\circ} \mathrm{C} \\
\mathrm{Ni}(\mathrm{s})+\mathrm{Cl}_{2}(\mathrm{~g}) & =\mathrm{NiCl}_{2}(\mathrm{~s}) \\
\Delta G_{f}\left(\mathrm{NiCl}_{2}\right) & \approx-173.9 \mathrm{~kJ} / \mathrm{mol} \text { at } 600^{\circ} \mathrm{C}
\end{aligned}
$$

There are a few other reasons why $\mathrm{Ni}$ is selected over Fe. Ni has good high-temperature creep properties, which are required for load-bearing components at high temperatures. The formation of $\mathrm{NiO}$ is slower than those of $\mathrm{Fe}$ rich oxides, implying that oxide breakaway occurs slower. Ni-based alloys require less $\mathrm{Cr}$ compared to $\mathrm{Fe}$-based alloys to display the same high-temperature corrosion behavior. The diffusion of $\mathrm{Ni}$ in $\mathrm{Cr}_{2} \mathrm{O}_{3}$ is slower, which highly favors the delaying of the breakaway oxidation. The vapor pressure of $\mathrm{FeCl}_{2}$ is much higher than that of $\mathrm{NiCl}_{2}$ at a given temperature, implying that $\mathrm{NiCl}_{2}$ can be found in the solid state, while $\mathrm{FeCl}_{2}$ has already vaporized.

Figure 27(d) shows the predominance diagram of the $\mathrm{Ni}-\mathrm{O}-\mathrm{Cl}$ system. Both $\mathrm{NiO}$ and $\mathrm{NiCl}_{2}$ can be expected to form in a typical boiler condition. The addition of alloying elements or the formation of a protective oxide scale on the coating surface, which are discussed in the previous sections, may alter the amounts of $\mathrm{Cl}_{2}$ and $\mathrm{O}_{2}$ available for the formation of $\mathrm{NiO}$ and $\mathrm{NiCl}_{2}$.

\section{Si}

Low concentrations of $\mathrm{Si}$ are often used in high-temperature alloys. A small level of Si can also be found in thermal spray powder compositions to provide the high-temperature corrosion resistance by the formation of a protective $\mathrm{SiO}_{2}$ layer on the coating surface. A small level of $\mathrm{Si}$ can also facilitate formation of other protective oxide scales such as Al-rich or Cr-rich oxides (Ref 187). If $\mathrm{Cr}$ is also available in the composition, the high $\mathrm{O}$ affinity of $\mathrm{Si}$ leads to the formation of $\mathrm{SiO}_{2}$ layer beneath the chromia scale. Different crystal structures of $\mathrm{SiO}_{2}$ are possible, depending on the specific conditions prevailing (Ref 188). For instance, amorphous $\mathrm{SiO}_{2}$ is frequently encountered but crystalline phases may also form. $\mathrm{SiO}_{2}$ has excellent 
protective properties. However, the Si concentration should be kept below 2-3 wt.\% to avoid embrittlement of the material. Poor oxide adhesion has also been reported in the case of $\mathrm{SiO}_{2}$-forming alloys under thermal cycling conditions (Ref 189). Figure 27(e) shows a ternary phase diagram of the Si-O-Cl system at $600{ }^{\circ} \mathrm{C}$, which suggests that the formation of $\mathrm{SiO}_{2}$ is thermodynamically more favored than $\mathrm{SiCl}_{4}$ in $\mathrm{O}-\mathrm{Cl}$-containing environments.

\section{Mo}

Mo is found in the thermal spray powder compositions in from of Ni21Cr9Mo, or Alloy 625 (NiCrMoNb) (Ref $44,153)$. Based on the ternary phase diagram of the Mo-O$\mathrm{Cl}$ system at $600{ }^{\circ} \mathrm{C}$, shown in Fig. 27(f), various corrosion products can form in oxidizing-chloridizing environments. While the addition of Mo is frequently reported to be beneficial in reducing environments, the formation of volatile $\mathrm{MoCl}_{x}$ or $\mathrm{MoO}_{x} \mathrm{Cl}_{y}$ is found to be highly detrimental to the corrosion behavior of the alloys (Ref 168). Thermodynamically, the formation of such metallic chlorides is highly favored and spontaneous; see Eq 4.

$$
\begin{aligned}
& \mathrm{Mo}(\mathrm{s})+3 / 2 \mathrm{Cl}_{2}(\mathrm{~g})=\mathrm{MoCl}_{3}(\mathrm{~s}) \\
& \Delta G_{f}\left(\mathrm{MoCl}_{3}\right) \approx-253.7 \mathrm{~kJ} \text { at } 600^{\circ} \mathrm{C}
\end{aligned}
$$

\section{Rare Earth Elements (RE) or Dispersed Oxides $\left(R E_{x} O_{y}\right)$}

A range of MCrAlYs $(\mathrm{M}=\mathrm{Ni}, \mathrm{Co}$, or/and $\mathrm{Fe})$ with rare earth element additions are commercially available as thermal spray feedstock. Elements like Y, Hf, La, Sc, Ce, and $\mathrm{Zr}$ are known as rare earth elements (REs) or O-reactive elements, as their oxides are typically more stable compared to the oxide scales formed on most alloys upon exposure to a high-temperature environment. REs improve the adherences of alumina and chromia scales to the underlying substrates, although the growth rates of the two oxides may be influenced differently. Through the addition of REs, the growth rate of chromia is decreased, whereas that of alumina is not significantly altered. Even when they are added in the oxide form $\left(\mathrm{RE}_{\mathrm{x}} \mathrm{O}_{\mathrm{y}}\right)$, some of the REs may improve the oxide scale adherence. A great number of mechanisms have been proposed to reveal the effects of REs (Ref 190, 191, 192), such as

- Grain boundary segregation of RE, leading to a "site blocking" effect: REs may interrupt the outward diffusion of $\mathrm{Cr}$ and block the fast diffusion paths of $\mathrm{Cr}^{3+}$.

- Dynamic segregation of REs at the oxide grain boundaries: The RE sergeants at the oxide grain boundaries are not static. They can be transported outward along with the grain boundaries, driven by the
$\mathrm{O}_{2}$ potential (i.e., the chemical activity of $\mathrm{O}$ ) gradient across a growing alumina scale and their high affinities for $\mathrm{O}$.

- Segregation of RE at the alloy/oxide interface: RE atoms segregate to the scale/metal interface and pin the climb of misfit dislocations, required for scale growth.

- Incorporation of $\mathrm{RE}$ as an oxide $\left(\mathrm{RE}_{\mathrm{x}} \mathrm{O}_{\mathrm{y}}\right)$ in the oxide scale: After internal oxidation, $\mathrm{RE}_{\mathrm{x}} \mathrm{O}_{\mathrm{y}}$ is decomposed to produce ions $\left(\mathrm{RE}^{\mathrm{n}+}\right)$ that can segregate to the grain boundaries of the oxide scale to suppress the outward diffusion of $\mathrm{Cr}^{3+}$.

There have been several efforts to enhance the corrosion resistance of thermal spray coatings by incorporating certain O-active elements (like $\mathrm{SiO}_{2}, \mathrm{Al}_{2} \mathrm{O}_{3}$, or $\mathrm{Y}_{2} \mathrm{O}_{3}$ ) into the coating to fabricate composite structures (Ref $193,194,195)$. It has already been reported that the hightemperature corrosion performance can be improved with uniformly distributed oxide dispersoids, which act as nucleation sites and facilitate the eventual formation of a continuous dense and protective oxide scale on the surface (Ref 196). However, this proposed mechanism is debated and has been rejected by others (Ref 197), as no difference can be seen between the oxidation behavior of a dispersoidcontaining alloy and that of a free-dispersoid alloy during the early stages of oxidation exposure. Therefore, it is proposed that the dispersoids alter the microstructure of the formed oxide by reducing the grain size, which promotes the inward diffusion of $\mathrm{O}^{2-}$ rather than the outward diffusion of $\mathrm{Cr}^{3+}$ through the oxide grain boundaries (Ref 197). The dispersed oxides can lead to excellent scale adherence to the substrate material, based on a mechanism known as the "pegging effect" or "mechanical keying" that has been frequently reported by various authors (Ref 198, 199). Oxide scale protrusions into the underlying alloy were also found, which pinned the scale to the substrate. The dispersed oxides in the alloy were also reported to act as the preferred sites for the nucleation of vacancies, which are thereby prevented from accumulating at the oxide scale/metal interface (Ref 200).

Recently, an interpretation on the effect of ceria particle dispersion on the growth process of alumina scales was proposed (Ref 201, 202); see Fig. 28. It was found that (1) there is no dissolution of the original $\mathrm{CeO}_{2}$ particles in the metal during oxidation; (2) the thermally grown oxide (TGO) scale is composed of the outward growing $\gamma-\mathrm{Al}_{2} \mathrm{O}_{3}$ and the inward growing $\alpha-\mathrm{Al}_{2} \mathrm{O}_{3}$, and the $\mathrm{CeO}_{2}$ particles in the metal can be swept over by the inwardly growing $\alpha$ $\mathrm{Al}_{2} \mathrm{O}_{3}$; (3) the $\mathrm{Ce}$ ions segregated to the grain boundaries (GBs) of the inner $\alpha-\mathrm{Al}_{2} \mathrm{O}_{3}$; and finally (iv) novel $\mathrm{Ce}_{2} \mathrm{O}_{3}$ particles precipitated along the twin boundaries of the outer $\gamma-\mathrm{Al}_{2} \mathrm{O}_{3}$. 

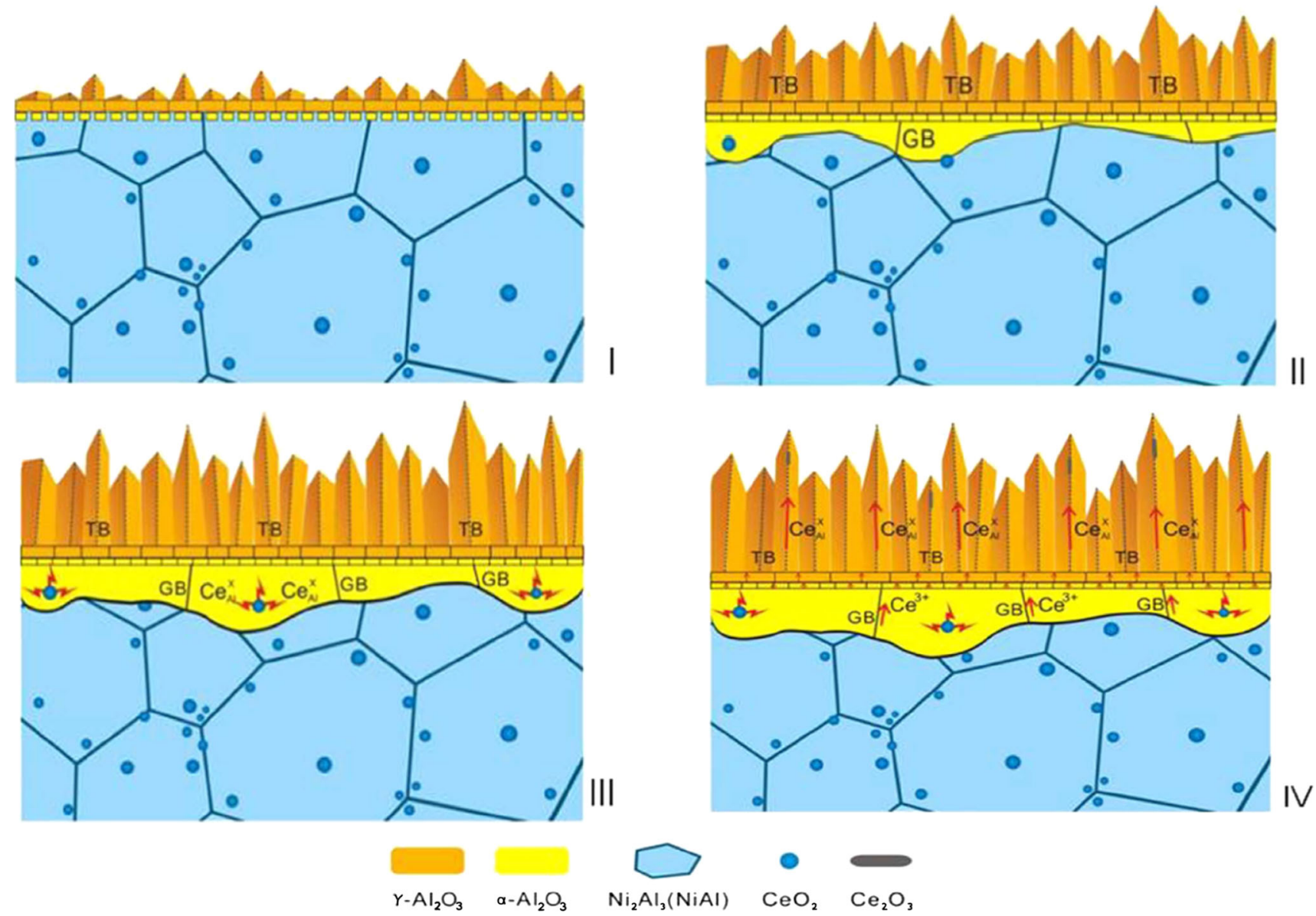

Fig. 28 Schematic of the steps for the evolution of the $\mathrm{CeO}_{2}$ dispersion in an aluminide from being incorporated into an inner $\mathrm{Al}_{2} \mathrm{O}_{3} \mathrm{scale}$ to being precipitated as $\mathrm{Ce}_{2} \mathrm{O}_{3}$ in the outer $\mathrm{Al}_{2} \mathrm{O}_{3}$ scale (Ref 201). Reprinted with permission from Elsevier

\section{Final Remarks on Thermodynamic Considerations}

The corrosion behavior of the alloying elements in oxidizing-chloridizing environments was discussed and compared by using the thermodynamics analysis of Grabke et al. (Ref 188); see Fig. 29. The more negative Gibbs free energy of the metal + chlorine $=$ metal chloride reaction indicates the greater stability of the products. The abovementioned elements can be ranked based on this parameter from the most to the least stable product:

$\mathrm{SiCl}_{4}>\mathrm{AlCl}_{3}>\mathrm{CrCl}_{3}>\mathrm{MoCl}_{3}>\mathrm{FeCl}_{3}>\mathrm{NiCl}_{2}$

Apart from the Gibbs free energy, there are three other important factors affecting the corrosion mechanism: (1) the vapor pressure of the chlorides for the solid-to-gas transformation, (2) the diffusivities of the metallic chlorides, and (3) the $\mathrm{O}_{2}$ pressure for the chloride-to-oxide transformation. The vapor pressures of the chlorides play a major role in determining the corrosion products, evaporation, or oxidation. The vapor pressures of the different metallic chlorides can be ranked from the highest (the highest tendency for vaporization and the lowest tendency for oxidation) to the lowest (the lowest tendency for vaporization and the highest tendency for oxidation) at a fixed temperature as

$\mathrm{AlCl}_{3}>\mathrm{FeCl}_{2}>\mathrm{FeCl}_{3}>\mathrm{CrCl}_{2}>\mathrm{NiCl}_{2}>\mathrm{MoCl}_{4}$

Once the solid metallic chlorides transform to the gaseous state, they diffuse outward to reach the atmosphere. The diffusivities of the different compounds in an oxide formed on a Fe-based alloy/coating can be ranked from the fastest to the slowest diffusing species in comparison with $\mathrm{O}_{2}$ and $\mathrm{Cl}_{2}$ as

$$
\begin{aligned}
\mathrm{O}_{2} & >\mathrm{Cl}_{2}>\mathrm{NiCl}_{2} \approx \mathrm{CrCl}_{2}>\mathrm{CrCl}_{3}>\mathrm{AlCl}_{3} \\
& >\mathrm{MoCl}_{4}>\mathrm{FeCl}_{2} \approx \mathrm{FeCl}_{3}
\end{aligned}
$$

Finally, for the transformation of the metallic chlorides to oxides, a minimum $p \mathrm{O}_{2}$ is needed. The lower this $\mathrm{O}_{2}$ pressure, the smaller is the distance from the metal surface at which the oxide is formed. The $p \mathrm{O}_{2}$ required for the different reactions can be ranked from the highest to the lowest as 
Fig. 29 Schematic of the thermodynamics and the reactions associated with the corrosion of alloys containing the elements $\mathrm{Mn}, \mathrm{Cr}, \mathrm{Fe}, \mathrm{Ni}$, and Mo in a flowing oxidizing and chloridizing atmosphere (Ref 181). Reprinted with permission from Elsevier

\section{Flowing gas atmosphere}

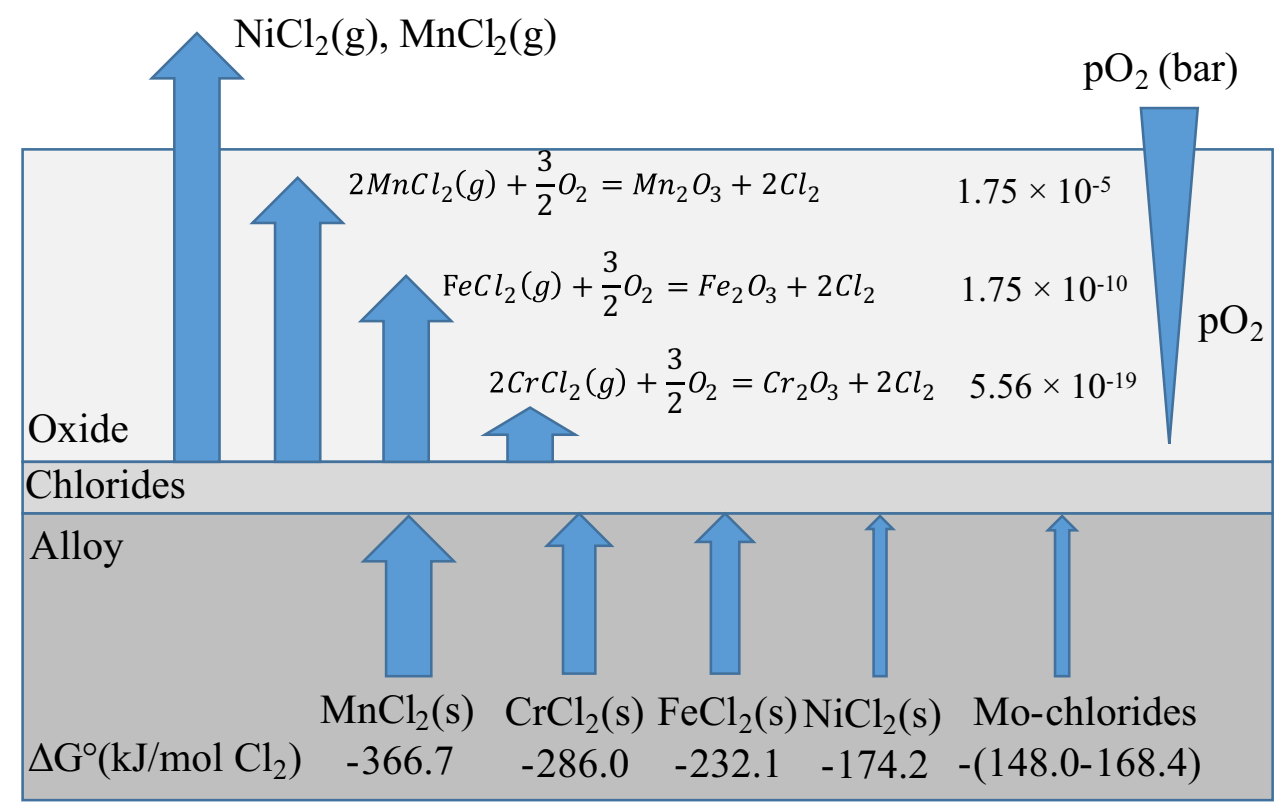

$\mathrm{NiCl}_{2}-\mathrm{NiO}>\mathrm{FeCl}_{2}-\mathrm{Fe}_{2} \mathrm{O}_{3}>\mathrm{CrCl}_{3}$

$-\mathrm{Cr}_{2} \mathrm{O}_{3}>\mathrm{CrCl}_{2}-\mathrm{Cr}_{2} \mathrm{O}_{3}$

Considering a coating consisting of $\mathrm{Ni}, \mathrm{Fe}$, and $\mathrm{Cr}$, the plausible oxide layers are outer $\mathrm{Ni}$ or $\mathrm{Fe}$-rich scales and inner $\mathrm{Cr}$-rich scale. In general, solid $\mathrm{NiCl}_{2}$ is less stable than other chlorides (owing to its less negative Gibbs free energy). It is also difficult for volatile $\mathrm{NiCl}_{2}$ to form, as it has a low vapor pressure but, when it forms, it should be considered that $\mathrm{NiCl}_{2}$ is transported away (due to its high diffusivity and the high $p \mathrm{O}_{2}$ required to form the oxide) to a great extent, unoxidized by the gas flow.

\section{Concluding Remarks}

The power generation industry is progressively shifting toward the use of renewable energies derived from sources such as biomass and waste to suppress emission of environmental pollutants like $\mathrm{CO}_{2}$, and increase the electrical/ thermal efficiency. However, such power plants suffer from severe high-temperature corrosion of critical load-bearing components such as water walls and superheater tubes. Thermal spray processes are now increasingly used in these sectors, particularly for protecting components with an ideal combination of bulk and surface properties that cannot be easily accomplished using conventional alloys. At the same time, there are several synergistic factors responsible for making thermal spray coatings increasingly attractive to be deployed for imparting economical and long-lasting protection against corrosion damage in harsh operating environments. These include the ability to deposit high-performance coatings reliably by virtue of continuing improvements of the computational hardware and software, development of more robust yet affordable equipment, improvements in automation, the enhanced knowledge base with respect to both the metallurgy and degradation of thermal sprayed coatings, a larger portfolio of available coating materials in terms of both chemical composition and powder size, advances in coatings testing and characterization, improved skills/expertise in coating processes so higher quality coatings. However, there also continues to be an incessant demand for further improvements in the performance of the coatings to impart extended durability. In the present review, various thermal spray techniques have been assessed for corrosion protection applications. Despite significant improvements in the spraying techniques to achieve dense and defect-free microstructures for corrosion protection applications, several scientific and technological issues still affect the quality and cost of thermal spray coatings. These challenges include the presence of inherent features in the coatings, such as pores, splat boundaries, coating/substrate adhesion, intersplat bonding (cohesion), surface quality, and residual stresses. More importantly, the applicability of the selected thermal spray process inside the boiler for 
coating and repair needs to be always considered. While deposition of a dense and adherent Ni-based coating containing protective scale-forming elements such as $\mathrm{Al}$ or/and $\mathrm{Cr}$ using more advanced thermal spray techniques like high-velocity air-fuel (HVAF) has been shown as a promising approach to extend the component's lifetime, hence increase the thermal/electrical efficiency of the boilers, the inherent features of the thermal spray coatings and coating/substrate bonding need to be thoroughly checked to enable wider commercial adaptation of the coatings in power plant applications.

The complex interaction of in-flight particles with supersonic flame in the thermal spray process, and formation of a complex deposit encumber understanding the inter-relation of process, microstructure, properties, and corrosion performance of the coatings under simplified laboratory-scale corrosion studies and complex field exposures. An additional challenge is the development of an in-depth understanding of high-temperature corrosion mechanisms of coatings due to their intricate microstructures. A better understanding of the thermal spray processes will be important to avoid the common defects and to ultimately tailor the composition, microstructure, and properties of thermal spray coatings based on scientific principles. Furthermore, greater market penetration of thermal spray coatings will require an increased level of standardization and control to achieve repeatable processes that can produce coatings with consistent properties. Developing a better metallurgical knowledge base of thermal spray coatings will require sustained research and development of the thermal spray processes and the structure and properties of thermal spray coatings over the coming decades.

Challenges also remain in improving the productivities of thermal spray processes, enhancing the performances of thermal spray coatings, lowering the high cost of producing quality metal powders, and making the equipment more affordable. Many unique technical capabilities such as spraying in small-diameter pipes, onsite spraying of boiler components, and repairing the worn coatings provide unprecedented business opportunities for thermal spraying. A more comprehensive understanding of the thermal spray processes and the innovations in these areas are needed for greater technological adaptation of the thermal spray processes.

Acknowledgment Open access funding provided by University West. Financial support of the Knowledge Foundation for the SCoPe project (RUN 20160201) and Västra Götalandsregionen (VGR) for the PROSAM project (RUN 2016-01489) are highly acknowledged.

Data availability All data included in this study are available upon request by contact with the corresponding author.
Open Access This article is distributed under the terms of the Creative Commons Attribution 4.0 International License (http://crea tivecommons.org/licenses/by/4.0/), which permits unrestricted use, distribution, and reproduction in any medium, provided you give appropriate credit to the original author(s) and the source, provide a link to the Creative Commons license, and indicate if changes were made.

\section{References}

1. N.L. Panwar, S.C. Kaushik, and S. Kothari, Role of Renewable Energy Sources in Environmental Protection: A Review, Renew. Sustain. Energy Rev., 2011, 15(3), p 1513-1524

2. G. Boyle, Renewable Energy Power for a Sustainable Future, 2nd ed., Oxford University Press, Oxford, 2004

3. M. Li, N. Luo, and Y. Lu, Biomass Energy Technological Paradigm (BETP): Trends in this Sector, Sustainability, 2017, 9(4), p 567

4. A. Demirbas, Potential Applications of Renewable Energy Sources, Biomass Combustion Problems in Boiler Power Systems and Combustion Related Environmental Issues, Prog. Energy Combust. Sci., 2005, 31(2), p 171-192

5. A.A. Khan, W. De Jong, P.J. Jansens, and H. Spliethoff, Biomass Combustion in Fluidized Bed Boilers: Potential Problems and Remedies, Fuel Process. Technol., 2009, 90(1), p 21-50

6. P. McKendry, Energy Production from Biomass (Part 1): Overview of Biomass, Bioresour. Technol. , 2002, 83(1), p 3746

7. D.A. Tillman, Biomass Cofiring: The Technology, the Experience, the Combustion Consequences, Biomass Bioenergy, 2000, 19(6), p 365-384

8. H.P. Nielsen, F.J. Frandsen, K. Dam-Johansen, and L.L. Baxter, Implications of Chlorine-Associated Corrosion on the Operation of Biomass-Fired Boilers, Prog. Energy Combust. Sci., 2000, 26(3), p 283-298

9. D. Fähsing, M. Rudolphi, L. Konrad, and M.C. Galetz, Fireside Corrosion of Chromium- and Aluminum-Coated FerriticMartensitic Steels, Oxid. Metals, 2017, 88(1-2), p 155-164

10. P. Fauchais, and A. Vardelle, Thermal sprayed coatings used against corrosion and corrosive wear, Adv. Plasma Spray Appl., 2012.

11. K. Szymański, A. Hernas, G. Moskal, and H. Myalska, Thermally Sprayed Coatings Resistant to Erosion and Corrosion for Power Plant Boilers: A Review, Surf. Coat. Technol., 2015, 268, p 153-164

12. D. Mudgal, S. Singh, and S. Prakash, "Corrosion problems in incinerators and biomass-fuel-fired boilers," International Journal of Corrosion, 2014, 2014.

13. S.A. Galedari, A. Mahdavi, F. Azarmi, Y. Huang, and A. McDonald, A Comprehensive Review of Corrosion Resistance of Thermally-Sprayed and Thermally-Diffused Protective Coatings on Steel Structures, J. Therm. Spray Technol., 2019, 28(4), p 645-677

14. R. Viswanathan, K. Coleman, and U. Rao, Materials for UltraSupercritical Coal-Fired Power Plant Boilers, Int. J. Press. Vessels Pip., 2006, 83(11-12), p 778-783

15. S. Saber-Samandari and C.C. Berndt, IFTHSE Global 21: Heat Treatment and Surface Engineering in the Twenty-First Century Part 10 - Thermal Spray Coatings: A Technology Review, Int. Heat Treat. Surf. Eng., 2010, 4(1), p 7-13

16. M. Kaur, H. Singh, and S. Prakash, A Survey of the Literature on the Use of High Velocity Oxy-Fuel Spray Technology for High Temperature Corrosion and Erosion-Corrosion Resistant Coatings, Anti-Corros. Methods Mater., 2008, 55(2), p 86-96 
17. H. Singh, T. S. Sidhu, and S. B. S. Kalsi, "Effect of Nano Coatings On Waste to Energy (WTE) Plant: A Review," $i$ Manager's Journal on Electronics Engineering, 20101, 1, p 1

18. Y. Kawahara, Application of High Temperature Corrosion-Resistant Materials and Coatings Under Severe Corrosive Environment in Waste-to-Energy Boilers, J. Therm. Spray Technol., 2007, 16(2), p 202-213

19. J. Mehta, V.K. Mittal, and P. Gupta, Role of Thermal Spray Coatings on Wear, Erosion and Corrosion Behavior: A Review, J. Appl. Sci. Eng., 2017, 20(4), p 445-452

20. S. Amin, and H. Panchal, A Review on Thermal Spray Coating Processes, Transfer, 2016 2, p 4

21. Y. Kawahara, An overview on corrosion-resistant coating technologies in biomass/waste-to-energy plants in recent decades. Coatings, 2016, 6(3), p 34

22. E. Sadeghi, S. Raman, and S. Joshi, "High Temperature Erosion-Corrosion of HVAF-Sprayed Ni-based Coatings", in 8th Rencontres Internationales sur la Projection Thermique, Limoges, France, 2017

23. L.L. Baxter et al., The Behavior of Inorganic Material in Biomass-Fired Power Boilers: Field and Laboratory Experiences, Fuel Process. Technol., 1998, 54(1-3), p 47-78

24. A. Singh, V. Sharma, S. Mittal, G. Pandey, D. Mudgal, and P. Gupta, An Overview of Problems and Solutions for Components Subjected to Fireside of Boilers, Int. J. Ind. Chem., 2018, 9(1), p 1-15

25. P. Henderson, P. Szakálos, R. Pettersson, C. Andersson, and J. Högberg, Reducing Superheater Corrosion in Wood-Fired Boilers, Mater. Corros., 2006, 57(2), p 128-134

26. S. Karlsson, L.-E. Åmand, and J. Liske, Reducing High-Temperature Corrosion on High-Alloyed Stainless Steel Superheaters by co-Combustion of Municipal Sewage Sludge in a Fluidised Bed Boiler, Fuel, 2015, 139, p 482-493

27. J. Koppejan, and S. Van Loo, The Handbook of Biomass Combustion and Co-firing. Routledge, London, 2012.

28. M.A. Olivas-Ogaz, J. Eklund, J.-E. Svensson, J. Liske, and T. Jonsson, Microstructural Study of the Influence of $\mathrm{KCl}$ and $\mathrm{HCl}$ on Preformed Corrosion Product Layers on Stainless Steel, Oxid. Metals, 2017, 87(5-6), p 801-811

29. C. Yin, L.A. Rosendahl, and S.K. Kær, Grate-Firing of Biomass for Heat and Power Production, Prog. Energy Combust. Sci., 2008, 34(6), p 725-754

30. I. Obernberger, T. Brunner, and G. Bärnthaler, Chemical Properties of Solid Biofuels-Significance and Impact, Biomass Bioenerg., 2006, 30(11), p 973-982

31. A. Miltner, G. Beckmann, and A. Friedl, Preventing the Chlorine-Induced High Temperature Corrosion In Power Boilers Without Loss of Electrical Efficiency In steam Cycles, Appl. Therm. Eng., 2006, 26(16), p 2005-2011

32. D. Leclerc, W.L. Duo, and M. Vessey, Effects of Combustion and Operating Conditions on PCDD/PCDF Emissions from Power Boilers Burning Salt-Laden Wood Waste, Chemosphere, 2006, 63(4), p 676-689

33. G. Scheffknecht, L. Al-Makhadmeh, U. Schnell, and J. Maier, Oxy-Fuel Coal Combustion: A Review of the Current State-ofthe-Art, Int. J. Greenhouse Gas Control, 2011, 5(SUPPL. 1), p S16-S35

34. A. Zahs, M. Spiegel, and H.J. Grabke, Chloridation and Oxidation of Iron, Chromium, Nickel and Their Alloys in Chloridizing and Oxidizing Atmospheres at 400-700 ${ }^{\circ} \mathrm{C}$, Corros. Sci., 2000, 42(6), p 1093-1122

35. N. Israelsson et al., A Microstructural and Kinetic Investigation of the $\mathrm{KCl}$-Induced Corrosion of an $\mathrm{FeCrAl}$ Alloy at $600{ }^{\circ} \mathrm{C}$, Oxid. Metals, 2015, 84(1-2), p 105-127

36. Y. Liu, W. Fan, X. Wu, and X. Zhang, Chlorine-Induced HighTemperature Corrosion of Boiler Steels Combusting Sha Erhu
Coal Compared to Biomass, Energy Fuels, 2018, 32(4), p 4237 4247

37. J.E. Indacochea, J.L. Smith, K.R. Litko, E.J. Karell, and A.G. Rarez, High-Temperature Oxidation and Corrosion of Structural Materials in Molten Chlorides, Oxid. Metals, 2001, 55(1-2), p 116

38. T. Ishitsuka and K. Nose, Stability of Protective Oxide Films in Waste Incineration Environment-Solubility Measurement of Oxides in Molten Chlorides, Corros. Sci., 2002, 44(2), p 247 263

39. B. Verbinnen, J. De Greef, and J. Van Caneghem, Theory and Practice of Corrosion Related to Ashes and Deposits in a WtE Boiler, Waste Manag, 2018, 73, p 307-312

40. R. Jafari and E. Sadeghi, "High-temperature corrosion performance of HVAF-sprayed $\mathrm{NiCr}, \mathrm{NiAl}$, and NiCrAlY coatings with alkali sulfate/chloride exposed to ambient air," Corrosion Science, p 108066, 2019.

41. T. Sharobem and M. J. Castaldi, The effect of $\mathrm{SO} / \mathrm{HCl}$ ratio on superheater high temperature corrosion, presented at the 20th Annual North American Waste-to-Energy Conference, NAWTEC 2012, 2012, 23-27

42. Y.S. Li, Y. Niu, and W.T. Wu, Accelerated Corrosion of Pure $\mathrm{Fe}, \mathrm{Ni}, \mathrm{Cr}$ and Several Fe-Based Alloys Induced by $\mathrm{ZnCl} 2-\mathrm{KCl}$ at $450{ }^{\circ} \mathrm{C}$ in Oxidizing Environment, Mater. Sci. Eng. A, 2003, 345(1-2), p 64-71

43. C. Proff, T. Jonsson, C. Pettersson, J.-E. Svensson, L.-G. Johansson, and M. Halvarsson, Microstructural Investigation of the KCl-Induced Corrosion of the Austenitic Alloy Sanicro 28 $(35 \mathrm{Fe} 27 \mathrm{Cr} 31 \mathrm{Ni})$ at $600{ }^{\circ} \mathrm{C}$, Mater. High Temp., 2009, 26(2), p 113-125

44. D. Fantozzi, V. Matikainen, M. Uusitalo, H. Koivuluoto, and P. Vuoristo, Chlorine-Induced High Temperature Corrosion of Inconel 625 Sprayed Coatings Deposited with Different Thermal Spray Techniques, Surf. Coat. Technol., 2017, 318, p 233-243

45. J. Zhou, J.K. Walleser, B.E. Meacham, and D.J. Branagan, Novel in Situ Transformable Coating for Elevated-Temperature Applications, J. Therm. Spray Technol., 2010, 19(5), p 950-957

46. M. Oksa, S. Tuurna, and T. Varis, Increased Lifetime for Biomass and Waste to Energy Power Plant Boilers with HVOF Coatings: High Temperature Corrosion Testing Under ChlorineContaining Molten Salt, J .Therm Spray Technol., 2013, 22(5), p 783-796

47. M. Oksa, P. Auerkari, J. Salonen, and T. Varis, Nickel-Based HVOF Coatings Promoting High Temperature Corrosion Resistance of Biomass-Fired Power Plant Boilers, Fuel Process. Technol., 2014, 125, p 236-245

48. L. Reddy, P. Shipway, C. Davis, and T. Hussain, HVOF and Laser-Cladded Fe-Cr-B Coating in Simulated Biomass Combustion: Microstructure and Fireside Corrosion, Oxid. Metals, 2017, 87(5-6), p 825-835

49. H.J. Grabke, E. Reese, and M. Spiegel, The Effects Of Chlorides, Hydrogen Chloride, And Sulfur Dioxide in the Oxidation of Steels Below Deposits, Corros. Sci., 1995, 37(7), p 1023 1043

50. K. Salmenoja, Black-Liquor Gasification: Theoretical and Experimental Studies, Bioresour. Technol., 1993, 46(1), p 167171

51. J. Sandberg, C. Karlsson, and R.B. Fdhila, A 7 year Long Measurement Period Investigating the Correlation of Corrosion, Deposit and Fuel in a Biomass Fired Circulated Fluidized Bed Boiler, Appl. Energy, 2011, 88(1), p 99-110

52. S. Poskrobko, J. Łach, and D. Król, Experimental Investigation of Hydrogen Chloride Bonding with Calcium Hydroxide in the Furnace of a Stoker-Fired Boiler, Energy Fuels, 2010, 24(3), p 1948-1957 
53. A. Fry, B. Adams, K. Davis, D. Swensen, S. Munson, and W. Cox, An Investigation into the Likely Impact of Oxy-Coal Retrofit on Fire-Side Corrosion Behavior in Utility Boilers, Int. J. Greenhouse Gas Control, 2011, 5, p S179-S185

54. R.A. Khalil et al., Experimental Investigation on Corrosion Abatement in Straw Combustion by Fuel Mixing, Energy Fuels, 2011, 25(6), p 2687-2695

55. S.C. Okoro, M. Montgomery, F.J. Frandsen, and K. Pantleon, Time and Temperature Effects on Alkali Chloride Induced High Temperature Corrosion of Superheaters during Biomass Firing, Energy Fuels, 2018, 32(7), p 7991-7999

56. S. Karlsson, T. Jonsson, J. Hall, J.-E. Svensson, and J. Liske, Mitigation of Fireside Corrosion of Stainless Steel in Power Plants: A Laboratory Study of the Influences of $\mathrm{SO} 2$ and $\mathrm{KCl}$ on Initial Stages of Corrosion, Energy Fuels, 2014, 28(5), p 31023109

57. S.C. van Lith, F.J. Frandsen, M. Montgomery, T. Vilhelmsen, and S.A. Jensen, Lab-scale Investigation of Deposit-induced Chlorine Corrosion of Superheater Materials under Simulated Biomass-Firing Conditions. Part 1: Exposure at $560{ }^{\circ} \mathrm{C}$, Energy Fuels, 2009, 23(7), p 3457-3468

58. S. Andersson et al., Sulfur Recirculation for Increased Electricity Production in Waste-to-Energy Plants, Waste Manag, 2014, 34(1), p 67-78

59. Y. Kawahara, High Temperature Corrosion Mechanisms and Effect Of Alloying Elements for Materials Used in Waste Incineration Environment, Corros. Sci., 2002, 44(2), p 223-245

60. M. Fukuda, "22 - Advanced USC technology development in Japan," in Materials for Ultra-Supercritical and Advanced Ultra-Supercritical Power Plants, A. Di Gianfrancesco, Ed. Woodhead Publishing, 2017, 733-754.

61. K. Kurokawa, T. Sudiro, T. Sano, S. Kyo, O. Ishibashi, and M. Nakamori, High-Temperature Corrosion Resistance of $\mathrm{SiO}_{2}{ }^{-}$ Forming Materials, Corros. Rev., 2018, 36(1), p 65-74

62. P.S. Sidky and M.G. Hocking, Review of Inorganic Coatings and Coating Processes for Reducing Wear and Corrosion, $\mathrm{Br}$. Corros. J., 1999, 34(3), p 171-183

63. A. Hjörnhede, Erosion - Corrosion Resistance and Adhesion of Laser and Thermally Deposited Coatings in Fluidised Beds, 2004

64. B. Song, K.T. Voisey, and T. Hussain, High Temperature Chlorine-Induced Corrosion of Ni50Cr Coating: HVOLF, HVOGF, Cold Spray and Laser Cladding, Surf. Coat. Technol., 2018, 337, p 357-369

65. B. Backer, S. Kizer, and R. Zhang, "Recent experience with materials utilized to resist coal ash corrosion", presented at the CORROSION/2011, NACE, Houston, TX, USA, 2011

66. S.S. Sandhu and A.S. Shahi, Metallurgical, Wear and Fatigue Performance of Inconel 625 Weld Claddings, J. Mater. Process. Technol., 2016, 233, p 1-8

67. J. R. Davis, Handbook of Thermal Spray Technology. ASM International, 2004.

68. F. B. Quinlan and L. P. Grobel, "Treatment of metals," US2303869A, 01-Dec-1942.

69. P. Fauchais, G. Montavon, and G. Bertrand, From Powders to Thermally Sprayed Coatings, J. Therm. Spray Technol., 2010, 19(1-2), p 56-80

70. J.A. Browning, Hypervelocity Impact Fusion-A Technical Note, JTST, 1992, 1(4), p 289-292

71. J. Kiilakoski, J. Puranen, E. Heinonen, H. Koivuluoto, and P. Vuoristo, Characterization of Powder-Precursor HVOF-Sprayed A12O3-YSZ/ZrO2 Coatings, J. Therm. Spray Technol., 2019, 28(1), p 98-107

72. S.V. Joshi, G. Sivakumar, T. Raghuveer, and R.O. Dusane, Hybrid Plasma-Sprayed Thermal Barrier Coatings Using
Powder and Solution Precursor Feedstock, J. Therm. Spray Technol., 2014, 23(4), p 616-624

73. J.W. Murray, A. Leva, S. Joshi, and T. Hussain, Microstructure and Wear Behaviour of Powder and Suspension Hybrid Al2O3YSZ Coatings, Ceram. Int., 2018, 44(7), p 8498-8504

74. S. Björklund, S. Goel, and S. Joshi, Function-Dependent Coating Architectures by Hybrid Powder-Suspension Plasma Spraying: Injector Design, Processing and Concept Validation, Mater. Des., 2018, 142, p 56-65

75. B. Song, Z. Pala, K.T. Voisey, and T. Hussain, Gas and LiquidFuelled HVOF Spraying of Ni50Cr Coating: Microstructure and High Temperature Oxidation, Surf. Coat. Technol., 2017, 318, p 224-232

76. M. Oksa, "Nickel- and iron-based HVOF thermal spray coatings for high temperature corrosion protection in biomass-fired power plant boilers: Dissertation," 2015.

77. M. Oksa, E. Turunen, T. Suhonen, T. Varis, and S.-P. Hannula, Optimization and Characterization of High Velocity Oxy-fuel Sprayed Coatings: Techniques, Materials, and Applications, Coatings, 2011, 1(1), p 17-52

78. N. Rana, M.M. Mahapatra, R. Jayaganthan, and S. Prakash, High-Temperature Oxidation and Hot Corrosion Studies on NiCrAlY Coatings Deposited by Flame-Spray Technique, $J$. Therm. Spray Technol., 2015, 24(5), p 769-777

79. Y. Korobov, S. Nevezhin, and M. Filippov, "Study of high velocity arc sprayed heat resistant coatings from $\mathrm{FeCrAlBY}$ cored wire. Thermal spray. Fostering a sustainable world for a better life," in of the Int. Thermal Spray Conf. and Exposition ITSC 2016 (10-13 May, 2016, Shanghai, China), 2016, 852-856.

80. P. Fauchais, Understanding Plasma Spraying, J. Phys. D Appl. Phys., 2004, 37(9), p R86

81. C. Moreau, P. Gougeon, M. Lamontagne, V. Lacasse, G. Vaudreuil, P. Cielo, "On-Line Control of the Plasma Spraying Process by Monitoring the Temperature, Velocity, and Trajectory of in-Flight Particles," (1994).

82. Y. Wang et al., A Transmission Electron Microscopy Study of the Microstructure and Interface of Zirconia-Based Thermal Barrier Coatings, J. Alloys Compd., 2015, 619, p 820-825

83. R. Ghasemi, R. Shoja-Razavi, R. Mozafarinia, and H. Jamali, Comparison of Microstructure and Mechanical Properties of Plasma-Sprayed Nanostructured and Conventional Yttria Stabilized Zirconia Thermal Barrier Coatings, Ceram. Int., 2013, 39, $p$ 8805-8813

84. T. Hussain, T. Dudziak, N.J. Simms, and J.R. Nicholls, Fireside Corrosion Behavior of HVOF and Plasma-Sprayed Coatings in Advanced Coal/Biomass Co-fired Power Plants, J. Therm. Spray Technol., 2013, 22(5), p 797-807

85. H. Singh, D. Puri, and S. Prakash, High Temperature Oxidation Behaviour of Plasma Sprayed NiCrAlY Coatings on Ni-Based Superalloys in Air, Trans. Indian Inst. Metals, 2005, 59, p 215227

86. T.C. Hanson, C.M. Hackett, and G.S. Settles, Independent Control of HVOF Particle Velocity and Temperature, J. Therm. Spray Technol., 2002, 11(1), p 75-85

87. S. Shrestha and A.J. Sturgeon, Use of Advanced Thermal Spray Processes for Corrosion Protection in Marine Environments, Surf. Eng., 2004, 20(4), p 237-243

88. R. Molins, B. Normand, G. Rannou, B. Hannoyer, and H. Liao, Interlamellar Boundary Characterization in Ni-Based Alloy Thermally Sprayed Coating, Mater. Sci. Eng., A, 2003, 351(1), p 325-333

89. D. Shi, M. Li, and P.D. Christofides, Diamond Jet Hybrid HVOF Thermal Spray: Rule-Based Modeling of Coating Microstructure, Ind. Eng. Chem. Res., 2004, 43(14), p 3653-3665 
90. D. Zhang, S.J. Harris, and D.G. McCartney, Microstructure Formation and Corrosion Behaviour in HVOF-Sprayed Inconel 625 Coatings, Mater. Sci. Eng., A, 2003, 344(1-2), p 45-56

91. M. Bai, L. Reddy, and T. Hussain, Experimental and Thermodynamic Investigations on the Chlorine-Induced Corrosion of HVOF Thermal Sprayed NiAl Coatings and 304 Stainless Steels at $700{ }^{\circ}$ C, Corros. Sci., 2018, 135, p 147-157

92. S. Hong, Y. Wu, G. Li, B. Wang, W. Gao, and G. Ying, Microstructural Characteristics of High-Velocity Oxygen-Fuel (HVOF) Sprayed Nickel-Based Alloy Coating, J. Alloys Compd., 2013, 581, p 398-403

93. X.Q. Ma, D.W. Gandy, and G.J. Frederick, Innovation of Ultrafine Structured Alloy Coatings Having Superior Mechanical Properties and High Temperature Corrosion Resistance, $J$. Therm. Spray Technol., 2008, 17(5-6), p 933-941

94. P. Cavaliere, Cold-Spray Coatings: Recent Trends and Future perspectives, Springer, Berlin, 2018

95. N. Bala, H. Singh, J. Karthikeyan, and S. Prakash, Cold Spray Coating Process for Corrosion Protection: A Review, Surf. Eng., 2014, 30(6), p 414-421

96. A. Verstak and V. Baranovski, Activated Combustion HVAF Coatings for Protection Against Wear and High Temperature Corrosion, Presented at the International Thermal Spray Conference and Exposition, ITSC 2003, Orlando, Florida, 2003

97. C. Lyphout and S. Björklund, Internal Diameter HVAF Spraying for Wear and Corrosion Applications, J. Therm. Spray Technol., 2015, 24, p 235-243

98. C. Lyphout, S. Björklund, M. Karlsson, M. Runte, G. Reisel, and P. Boccaccio, Screening Design of Supersonic Air Fuel Processing for Hard Metal Coatings, J. Therm. Spray Technol., 2014, 23(8), p 1323-1332

99. K. Tao, X. Zhou, H. Cui, and J. Zhang, Microhardness Variation in Heat-Treated Conventional and Nanostructured $\mathrm{NiCrC}$ Coatings Prepared by HVAF Spraying, Surf. Coat. Technol., 2009, 203(10-11), p 1406-1414

100. Y.-Y. Wang, C.-J. Li, and A. Ohmori, Examination of Factors Influencing the Bond Strength of High Velocity Oxy-Fuel Sprayed Coatings, Surf. Coat. Technol., 2006, 200(9), p 29232928

101. G.-J. Yang, X.-D. Xiang, L.-K. Xing, D.-J. Li, C.-J. Li, and C.$\mathrm{X}$. Li, Isothermal Oxidation Behavior of NiCoCrAlTaY Coating Deposited by High Velocity Air-Fuel Spraying, J. Therm. Spray Technol., 2012, 21(3-4), p 391-399

102. A.P. Wang, Z.M. Wang, J. Zhang, and J.Q. Wang, Deposition of HVAF-Sprayed Ni-Based Amorphous Metallic Coatings, $J$. Alloys Comp., 2007, 440(1-2), p 225-228

103. A.P. Wang, X.C. Chang, W.L. Hou, and J.Q. Wang, Preparation and Corrosion Behaviour of Amorphous Ni-Based Alloy Coatings, Mater. Sci. Eng., A, 2007, 449-451, p 277-280

104. E. Sadeghimeresht, N. Markocsan, P. Nylén, and S. Björklund, Corrosion Performance of Bi-Layer Ni/Cr2C3-NiCr HVAF Thermal Spray Coating, Appl. Surf. Sci., 2016, 369, p 470-481

105. J. Eklund, J. Phother, E. Sadeghi, S. Joshi, and J. Liske, HighTemperature Corrosion of HVAF-Sprayed Ni-Based Coatings for Boiler Applications, Oxid. Metals, 2019, 91(5), p 729-747

106. P. Zhang et al., Effects of Surface Finish on the Initial Oxidation of HVAF-Sprayed NiCoCrAlY Coatings, Surf. Coat. Technol., 2019, 364, p 43-56

107. E. Sadeghimeresht, J. Eklund, J.P. Simon, J. Liske, N. Markocsan, and S. Joshi, Effect of Water Vapor on the Oxidation Behavior of HVAF-Sprayed NiCr and NiCrAlY Coatings, Mater. Corros., 2018, 69(10), p 1431-1440

108. E. Sadeghimeresht, L. Reddy, T. Hussain, M. Huhtakangas, N. Markocsan, and S. Joshi, Influence of $\mathrm{KCl}$ and $\mathrm{HCl}$ on High Temperature Corrosion of HVAF-Sprayed NiCrAlY and NiCrMo Coatings, Mater. Des., 2018, 148, p 17-29
109. E. Sadeghimeresht, L. Reddy, T. Hussain, N. Markocsan, and S. Joshi, Chlorine-Induced High Temperature Corrosion of HVAFSprayed Ni-Based Alumina and Chromia Forming Coatings, Corros. Sci., 2018, 132, p 170-184

110. S.L. Liu and X.P. Zheng, Microstructure and Properties of ACHVAF Sprayed Ni60/WC Composite Coating, J. Alloys Comp., 2009, 480(2), p 254-258

111. E. Sadeghimeresht, N. Markocsan, and P. Nylén, A Comparative Study on Ni-Based Coatings Prepared by HVAF, HVOF, and APS Methods for Corrosion Protection Applications, J. Therm. Spray Technol., 2016, 25(8), p 1604-1616

112. R. Jafari, E. Sadeghimeresht, T.S. Farahani, M. Huhtakangas, N. Markocsan, and S. Joshi, KCl-Induced High-Temperature Corrosion Behavior of HVAF-Sprayed Ni-Based Coatings in Ambient Air, J. Therm. Spray Technol., 2018, 27(3), p 500-511

113. R. Jafari, E. Sadeghi, T. Shahrabi Farahani, N. Markocsan, S. Joshi, High Temperature Corrosion Mechanisms of HVAFSprayed Ni-Based Coatings Exposed to Alkali-Sulphate and Chloride Mixture Environments. 8th Rencontres Internationales sur la Projection Thermique, Limoges, France (2017).

114. R. Jafari, E. Sadeghimeresht, T. Shahrabi Farahani, N. Markocsan, S. V. Joshi, KCI-induced corrosion behavior of HVAF-sprayed Ni-based coatings in ambient air. Presented at the International Thermal Spray Conference and Exposition, ITSC 2017; Dusseldorf; Germany; 7 June 2017 through 9 June 2017, 2017, vol. 2, pp 946-950 (2017).

115. P.L. Fauchais, J.V.R. Heberlein, and M.I. Boulos, Industrial Applications of Thermal Spraying Technology. Thermal Spray Fundamentals, Springer, New York, 2014, p 1401-1566

116. V.A.D. Souza and A. Neville, Linking Electrochemical Corrosion Behaviour and Corrosion Mechanisms of Thermal Spray Cermet Coatings (WC-CrNi and $\mathrm{WC} / \mathrm{CrC}-\mathrm{CoCr}$ ), Mater. Sci. Eng., A, 2003, 352(1-2), p 202-211

117. M. Rodriguez, M. Staia, L. Gil, F. Arenas, and A. Scagni, Effect of Heat Treatment on Properties of Nickel Hard Surface Alloy Deposited by HVOF, Surf. Eng., 2000, 16(5), p 415-420

118. J. Saaedi, T.W. Coyle, H. Arabi, S. Mirdamadi, and J. Mostaghimi, Effects of HVOF Process Parameters on the Properties of Ni-Cr Coatings, J. Therm. Spray Technol., 2010, 19(3), p 521530

119. T.S. Sidhu, S. Prakash, and R.D. Agrawal, Studies on the Properties of High-velocity Oxy-Fuel Thermal Spray Coatings for Higher Temperature Applications, Mater. Sci., 2005, 41(6), p 805-823

120. K.A. Unocic et al., High-Temperature Behavior of Oxide Dispersion Strengthening CoNiCrAlY, Mater. High Temp., 2017, O(0), p 1-12

121. S.S. Chatha, H.S. Sidhu, and B.S. Sidhu, High-Temperature Behavior of a NiCr-Coated T91 Boiler Steel in the Platen Superheater of Coal-Fired Boiler, J. Therm. Spray Technol., 2013, 22(5), p 838-847

122. M. Torrell, S. Dosta, J.R. Miguel, and J.M. Guilemany, Optimisation of HVOF Thermal Spray Coatings for Their Implementation as MSWI, Superheater Protectors, Corros. Eng., Sci. Technol., 2010, 45(1), p 84-93

123. M. Oksa, J. Metsäjoki, and J. Kärki, Thermal Spray Coatings for High-Temperature Corrosion Protection in Biomass Co-Fired Boilers, J. Therm. Spray Technol., 2014, 24(1-2), p 194-205

124. G. Kaushal, N. Bala, N. Kaur, H. Singh, and S. Prakash, Comparative High-Temperature Corrosion Behavior of Ni-20Cr Coatings on T22 Boiler Steel Produced by HVOF, D-Gun, and Cold Spraying, Metall. Mater. Trans. A, 2013, 45, p 395-410

125. M. Oksa and J. Metsäjoki, Optimizing $\mathrm{NiCr}$ and $\mathrm{FeCr}$ HVOF Coating Structures for High Temperature Corrosion Protection Applications, J. Therm. Spray Technol., 2014, 24(3), p 436-453 
126. A.J. López, M. Proy, V. Utrilla, E. Otero, and J. Rams, HighTemperature Corrosion Behavior of Ni-50Cr Coating Deposited by High Velocity Oxygen-Fuel Technique on Low Alloy Ferritic Steel, Mater. Des., 2014, 59, p 94-102

127. M.A. Uusitalo, P.M.J. Vuoristo, and T.A. Mäntylä, High Temperature Corrosion of Coatings and Boiler Steels in Reducing Chlorine-Containing Atmosphere, Surf. Coat. Technol., 2002, 161(2-3), p 275-285

128. P. Zhang et al., Isothermal Oxidation Behavior of HVAFSprayed NiCoCrAlY Coatings: Effect of Surface Treatment, DIVA, pp 456-461 (2017).

129. E.N.A. Durul and M. Nurbaş, Corrosion Behavior of Different Thermal Spray Coatings and Hard Chromium Electroplating on A286 Super Alloy, Adv. Mater. Res., 2010, 154-155, p 226-229

130. Z. Zhou, L. Wang, F. Wang, and Y. Liu, Formation and Corrosion Behavior of Fe-Based Amorphous Metallic Coatings Prepared by Detonation Gun Spraying, Trans. Nonferrous Metals Soc. China, 2009, 19(Supplement 3), p s634-s638

131. C. Xu, L. Du, B. Yang, and W. Zhang, Study on Salt Spray Corrosion of Ni-Graphite Abradable Coating with 80Ni20Al and 96NiCr-4Al as Bonding Layers, Surf. Coat. Technol., 2011, 205(17-18), p 4154-4161

132. Y. Tao et al., Microstructure and Corrosion Performance of a Cold Sprayed Aluminium Coating on AZ91D Magnesium Alloy, Corros. Sci., 2010, 52(10), p 3191-3197

133. C. Zhang, K.C. Chan, Y. Wu, and L. Liu, Pitting Initiation in FeBased Amorphous Coatings, Acta Mater., 2012, 60(10), p 41524159

134. C. Xu, L. Du, B. Yang, and W. Zhang, The Effect of Al Content on the Galvanic Corrosion Behaviour of Coupled Ni/Graphite and Ni-Al Coatings, Corros. Sci., 2011, 53(6), p 2066-2074

135. W.-M. Zhao, Y. Wang, T. Han, K.-Y. Wu, and J. Xue, Electrochemical Evaluation of Corrosion Resistance of NiCrBSi Coatings Deposited by HVOF, Surf. Coat. Technol., 2004, 183(1), p 118-125

136. G. Bolelli et al., Functionally Graded WC-Co/NiAl HVOF Coatings for Damage Tolerance, wear and Corrosion Protection, Surf. Coat. Technol., 2012, 206(8-9), p 2585-2601

137. D. Rezakhani, Corrosion Behaviours of Several Thermal Spray Coatings Used on Boiler Tubes at Elevated Temperatures, Anti Corros. Methods Mater., 2007, 54(4), p 237-243

138. Q. Wang, S. Zhang, Y. Cheng, J. Xiang, X. Zhao, and G. Yang, Wear and Corrosion Performance of WC-10Co4Cr Coatings Deposited by Different HVOF and HVAF Spraying Processes, Surf. Coat. Technol., 2013, 218, p 127-136

139. J.M. Guilemany, J. Fernández, J. Delgado, A.V. Benedetti, and F. Climent, Effects of Thickness Coating on the Electrochemical Behaviour of Thermal Spray $\mathrm{Cr}_{3} \mathrm{C}_{2}-\mathrm{NiCr}$ Coatings, Surf. Coat. Technol., 2002, 153(2-3), p 107-113

140. M. Campo et al., Corrosion Resistance of Thermally Sprayed Al and $\mathrm{Al} / \mathrm{SiC}$ Coatings on Mg, Surf. Coat. Technol., 2009, 203(2021), p 3224-3230

141. C. Monticelli, A. Frignani, and F. Zucchi, Investigation on the Corrosion Process of Carbon Steel Coated by HVOF WC/Co Cermets in Neutral Solution, Corros. Sci., 2004, 46(5), p 12251237

142. G. Bolelli, L. Lusvarghi, and R. Giovanardi, A Comparison Between the Corrosion Resistances of Some HVOF-Sprayed Metal Alloy Coatings, Surf. Coat. Technol., 2008, 202, p 47934809

143. Y. Wang, B. Normand, N. Mary, M. Yu, and H. Liao, Microstructure and Corrosion Behavior of Cold Sprayed $\mathrm{SiCp} /$ Al 5056 Composite Coatings, Surf. Coat. Technol., 2014, 251, p 264-275

144. A. Milanti, V. Matikainen, H. Koivuluoto, G. Bolelli, L. Lusvarghi, and P. Vuoristo, Effect of Spraying Parameters on the
Microstructural and Corrosion Properties of HVAF-Sprayed FeCr-Ni-B-C Coatings, Surf. Coat. Technol., 2015, 277, p 81-90

145. S.D. Zhang, J. Wu, W.B. Qi, and J.Q. Wang, Effect of Porosity Defects on the Long-Term Corrosion Behaviour of Fe-Based Amorphous Alloy Coated Mild Steel, Corros. Sci., 2016, 110, p 57-70

146. R. Arrabal, A. Pardo, M.C. Merino, M. Mohedano, P. Casajús, and $\mathrm{S}$. Merino, Al/SiC Thermal Spray Coatings for Corrosion Protection of Mg-Al Alloys in Humid and Saline Environments, Surf. Coat. Technol., 2010, 204, p 2767-2774

147. N. Espallargas, J. Berget, J.M. Guilemany, A.V. Benedetti, and P.H. Suegama, Cr3C2-NiCr and WC-Ni Thermal Spray Coatings as Alternatives to Hard Chromium for Erosion-Corrosion Resistance, Surf. Coat. Technol., 2008, 202(8), p 1405-1417

148. G. Bolelli et al., Tribology of FeVCrC Coatings Deposited by HVOF and HVAF Thermal Spray Processes, Wear, 2018, 394395, p 113-133

149. M.R. Rokni, S.R. Nutt, C.A. Widener, V.K. Champagne, and R.H. Hrabe, Review of Relationship Between Particle Deformation, Coating Microstructure, and Properties in High-Pressure Cold Spray, J. Therm. Spray Technol., 2017, 26(6), p 1308-1355

150. A. Valarezo and S. Sampath, An Integrated Assessment of Process-Microstructure-Property Relationships for ThermalSprayed NiCr Coatings, J. Therm. Spray Technol., 2011, 20(6), p $1244-1258$

151. A. Valarezo, W.B. Choi, W. Chi, A. Gouldstone, and S. Sampath, Process Control and Characterization of $\mathrm{NiCr}$ Coatings by HVOF-DJ2700 System: A Process Map Approach, J. Therm. Spray Technol., 2010, 19(5), p 852-865

152. E. Sadeghimeresht, N. Markocsan, M. Huhtakangas, and S. Joshi, Isothermal Oxidation of HVAF-Sprayed Ni-Based Chromia, Alumina and Mixed-Oxide Scale Forming Coatings in Ambient Air, Surf. Coat. Technol., 2017, 316, p 10-21

153. E. Sadeghi, N. Markocsan, T. Hussain, M. Huhtakangas, S. Joshi, Effect of $\mathrm{SiO} 2$ Dispersion on Chlorine-Induced HighTemperature Corrosion of High-Velocity Air-Fuel Sprayed NiCrMo Coating, Corrosion, pp 984-1000 (2018).

154. N. Mu, K.Y. Jung, N.M. Yanar, G.H. Meier, F.S. Pettit, and G.R. Holcomb, Water Vapor Effects on the Oxidation Behavior of $\mathrm{Fe}-\mathrm{Cr}$ and $\mathrm{Ni}-\mathrm{Cr}$ Alloys in Atmospheres Relevant to OxyFuel Combustion, Oxid. Metals, 2012, 78(3-4), p 221-237

155. R. Bender and M. Schütze, The Role of Alloying Elements in Commercial Alloys for Corrosion Resistance in OxidizingChloridizing Atmospheres. Part I: Literature Evaluation and Thermodynamic Calculations on Phase Stabilities, Mater. Corros., 2003, 54(8), p 567-586

156. R. Bender and M. Schütze, The Role of Alloying Elements in Commercial Alloys for Corrosion Resistance in OxidizingChloridizing Atmospheres. Part II: Experimental Investigations, Mater. Corros., 2003, 54(9), p 652-686

157. E. Guerin, E. Sadeghi, N. Markocsan, S. Joshi, Role of Chemistry on Oxidation Behavior of Various Ni-based HVAFSprayed Coatings in Simulated Boiler Environments, 8th Rencontres Internationales sur la Projection Thermique, Limoges, France (2017)

158. K. Ma and J.M. Schoenung, Thermodynamic Investigation into the Equilibrium Phases in the NiCoCrAl System at Elevated Temperatures, Surf. Coat. Technol., 2010, 205(7), p 2273-2280

159. T.J. Nijdam and W.G. Sloof, Microstructural Evolution of a MCrAlY Coating Upon Isothermal Annealing, Mater. Charact., 2008, 59(12), p 1697-1704

160. K. Ma, F. Tang, and J.M. Schoenung, Investigation into the Effects of Fe Additions on the Equilibrium Phase Compositions, Phase Fractions and Phase Stabilities in the Ni-Cr-Al System, Acta Mater., 2010, 58(5), p 1518-1529 
161. J.J. Liang, H. Wei, Y.L. Zhu, T. Jin, X.F. Sun, and Z.Q. Hu, Phase Stabilities in a NiCrAlYRe Coating Alloy, Surf. Coat. Technol., 2012, 206(11), p 2746-2750

162. J.J. Liang et al., Phase Constituents and Thermal Expansion Behavior of a NiCrAlYRe Coating Alloy, J. Mater. Sci., 2011, 46(2), p 500-508

163. B. Baufeld and M. Schmücker, Microstructural Evolution of a NiCoCrAlY Coating on an IN100 Substrate, Surf. Coat. Technol., 2005, 199(1), p 49-56

164. D.R.G. Achar, R. Munoz-Arroyo, L. Singheiser, and W.J. Quadakkers, Modelling of Phase Equilibria in MCrAlY Coating Systems, Surf. Coat. Technol., 2004, 187(2), p 272-283

165. L.T. Wu, R.T. Wu, P. Xiao, T. Osada, K.I. Lee, and M. Bai, A Prominent Driving Force for the Spallation of Thermal Barrier Coatings: Chemistry Dependent Phase Transformation of the Bond Coat, Acta Mater., 2017, 137, p 22-35

166. M. Born, J. Korb, D. Rafaja, M. Dopita, and R.W. Schülein, Capability of Thermodynamic Calculation in the Development of Alloys for Deposition of Corrosion-Protection Coatings via Thermal Spraying, Mater. Corros., 2007, 58(9), p 673-680

167. E. Sadeghimeresht, J. Eklund, J. Phother Simon, J. Lyske, N. Markocsan, S. V. Joshi, Oxidation behaviour of HVAF-sprayed $\mathrm{NiCr}$ coating in moisture-laden environment. Presented at the nternational Thermal Spray Conference and Exposition, ITSC 2017; Dusseldorf; Germany; 7 June 2017 through 9 June 2017, 2017, vol. 2, pp 644-646.

168. A. Zahs, M. Spiegel, and H. Grabke, The Influence of Alloying Elements on the Chlorine-Induced High Temperature Corrosion of $\mathrm{Fe}-\mathrm{Cr}$ Alloys in Oxidizing Atmospheres, Mater. Corros., 1999, 50(10), p 561-578

169. N. Israelsson, High Temperature Oxidation and Chlorination of $\mathrm{FeCrAl}$ alloys. Doctoral thesis, Chalmers University of Technology (2014).

170. R. Bender and M. Schütze, The Role of Alloying Elements in Commercial Alloys for Corrosion Resistance in OxidizingChloridizing Atmospheres Part I: Literature Evaluation and Thermodynamic Calculations on Phase Stabilities, Mater. Corros., 2003, 54(8), p 567-586

171. E. Sadeghimeresht, N. Markocsan, P. Nylén, HVAF thermal spray Fe-based coating: An environmentally acceptable alternative to cobalt-based coating. Presented at the EUROCORR 2015,EUROPEAN CORROSION CONGRESS 6-10 September 2015 Graz / Austria The annual event of the European Federation of Corrosion (2015)

172. E. Sadeghimeresht, N. Markocsan, P. Nylén, S. Dizdar, Corrosion behavior of high-chromium Fe-based coatings produced by HVAF thermal spraying technique. Presented at the 7th Rencontres Internationales sur la Projection Thermique. 9th to 11 th December 2015-Limoges, France (2015)

173. E. Sadeghi and S. Joshi, Chlorine-Induced High-Temperature Corrosion and Erosion-Corrosion of HVAF and HVOF-Sprayed Amorphous Fe-Based Coatings, Surf. Coat. Technol., 2019, 371, p 20-35

174. C.A.C. Souza, D.V. Ribeiro, and C.S. Kiminami, Corrosion Resistance of Fe-Cr-Based Amorphous Alloys: An Overview, $J$. Non-Cryst. Solids, 2016, 442, p 56-66

175. C. Suryanarayana and A. Inoue, Iron-Based Bulk Metallic Glasses, Int. Mater. Rev., 2013, 58(3), p 131-166

176. D. Zenebe, S. Yi, and S.S. Kim, Sliding Friction and Wear Behavior of Fe-Based Bulk Metallic Glass in $3.5 \% \mathrm{NaCl}$ Solution, J. Mater. Sci., 2012, 47(3), p 1446-1451

177. Y. Wang et al., Corrosion and Erosion-Corrosion Behaviour of Activated Combustion High-Velocity Air Fuel Sprayed FeBased Amorphous Coatings in Chloride-Containing Solutions, Corros. Sci., 2015, 98, p 339-353
178. Z.B. Zheng, Y.G. Zheng, W.H. Sun, and J.Q. Wang, ErosionCorrosion of HVOF-Sprayed Fe-Based Amorphous Metallic Coating Under Impingement by a Sand-Containing NaCl Solution, Corros. Sci., 2013, 76, p 337-347

179. Y. Wang et al., Slurry Erosion-Corrosion Behaviour of HighVelocity Oxy-Fuel (HVOF) Sprayed Fe-Based Amorphous Metallic Coatings for Marine Pump in Sand-Containing $\mathrm{NaCl}$ Solutions, Corros. Sci., 2011, 53(10), p 3177-3185

180. X.Q. Liu et al., Microstructure and Properties of Fe-Based Amorphous Metallic Coating Produced by High Velocity Axial Plasma Spraying, J. Alloys Comp., 2009, 484(1-2), p 300-307

181. Y. Wu, P. Lin, G. Xie, J. Hu, and M. Cao, Formation of Amorphous and Nanocrystalline Phases in High Velocity OxyFuel Thermally Sprayed a Fe-Cr-Si-B-Mn Alloy, Mater. Sci. Eng., A, 2006, 430(1-2), p 34-39

182. R.Q. Guo, C. Zhang, Q. Chen, Y. Yang, N. Li, and L. Liu, Study of Structure and Corrosion Resistance of Fe-Based Amorphous Coatings Prepared by HVAF and HVOF, Corros. Sci., 2011, 53(7), p 2351-2356

183. J. Farmer et al., Iron-Based Amorphous Metals: High-Performance Corrosion-Resistant Material Development, Metall. Mater. Trans. A Phys. Metall. Mater. Sci., 2009, 40(6), p 12891305

184. W. Yuping, L. Pinghua, C. Chenglin, W. Zehua, C. Ming, and H. Junhua, Cavitation Erosion Characteristics of a Fe-Cr-Si-BMn Coating Fabricated by High Velocity Oxy-Fuel (HVOF) Thermal Spray, Mater. Lett., 2007, 61(8-9), p 1867-1872

185. J.C. Farmer et al., Corrosion Resistance of Thermally Sprayed High-Boron Iron-Based Amorphous-Metal Coatings: Fe49.7Cr17.7 Mn1.9Mo7.4W1.6B15.2 C3.8Si2.4, J. Mater. Res., 2007, 22(8), p 2297-2311

186. E. Sadeghimeresht, Ni-Based Coatings for High Temperature Corrosion Protection, DIVA (2018).

187. J. Eklund, B. Jönsson, A. Persdotter, J. Liske, J.-E. Svensson, and T. Jonsson, The Influence of Silicon on the Corrosion Properties of FeCrAl Model Alloys in Oxidizing Environments at $600{ }^{\circ} \mathrm{C}$, Corros. Sci., 2018, 144, p 266-276

188. H.J. Grabke, M. Spiegel, and A. Zahs, Role of Alloying Elements and Carbides in the Chlorine-Induced Corrosion of Steels and Alloys, Mater. Res., 2004, 7(1), p 89-95

189. P. Viklund, High Temperature Corrosion During Waste Incineration: Characterisation, Causes and Prevention of ChlorineInduced Corrosion, KTH Royal Institute of Technology, Stockholm, 2011

190. K. Przybylski, A.J. Garratt-Reed, B.A. Pint, E.P. Katz, and G.J. Yurek, Segregation of $Y$ to Grain Boundaries in the $\mathrm{Al}_{2} \mathrm{O}_{3}$ Scale Formed on an ODS Alloy, J. Electrochem. Soc., 1987, 134(12), p 3207-3208

191. B.A. Pint, Experimental observations in support of the dynamicsegregation theory to explain the reactive-element effect, Oxid. Met., 1996, 45(1-2), p 1-37

192. T.A. Ramanarayanan, M. Raghavan, and R. Petkovic-Luton, The Characteristics of Alumina Scales Formed on Fe-Based Yttria-Dispersed Alloys, J. Electrochem. Soc., 1984, 131(4), p 923-931

193. K.A. Unocic et al., High-Temperature Behavior of Oxide Dispersion Strengthening CoNiCrAlY, Mater. High Temp., 2017, 1(1), p 1-12

194. P.S. Mohanty, A.D. Roche, R.K. Guduru, and V. Varadaraajan, Ultrafine Particulate Dispersed High-Temperature Coatings by Hybrid Spray Process, J. Therm. Spray Technol., 2010, 19(1-2), p 484-494

195. B. Wang and S.W. Lee, Erosion-Corrosion Behaviour of HVOF NiAl- $\mathrm{Al}_{2} \mathrm{O}_{3}$ Intermetallic-Ceramic Coating, Wear, 2000, 239(1), p 83-90 
196. B.A. Pint, Study of the Reactive Element Effect in ODS IronBase Alumina Formers, Mater. Sci. Forum, 1997, 251-254, p 397-404

197. D.N. Braski, P.D. Goodell, J.V. Cathcart, and R.H. Kane, Effect of $\mathrm{Y}_{2} \mathrm{O}_{3}$ Dispersoids in $80 \mathrm{Ni}-20 \mathrm{Cr}$ Alloy on the Early Stages of Oxidation at Low-Oxygen Potential, Oxid. Metals, 1986, 25(12), $\mathrm{p} 29-50$

198. T. Huang, J. Bergholz, G. Mauer, R. Vassen, D. Naumenko, and W.J. Quadakkers, Effect of Test Atmosphere Composition on High-Temperature Oxidation Behaviour of CoNiCrAlY Coatings Produced from Conventional and ODS Powders, Mater. High Temp., 2017, 0(0), p 1-11

199. D.P. Whittle and J. Stringer, Improvements in High Temperature Oxidation Resistance by Additions of Reactive Elements or Oxide Dispersions, Philos. Trans. R. Soc. Lond. A, 1980, 295(1413), p 309-329

200. J. Stringer, B.A. Wilcox, and R.I. Jaffee, The High-Temperature Oxidation of Nickel-20 wt.\% Chromium Alloys Containing Dispersed Oxide Phases, Oxid. Metals, 1972, 5(1), p 11-47

201. X. Wang, X. Peng, X. Tan, and F. Wang, The Reactive Element Effect of Ceria Particle Dispersion on Alumina Growth: A Model Based on Microstructural Observations, Sci. Rep., 2016, 6, p 29593

202. X. Peng, Y. Guan, Z. Dong, C. Xu, and F. Wang, A Fundamental Aspect of the Growth Process of Alumina Scale on a Metal with Dispersion of $\mathrm{CeO} 2$ Nanoparticles, Corros. Sci., 2011, 53(5), p 1954-1959

203. M. Oksa, T. Varis, and K. Ruusuvuori, Performance Testing of Iron Based Thermally Sprayed HVOF Coatings in a BiomassFired Fluidised Bed Boiler, Surf. Coat. Technol., 2014, 251, p 191-200

204. N.F. Ak, C. Tekmen, I. Ozdemir, H.S. Soykan, and E. Celik, NiCr Coatings on Stainless Steel by HVOF Technique, Surf. Coat. Technol., 2003, 174-175, p 1070-1073

205. H. Singh, D. Puri, and S. Prakash, Some Studies on Hot Corrosion Performance of Plasma Sprayed Coatings on a Fe-Based Superalloy, Surf. Coat. Technol., 2005, 192(1), p 27-38

206. F.H. Yuan, Z.X. Chen, Z.W. Huang, Z.G. Wang, and S.J. Zhu, Oxidation Behavior of Thermal Barrier Coatings with HVOF and Detonation-Sprayed NiCrAlY Bondcoats, Corros. Sci., 2008, 50(6), p 1608-1617

207. V. Higuera, F.J. Belzunce, A. Carriles, and S. Poveda, Influence of the Thermal-Spray Procedure on the Properties of a NickelChromium Coating, J. Mater. Sci., 2002, 37(3), p 649-654
208. G. Zhang, A.-F. Kanta, W.-Y. Li, H. Liao, and C. Coddet, Characterizations of AMT-200 HVOF NiCrAlY Coatings, Mater. Des., 2009, 30(3), p 622-627

209. S.F. Chen et al., Microstructure and Properties of HVOFSprayed NiCrAlY Coatings Modified by Rare Earth, J. Therm. Spray Technol., 2014, 23(5), p 809-817

210. G. Marland, T. Boden, R.J. Andres, National $\mathrm{CO}_{2}$ Emissions from Fossil-Fuel Burning, Cem. Manu. Gas Flaring., 1751, 54, p. 2005

211. R. Narayan, An introduction to metallic corrosion and its prevention. Mohan Primlani for Oxford \& IBH Publishing Company, 1983.

212. Y. Shao et al., Ash Deposition in Biomass Combustion or CoFiring for Power/Heat Generation, Energies, 2012, 5(12), p 5171-5189

213. K. Veijonen, P. Vainikka, T. Järvinen, and E. Alakangas, "Biomass co-firing: an efficient way to reduce greenhouse gas emissions - Altener programme - Energy - European Commission," European Bioenergy Networks, 2000. [Online]. Available: /energy/en/studies/biomass-co-firing-efficient-way-reducegreenhouse-gas-emissions-\%E2\%80\%93-altener-programme. [Accessed: 15-Aug-2018].

214. V. Kumar and B. Kandasubramanian, Processing and Design Methodologies for Advanced and Novel Thermal Barrier Coatings for Engineering Applications, Particuology, 2016, 27, p 1-28

215. K. Holmberg, A. Laukkanen, E. Turunen, and T. Laitinen, Wear Resistance Optimisation of Composite Coatings by Computational Microstructural Modelling, Surf. Coat. Technol., 2014, 247, p 1-13

216. "Oerlicon metco." .

217. E. Sadeghimeresht, H. Hooshyar, N. Markocsan, S. Joshi, and P. Nylén, Oxidation Behavior of HVAF-Sprayed NiCoCrAlY Coating in H2-H2O Environment, Oxid. Metals, 2016, 86(3-4), p 299-314

218. A. Vardelle et al., The 2016 Thermal Spray Roadmap, J. Therm. Spray Technol., 2016, 25(8), p 1376-1440

Publisher's Note Springer Nature remains neutral with regard to jurisdictional claims in published maps and institutional affiliations. 